\title{
Trade and Welfare Effects of Standards in Agricultural Markets
}

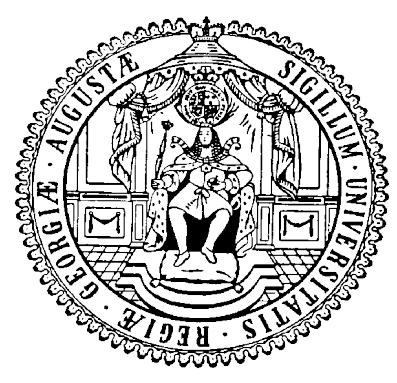

Dissertation

to attain the Ph.D. degree

in the International Ph.D. Program for Agricultural Sciences in Göttingen (IPAG) at the Department of Agricultural Economics and Rural Development

Faculty of Agricultural Sciences,

Georg-August-University Göttingen, Germany

presented by

Dela-Dem Doe Fiankor

born in Aflao, Ghana

Göttingen, December 2019 
1st Supervisor: Prof. Dr. Bernhard Brümmer

2nd Supervisor: Prof. Inmaculada Martínez-Zarzoso, PhD

3rd Supervisor: Prof. Dr. Stephan von Cramon-Taubadel

Date of dissertation: December 12, 2019 
"In their hearts human beings plan their course, but the Lord establishes their steps."

Proverbs 16:9

"Most of the people in the world are poor, so if we knew the economics of being poor, we would know much of the economics that really matters. Most of the world's poor people earn their living from agriculture, so if we knew the economics of agriculture, we would know much of the economics of being poor."

Theodore Schultz - Nobel Lecture, 1979

"Free trade, one of the greatest blessings which a government can confer on a people, is in almost every country unpopular."

Lord Thomas Macauley, 1824

"The line it is drawn. The curse it is cast. The slow one now. Will later be fast. As the present now. Will later be past. The order is rapidly fadin'. And the first one now. Will later be last. For the times they are a-changin'."

Bob Dylan, 1963 
This page intentionally left blank 


\section{Abstract}

Integrating developing countries (DCs) into the global trading system is key to their economic development. To that effect, several rounds of trade negotiations have reduced tariffs to a historic low. Despite this remarkable feat, international trade is still far from free as non-tariff measures (NTMs) - i.e., policies aside tariffs that can affect trade, e.g., standards - have proliferated. In many markets, export success is now conditional on compliance with NTMs. Thus, tariff liberalisation and reductions in global logistic charges have not improved the integration, especially of DCs, into global value chains. Yet, our knowledge of the NTM-trade relationship is nuanced. This has implications for evidence-based trade policy-making. On this premise, this thesis contributes three essays that assess the implications of standards for trade, and welfare via the channels of prices, varieties and quality upgrading in the agrifood sector. The development implication of this dissertation is obvious; the agrifood sector is particularly subject to standards but forms a major share of exports in many DCs.

In global agricultural value chains, private food standards have proliferated. While they are de jure voluntary, compliance is fast becoming de facto mandatory. This has cost implications, especially for smallholder DC farmers. But, does voluntary certification guarantee market access? The first essay contributes the first multi-product/country study that examines the effects of GlobalGAP on global agrifood trade. We estimate a structural gravity model using a dataset of certified producers and the share of certified land area in total harvest area. While our results confirm GlobalGAP standards as catalysts to trade, we find that the trade-enhancing effect varies across products and destination markets. Voluntary certification poses extra costs for producers but sustains market access.

It is a well-known fact that institutional differences across countries affect bilateral trade. Trade is sensitive to the quality of contractual institutions. For DCs, this supply-side constraint further hinders their inclusion in the global trading system. The second essay asks the crucial question; how do countries enhance trade when institutional differences exist? Using a sample of EU/EFTA imports, we study how adopting GlobalGAP standards modify the effect of governance distance - measured as the degree to which governance and institutions differ between countries - on exports. We find that while increasing governance distance hinders bilateral trade, GlobalGAP certified countries see their trade-inhibiting effects reduced by about 50\%. Put differently, when institutional quality differs between countries, we show that standards can act as substitute governance institutions.

Finally, chemical use is important in agriculture to protect crops and enhance yields. But, depending on exposure levels, chemicals pose health risks. Thus, cross-country differences in chemicalrelated regulations will influence supply chain structures. The third essay assesses how this regulatory heterogeneity affects trade, product prices and quality upgrading. Exploiting the bilateral difference in maximum residue limits over time for 145 agrifood products across 59 countries, we show that differences in public regulations are trade-restrictive. However, conditional on trading, they increase product prices and quality-adjusted prices but have null effects on estimated product quality.

Food safety standards are here to stay; as non-tariff measures, they are not necessarily nontariff barriers. This dissertation shows that by harmonising global standards, retailer-driven private standards enhance trade. But if standards vary substantially across countries, as is the case for public mandatory standards, they reduce trade and induce welfare losses. 
This page intentionally left blank 


\section{Zusammenfassung}

Die Integration der Entwicklungsländer (EL) in das globale Handelssystem ist der Schlüssel zu ihrer wirtschaftlichen Entwicklung. Zu diesem Zweck wurden durch viele Verhandlungsrunden Zölle auf ein historisches Tief gesenkt. Trotz dieser bemerkenswerten Leistung ist der internationale Handel noch lange kein perfekter Markt. Speziell nicht tarifäre Handelshemmnisse (NTM), wie Standards, beeinflussen die Handelsströme weiterhin. In vielen Märkten ist der Exporterfolg heutzutage maßgeblich von der Einhaltung dieser NTMs abhängig. Daher wurde die Integration von EL in globale Wertschöpfungsketten trotz Zollliberalisierung und Senkung der globalen Transportkosten nicht verbessert. Dennoch sind die Handelseffekte von NTM nur sehr wenig erforscht. Dies hat Auswirkungen auf evidenzbasierte Handelspolitiken. Deshalb untersucht diese Arbeit, bestehend aus drei in sich geschlossenen Essays, mehrere Themenfelder. Im Agrar- und Nahrungsmittelmittelsektor werden Effekte von Standards auf den Handel, die Produktpreise und ob Anreize zur Verbesserung der Produktqualität im zu finden sind untersucht. Die entwicklungspolitische Bedeutung dieser Arbeit ist klar; der Agrar- und Ernährungssektor unterliegt in besonderem Maße den Normen und macht in vielen EL einen erheblichen Teil der Exporte aus.

In den globalen landwirtschaftlichen Wertschöpfungsketten nehmen die privaten Lebensmittelstandards zu. Während sie de jure freiwillig sind, wird die Einhaltung der Vorschriften schnell de facto zur Pflicht. Dies hat Auswirkungen auf die Kosten, insbesondere für Kleinbauern in den EL. Garantiert die freiwillige Zertifizierung den Marktzugang? Der erste Aufsatz liefert die erste Multiprodukt-/Länderstudie, die die Auswirkungen von GlobalGAP auf die Exporte von Nahrungsmitteln untersucht. Wir schätzen ein strukturelles Gravitationsmodell unter Verwendung eines neuartigen Datensatzes von zertifizierten Produzenten und des Anteils der zertifizierten Landfläche an der gesamten Erntefläche. Während unsere Ergebnisse die GlobalGAP-Standards als Katalysator für den Handel bestätigen, stellen wir fest, dass der handelsfördernde Effekt, je nach Produkt und Zielmarkt, unterschiedlich ist. Die freiwillige Zertifizierung verursacht zusätzliche Kosten für die Erzeuger, sichert aber den Marktzugang.

Sehr gut belegt ist, dass institutionelle Unterschiede zwischen Ländern den bilateralen Handel beeinflussen. Dabei sind die die vorherrschende Rechtssicherheit und die Möglichkeit Verträge durchzusetzen essenziell. Diese angebotsseitige Einschränkung behindert die Einbindung der EL in das globale Handelssystem zusätzlich. Der zweite Aufsatz stellt die entscheidende Frage: Wie fördern Länder den Handel, wenn institutionelle Unterschiede bestehen? Mit einer Stichprobe von EU/EFTAImporten werden die Effekte von GlobalGAP-Standards untersucht. Hierbei wird das Ausmaß von Unterschieden in der Regulierung zwischen Ländern auf ihre Handelseffekte untersucht. Wir stellen fest, dass zunehmende Unterschiede zwischen den Regulierungen zwar den bilateralen Handel behindern, die GlobalGAP Zertifizierung jedoch die handelshemmenden Effekte um etwa 50\% verringern. Anders ausgedrückt, wenn die institutionelle Qualität zwischen den Ländern unterschiedlich ist, zeigen wir, dass Standards als Ersatz für Regulierungs-Institutionen dienen können.

Schließlich ist die Nutzung von Pflanzenschutzmitteln und Ähnlichem in der Landwirtschaft wichtig, um Pflanzen zu schützen und die Erträge zu steigern. Der Kontakt mit diesen Chemikalien 
birgt allerdings Gesundheitsrisiken. Länderübergreifende Unterschiede bei den chemikalienbezogenen Vorschriften werden Lieferkettenstrukturen beeinflussen. Der dritte Aufsatz untersucht, wie sich diese regulatorische Heterogenität auf Handel, Produktpreise und Qualitätssteigerung auswirkt. Wir verwenden eine Stichprobe mit bilateralen Unterschiede bei Rückstandshöchstmengen über mehrere Jahre für 145 Agrarerzeugnisse in 59 Ländern. Unsere Ergebnisse zeigen einen klaren handelsbeschränkenden Einfluss von Unterschiede in den öffentlichen Vorschriften. Außerdem steigen, solange Handel stattfindet, die Produktpreise und die qualitätsbereinigten Preise. Es wurde jedoch keine Effekte auf die Produktqualität gefunden.

Die Lebensmittelsicherheitsstandards sind weiter auf dem Vormarsch. Diese Dissertation zeigt, dass durch die Harmonisierung globaler Standards, handelsgesteuerte, private Standards den Handel fördern. Wenn die Definitionen von Qualitätsstandards jedoch von Land zu Land unterschiedlich sind, wie es bei öffentlich verbindlichen Normen der Fall ist, gibt es Handels- und Wohlfahrtsverluste. 


\section{Acknowledgements}

I am most grateful to my supervisor Prof. Dr. Bernhard Brümmer. Thanks for believing in me and allowing me to carry out my doctoral research under your supervision and mentorship. You bring a human-side to leadership that is a rare find in the world. I appreciate my co-supervisor, Prof. Dr. Inmaculada Martínez-Zarzoso, who has been a pillar of support over the past years. I enjoyed the many insightful discussions in your office over matters big and small. This dissertation would not have been possible without your immense academic support. And to Prof. Dr. Stephan von-Cramon Taubadel, thank you for joining my thesis committee. These three are personalities I have looked up to in my career pursuit. It is a great honour to have them all on my thesis committee.

I cannot thank the Tutes (Christiane and Christoph) enough for picking me up at the airport in 2013, providing me with a comfortable home in Germany and allowing me to become a part of their wonderful family. Two people who shaped my research interests are Dr. Fatima Kareem and Dr. Malte Ehrich. These two piqued my interest in the study of standards and international trade even before I considered doing a $\mathrm{PhD}$. This thesis is in gratitude to these amazing personalities. My research visits to the University of Milano were nothing short of productive. I thank my hosts Prof. Alessandro Olper and Dr. Daniele Curzi for pushing me to explore the quality sorting literature. If I stay in research, it is because of the spark I see in the eyes of these two anytime we discuss research ideas.

The pursuit of a doctoral thesis deserves a support system. I acknowledge the roles of Dr. Melanie Grosse, Dr. Simone Pfeiffer and Frau Nina Enke; thank you for handling all the administrative issues that allowed me the freedom to focus on my research. I am grateful to Dr. Insa Flaschbarth for sharing her knowledge and expertise with me. To my office mates Nina Grassnick and Dr. Marwan Benali; I couldn't have asked for better office mates. To my colleagues Dr. Yuquan Chen, "Prof." Hengrong Luo and Oliver-Ken Haase, thanks for thought-provoking discussions that improved my work. To all my colleagues at GlobalFood thanks for providing the perfect working environment, especially Ayo, Cansin, Collins, and Jessie. Makaiko Khonje and Dr. Kibrom Sibhatu deserve special mention for helping me deal with the infamous "Referee 2" and being sources of motivation. To my people at the Chair of Agricultural Market Analysis: Bernhard Jnr., Yurij, Gabriel, Tim, Claudia, Yashree, Sebastien, Enrique, Ella, Yueming and Yuan - you guys are amazing. I always looked forward to the many meetings of the sliding/swimming group, the Indian food group, the running group and the GoT group. And to the students who attended my classes or whose theses I helped supervise, thanks for being useful distractions from the sometimes boring desk work that comes with doing a PhD.

Finally, I appreciate very much the support of my family. My father David, especially, for investing in my education. I hope I made you proud, dad. But also my mum Worlanyo and my wonderful sisters, Vivian, Selorm and Carlene whom I know never stop praying for me. One person that deserves an honourable mention is my partner, Aba Pokuaa Kuntu-Blankson O; now I get to return the favour. Last but not least, I acknowledge the love of the Lamegas (Doris and Sala). Funding is core to doing a $\mathrm{PhD}$. I acknowledge and appreciate financial support from the German Research Foundation through the GlobalFood Program, the Katholischer Akademischer Ausländer-Dienst and the LEAP-Agri project "Agricultural Trade and Market Assess for Food Security: Insights for Africa". 
This page intentionally left blank 


\section{Contents}

$\begin{array}{ll}\text { Abstract } & \text { V }\end{array}$

$\begin{array}{ll}\text { Acknowledgements } & \text { ix }\end{array}$

1 Introduction $\quad 1$

1.1 The economics of NTMs - a primer $\ldots \ldots \ldots \ldots \ldots$

1.2 Food standards and trade - the role of gravity $\ldots \ldots \ldots \ldots$

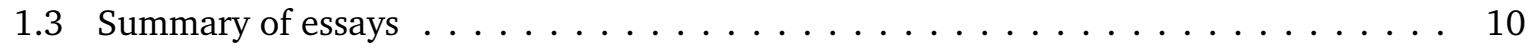

2 Does GlobalGAP certification promote agrifood exports? 13

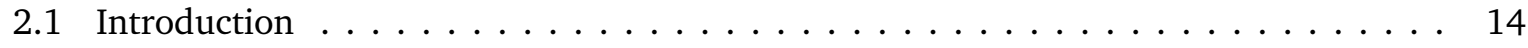

2.2 Private food standards and trade . . . . . . . . . . . . . . 16

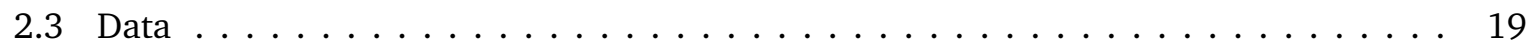

2.4 Empirical application . . . . . . . . . . . . . . . . . . . . 21

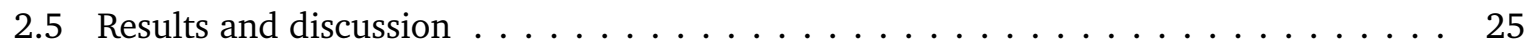

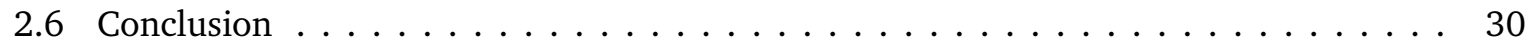

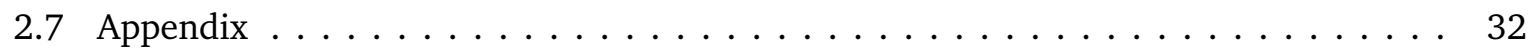

3 Exports and governance: the role of private voluntary agrifood standards 39

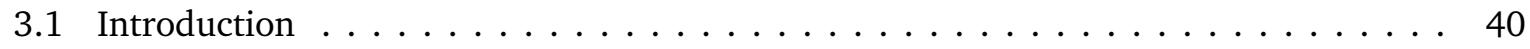

3.2 Conceptual discussion and hypotheses . . . . . . . . . . . . . . . . . . . . . . . . . . . . . . . . . . . . . . . . . . .

3.3 Empirical application . . . . . . . . . . . . . . . . . . . . . . 45

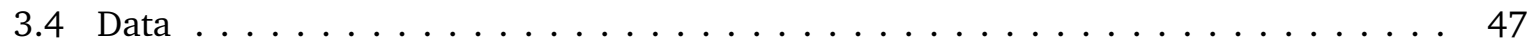

3.5 Results and discussion . . . . . . . . . . . . . . . . . . . . 49

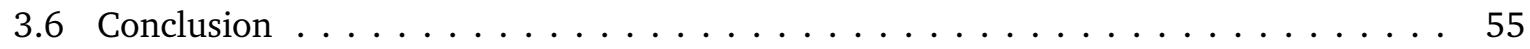

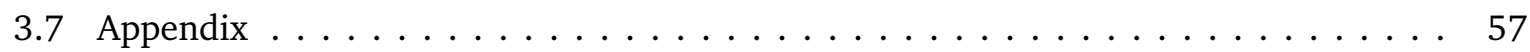

4 Trade, price and quality upgrading effects of agrifood standards 61

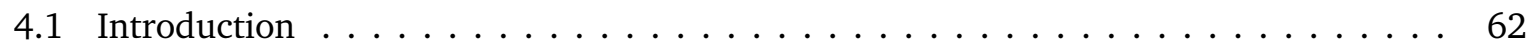

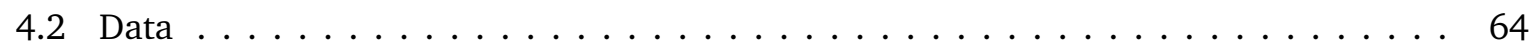

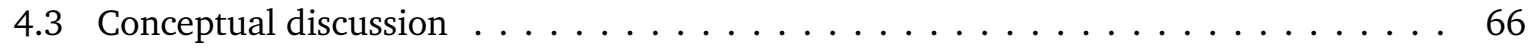

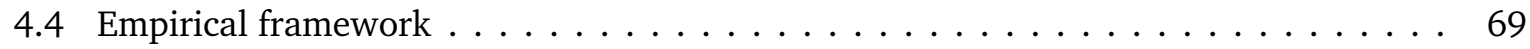

4.5 Results . . . . . . . . . . . . . . . . . . . . . . . 72

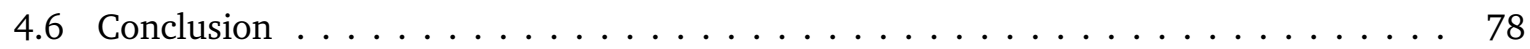

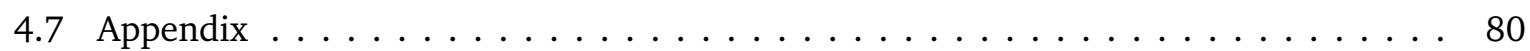

5 Conclusion $\quad \mathbf{8 5}$

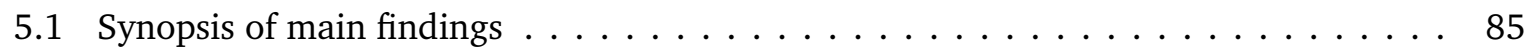

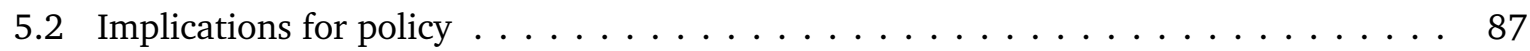

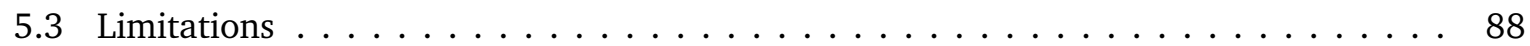

5.4 Outlook for further research $\ldots \ldots \ldots \ldots \ldots \ldots$

Bibliography $\quad 92$ 
This page intentionally left blank 


\section{List of Figures}

1.1 Increasing relevance of non-tariff measures $\ldots \ldots \ldots \ldots \ldots \ldots \ldots \ldots$

1.2 Trade effects of standards in a small open economy $\ldots \ldots \ldots \ldots \ldots \ldots$

2.1 Development of GlobalGAP certified producers and land area by region $\ldots . . . .217$ A2.1 GDP per capita, exports and spread of GlobalGAP certification (2010 - 2015) . . . . 32

3.1 Bilateral governance distance: 2010 - 2015 (using Germany as the importer) . . . . 48

4.1 Distribution of prices and estimated product quality of imports . . . . . . . . . 71

A4.1 EU border notifications relating to pesticide residues (1999-2018) . . . . . . . 82

A4.2 Relationship between estimated quality and prices by HS2 groups in 2014 . . . . . . 82

A4.3 Average number of regulated pesticides per country $(2005-2014) \ldots \ldots \ldots$. . . 83 
This page intentionally left blank 


\section{List of Tables}

2.1 Summary of empirical studies on the trade effects of voluntary food standards . . . 16

2.2 Overview of individual versus group certification per product $(2010-2015) \ldots \ldots$

2.3 GlobalGAP certification and agrifood exports: baseline results . . . . . . . . . . . 25

2.4 GlobalGAP certification and agrifood exports: product specific results . . . . . . . . . 26

2.5 GlobalGAP certification and agrifood exports: by income group . . . . . . . . . 27

2.6 GlobalGAP certification and agrifood exports: Heckman model . . . . . . . . . . 28

2.7 GlobalGAP certification and agrifood exports: destination market heterogeneity . . 29

A2.1 Average production and imports $(2010-2015) \ldots \ldots \ldots \ldots \ldots$. . . . . . 32

A2.2 Characteristics of selected certified countries $(2010-2015) \ldots \ldots \ldots 33$

A2.3 List of importing and exporting countries . . . . . . . . . . . . . . 34

A2.4 Summary statistics of variables used in the gravity equation $\ldots \ldots \ldots \ldots \ldots$

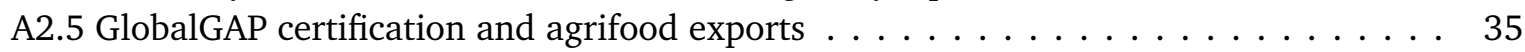

A2.6 Results of the Heckman Two-Step Estimation . . . . . . . . . . . . . . . . 36

A2.7 GlobalGAP certification and agrifood exports: IV regressions $\ldots \ldots \ldots \ldots \ldots$. . . 37

3.1 Brief description of the components of the Worldwide Governance Indicators . . . . 47

3.2 Total number of GlobalGAP certified producers per year ('000) . . . . . . . . . . . 49

3.3 Private food standards and governance distance - product-level exports . . . . . . . . 51

3.4 Private food standards and governance distance - income and product heterogeneities 52

3.5 Robustness check: bilateral product-level trade between all countries . . . . . . . . . 53

3.6 Private food standards and governance distance - all fruits and vegetables . . . . . . 54

A3.1 List of countries: non EU/EFTA exports to the EU/EFTA . . . . . . . . . . . . . 57

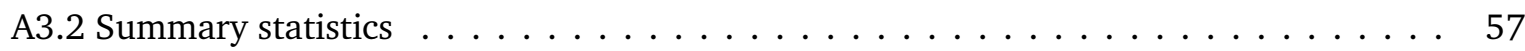

A3.3 Individual components of the composite bilateral governance distance measure . . . 58

A3.4 Measure of certification: number of certified farmers . . . . . . . . . . . . . . 59

A3.5 Using different measures of institutional quality . . . . . . . . . . . . 60

4.1 Comparison of maximum residue limits on selected products in 2014 . . . . . . . . 65

4.2 The effect of bilateral differences in MRLs on trade . . . . . . . . . . . . . . . . 74

4.3 The effect of standards on prices, quality and quality-adjusted prices . . . . . . . 75

4.4 The effect of standards on prices, quality and quality-adjusted prices: quality ladder . 76

4.5 Heterogeneities across different trade routes . . . . . . . . . . . . . . 77

A4.1 List of importing and exporting countries $\ldots \ldots \ldots \ldots \ldots \ldots \ldots \ldots$

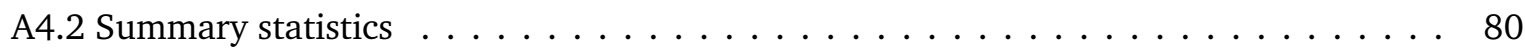

A4.3 The effect of bilateral differences in MRLs on trade: no bilateral fixed effects $\ldots \ldots$. . 80

A4.4 The effect of bilateral differences in MRLs on trade: one year lag of MRL $\ldots . . . .81$

A4.5 The effect of bilateral differences in MRLs on the probability of trade, market exit and

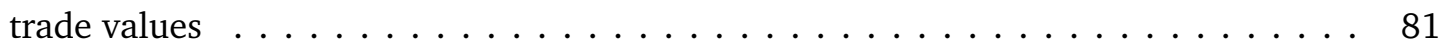


This page intentionally left blank 


\section{List of Abbreviations}

$\begin{array}{ll}\text { B2B } & \text { Business to Business } \\ \text { BRC } & \text { British Retail Consortium } \\ \text { CEPII } & \text { Centre d'Etudes Prospectives et d'Informations Internationales } \\ \text { CES } & \text { Constant Elasticity of Substitution } \\ \text { DCs } & \text { Developing Countries } \\ \text { EFTA } & \text { European Free Trade Area } \\ \text { EU } & \text { European Union } \\ \text { EUREPGAP } & \text { Euro-Retailer Produce Good Agricultural Practices } \\ \text { FAO } & \text { Food and Agricultural Organization } \\ \text { GAP } & \text { Good Agricultural Practices } \\ \text { GATT } & \text { General Arrangement on Tariffs and Trade } \\ \text { GDP } & \text { Gross Domestic Product } \\ \text { GVC } & \text { Global Value Chains } \\ \text { HS } & \text { Harmonised System } \\ \text { IV } & \text { Instrumental Variable } \\ \text { ISO } & \text { International Standards Organisation } \\ \text { I-TIP } & \text { Integrated Trade Intelligence Portal } \\ \text { MR } & \text { Multilateral Resistance } \\ \text { MRL } & \text { Maximum Residue Limits } \\ \text { NTB } & \text { Non Tariff Barriers } \\ \text { NTM } & \text { Non Tariff Measures } \\ \text { OLS } & \text { Ordinary Least Squares } \\ \text { PPML } & \text { Poisson Pseudo Maximum Likelihood } \\ \text { RTA } & \text { Regional Trade Agreement } \\ \text { SDG } & \text { Sustainable Development Goals } \\ \text { SPS } & \text { Sanitary and Phyto-Sanitary standards } \\ \text { TBT } & \text { Technical Barriers to Trade } \\ \text { TRAINS } & \text { Trade Analysis Information System } \\ \text { UNCTAD } & \text { United Nations Conference on Trade and Development } \\ \text { WGI } & \text { World Governance Indicators } \\ \text { WHO } & \text { World Health Organisation } \\ \text { WTO } & \text { World Trade Organisation } \\ \text { 2SLS } & \text { Two Stage Least Squares } \\ & \end{array}$


This page intentionally left blank 
für

David K. Fiankor

und

Christiane g. Christoph Tute

 
This page intentionally left blank 


\title{
Introduction
}

\begin{abstract}
"Just as all the world is against sin, so all the world is against non-tariff barriers to international trade - well, at least against everybody else's sin and non-tariff barriers. Similarly, just as the world has yet to discover a way of eliminating sin, it has a long way to go on removing non-tariff barriers." - (Winters, 1987)
\end{abstract}

There is enough evidence that trade is an engine for economic growth and a tool for combating poverty. Multilateral, bilateral and unilateral initiatives have facilitated this trade-led path to development by lowering custom tariffs. Between 1997 and 2015, average tariffs for non-agricultural products decreased from about $9 \%$ to $5 \%$. In agricultural markets, where levels of protection are traditionally high, average tariffs over the same period decreased from 18\% to 11\% (Niu et al., 2018). Despite this remarkable feat, international trade is still far from free. Today, average tariffs may be at historic lows but non-tariff measures (NTMs) have proliferated. NTMs are policy measures besides tariffs that also affect trade flows. These include technical standards and institutional red tapes. In 1997, 1456 product lines were subject to at least one type of NTM. By 2015, this number reached 2852 (Niu et al., 2018). Given the development implications of international trade, the threat or otherwise posed by NTMs to the global trade system deserves academic and public policy attention. ${ }^{1}$

In many high-value markets, export success is now conditional on compliance with NTMs as export competition has shifted from prices to quality (Curzi et al., 2015). So even with zero tariffs as guaranteed under many trade agreements, exports must pass NTMs before an importing country accepts them. Thus, tariff liberalisation, coupled with reductions in global logistic charges, have not completely improved the integration, especially of developing countries, into global value chains (GVCs). The economic gains from tariff cuts are offset by NTMs. This slows down globalisation-led economic development and has consequences for achieving the Sustainable Development Goals. ${ }^{2}$

Given their proliferation and increasing relevance as trade policy instruments (see, e.g., Figure 1.1), it is certain that we cannot ignore the role of NTMs in the push for inclusive economic development. Yet, our knowledge of the NTM-trade relationship is nuanced at best (Swinnen, 2016). This has implications for evidence-based policymaking. In this dissertation - made up of three self-contained essays - I contribute further clarity to this policy-relevant issue using the case of food

\footnotetext{
${ }^{1}$ Before the sudden surge in nationalism (e.g., "Trumpism" and Brexit), NTMs were the single most probable casus belli of the next trade war. But, due to recent events, e.g., the US-China trade war, tariffs are back in the news. Nevertheless, NTMs are still pressing and form the core of the 2020 World Development Report (World Bank, 2020).

${ }^{2}$ NTMs are (in)directly related to about nine of the 17 SDGs. To understand how NTMs interact with sustainable development, see https://unctad.org/en/Pages/DITC/Trade-Analysis/Non-Tariff-Measures/NTMs-and-SDGs.aspx
} 
safety standards in the agricultural sector. My immediate motivation is to assess the trade and welfare effects of two specific NTMs: (1) the private voluntary GlobalGAP standard and (2) public mandatory maximum residue limits. Why? GlobalGAP is arguably the most important private standard in the agrifood sector and maximum residue limits are fundamental to public regulations on food safety and quality. The specific research objectives are to (i) analyse the effects of standards on all bilateral trade flows (ii) assess their roles as alternative governance mechanisms when public institutions are weak and (iii) study their effects on consumer welfare via three channels: product varieties, product prices, and product quality upgrading. In so doing, this thesis makes new contributions to the standards and agricultural trade literature. This chapter motivates the need for another thesis on the standards-trade nexus, discusses the conceptual and empirical setup, and concludes with a summary of the essays. The individual chapters can, however, be read independently of each other.

\subsection{The economics of NTMs - a primer}

\subsubsection{Defining NTMs}

Formally, NTMs are policy measures, other than ordinary customs tariffs, that can potentially have an economic effect on international trade in goods, changing quantities traded, prices or both (UNCTAD, 2012). This definition's coverage of a range of trade policy measures may not be informative. To situate this dissertation in the broader NTMs and trade literature, I follow Staiger (2019) and define three broad categories of NTMs. ${ }^{3}$ The first two are applied at the border, either to imports (e.g., import quotas, import prohibitions, import licensing, and customs procedures), or to exports (e.g., export taxes, export subsidies, export quotas, export prohibitions, and voluntary export restraints). Like tariffs, these measures are by definition discriminatory. They affect only foreign exporting firms and drive a price wedge between domestic and foreign goods. Given their discriminatory nature, the trade effects of border NTMs are often obvious, e.g., import (export) bans will reduce imports (exports). A third category, the focus of this dissertation, are the so-called "behind-the-border" measures imposed internally in the importing country (e.g., domestic legislation covering health, product safety, standards and biosecurity). This includes also private voluntary standards. ${ }^{4}$

Unlike border measures, behind-the-border measures do not directly discriminate, but affect both home and foreign exporting firms. ${ }^{5}$ They are prima facie introduced to correct market imperfections, including alleviating information asymmetry, mitigating risks associated with consuming certain goods and enhancing sustainability. But, they can also be disguised instruments for protection. In fact, it can be a conceptual difficulty deciphering whether a particular regulation serves public interests or mercantilist objectives when both motives are often combined in a single measure (Swinnen, 2016). Hence, behind-the-border measures are much more complex, less uniform across commodities and

\footnotetext{
${ }^{3}$ Alternative classifications exist in the literature. For example, UNCTAD defines three categories: (i) technical measures (SPS and TBT), (ii) non-technical measures (price controls, quantity restrictions and prohibitions) and (iii) export related measures. Going by their definition, this dissertation focuses on the technical measures, specifically the SPS measures.

${ }^{4}$ The formal UNCTAD (2012) definition of NTMs does not include private standards. This is probably because a formal definition of what constitutes a private standard is still deadlocked at the WTO. In this thesis, however, we extend the definition of NTMs to include private standards.

${ }^{5}$ This is to ensure consistency with the WTO's national treatment principle (GATT Article III) which requires that once imported goods have crossed the border, they must be treated like locally produced goods. However, these measures tend to distort bilateral trade flows whether they are introduced for protectionist intents or not, e.g., introducing a stricter food standard will protect the health and safety of domestic consumers but will also increase trade costs for producers.
} 
countries, can be opaque and have political economy implications. The conventional wisdom that trade liberalisation improves welfare does not necessarily carry over to this category of NTMs. In the end, their trade and welfare effects are empirical questions. Going forward, unless otherwise stated, the use of the term NTM refers to behind-the-border measures. ${ }^{6}$

In this dissertation, I focus on standard-like NTMs, specifically food safety standards. In agricultural markets they are often the most important; driven among other things by increasing consumer awareness of food safety, shifting liability for food safety from governments to retailers, and growing public concern for consumer and environmental protection. Two main distinctions can be made regarding the definition of standard-like NTMs; i.e., public or private standards. These two differ mainly in who introduces the standard (the government versus private entities or NGOs), the extent to which they are mandatory (public standards are mostly by law mandatory but private standards are voluntary) and the extent to which they fall under WTO rules (for private standards the WTO has no authority). To provide a comprehensive overview of the issue, this thesis covers both sides of the standards divide. Chapters 2 and 3 focus on private standards and Chapter 4 focuses on public standards. And as our findings confirm, these two affect trade in different ways.

Why is there a disproportionate focus of the dissertation on private standards? The private sector, in particular, major retail chains, is developing and implementing private quality and safety standards, which can also be de facto mandatory requirements that condition assess to GVCs. Out of the 240 different standards listed in the International Trade Centre Standards Map database (as of September 2019), about 190 are private. In agricultural trade, these private sector led standards (e.g., GlobalGAP, Fairtrade, Organic, UTZ/Rainforest Alliance) are ubiquitous. Yet studies on public standards dominate the empirical literature. Part of the empirical difficulty is because data on private standards are often confidential and inaccessible. It is nevertheless important to analyse their trade effects because they are often more restrictive than public standards.

\subsubsection{Quantifying NTMs}

While tariff rates are not hard to find, data limitations make it difficult to document general trends in the use of NTMs. For public standards, key sources of data include efforts by international organisations (e.g., UNCTAD TRAINS), non-governmental institutions, various forms of government notification to the WTO or concerns raised through firm surveys. Using data from the WTO's I-TIP database, we see a clear increasing trend in the number of SPS measures notified to the WTO and the number of countries issuing a notification (Figure 1.1a). For private standards, the only probable sources of data are information from the standard setting bodies. Hence, there are few hard numbers to work with. If we use the case of GlobalGAP standards, we see that the number of farmers seeking voluntary certification and the number of certificates issued has increased over time (Figure 1.1b).

If we superimpose Figure 1.1 on a graph of average tariff rates over similar time frames, it becomes clear that the rise in NTMs coincides with a fall in tariffs (see, e.g., Figure 1 in Ehrich and Mangelsdorf, 2018). Due to the conceptual difficulty of converting NTMs into their ad valorem

\footnotetext{
${ }^{6}$ The decision to focus on behind-the-border NTMs also has a development implication. The NTMs typically employed in developing countries tend to be border measures, while in developed countries behind-the-border measures are prominent. Goldbeck and Yalcin (2018) show using data for the period 2000 and 2015 that applied tariffs are negatively correlated with income. This obvious asymmetry in the use of trade policy measures has relevant implications for developing countries pursuing an economic development model built around integration into global markets (de Melo and Nicita, 2018).
} 
Figure 1.1: Increasing relevance of non-tariff measures

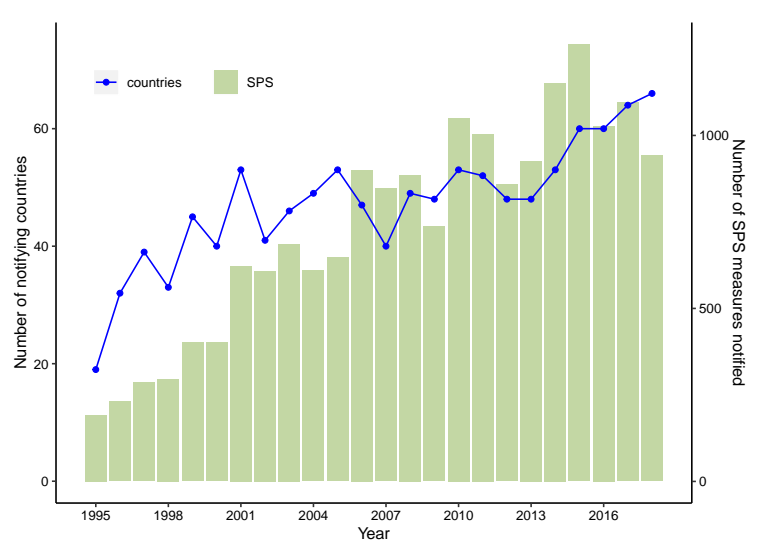

(a) SPS measures

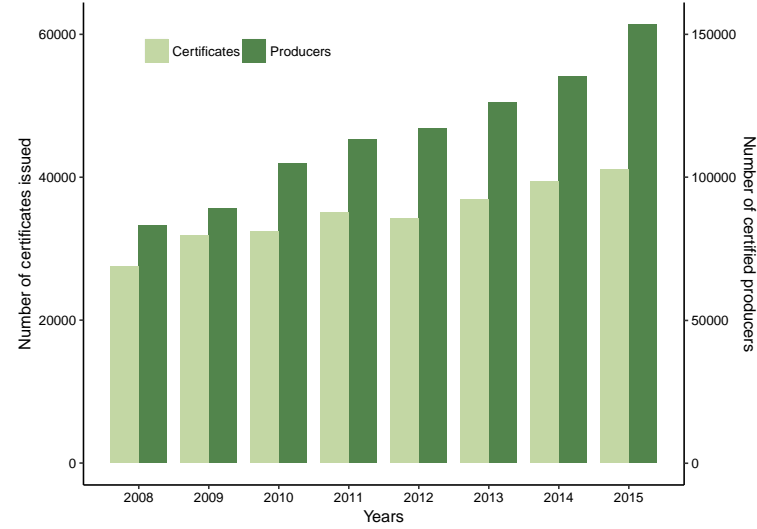

(b) GlobalGAP certification

Source: WTO I-TIP database and GlobalGAP data, own graph

equivalents, establishing a causal relationship between tariffs and NTMs has received limited attention in the literature. Empirical evidence, though scarce, confirm both substitutionary and complementary effects. This is a necessary field of research that lies outside the scope of this thesis.

Quantifying standards in a suitable form for empirical analyses is a challenge (Peterson et al., 2013). Many of the available public data sources contain counts of the different standards introduced by a country or for private standards the number of farmers or firms that are certified in a country. These counts are then used to construct frequency indices or coverage ratios. However, these measures are usually country-specific, and capture the prevalence of standards but not their strictness. This makes it difficult to compare the stringency of standards between countries. This dissertation addresses some of these data-related empirical challenges. For public standards we focus on maximum residue limits, henceforth MRLs. They are continuous measures of relative stringency set on specific products and thus comparable across country pairs. For instance, if two countries $i$ and $j$ set limits of $0.01 \mathrm{mg} \mathrm{kg}^{-1}$ and $0.50 \mathrm{mg} \mathrm{kg}^{-1}$ respectively on a pesticide-product pair, then it is clear that standards in $i$ are stricter than in $j$. For private standards, mandatory requirements are the same for producers regardless of location. ${ }^{7}$ This means that in terms of stringency there are no country variations. Adoption rates, however, differ and are the only objective measure of variation. Nevertheless, higher counts of certified firms, certified producers or certified land area in a country do not always imply a higher concentration of certified production in its total production. As a more appropriate measure, we propose the share of certified land area in the total harvest area of a country.

\subsubsection{Food safety standards and trade - a theoretical discussion}

As economists, we have always been aware of the importance of NTMs (see, e.g., Stern, 1973; Yeats, 1979; Winters, 1987) but empirical assessment of their trade effects gained prominence in the last decade. A recent review of the agricultural trade literature found that studies on the standards-trade effect increased from 14 in 2000 to 140 in 2017 (Santeramo and Lamonaca, 2019). This increase parallels the increase in the number of NTMs notified, notifying countries, and farmers pursuing

\footnotetext{
${ }^{7}$ This notwithstanding, it may be easier for producers in countries with well developed public standards to meet the requirements of private standards compared to their counterparts in countries with less-developed public standards.
} 
Figure 1.2: Trade effects of standards in a small open economy

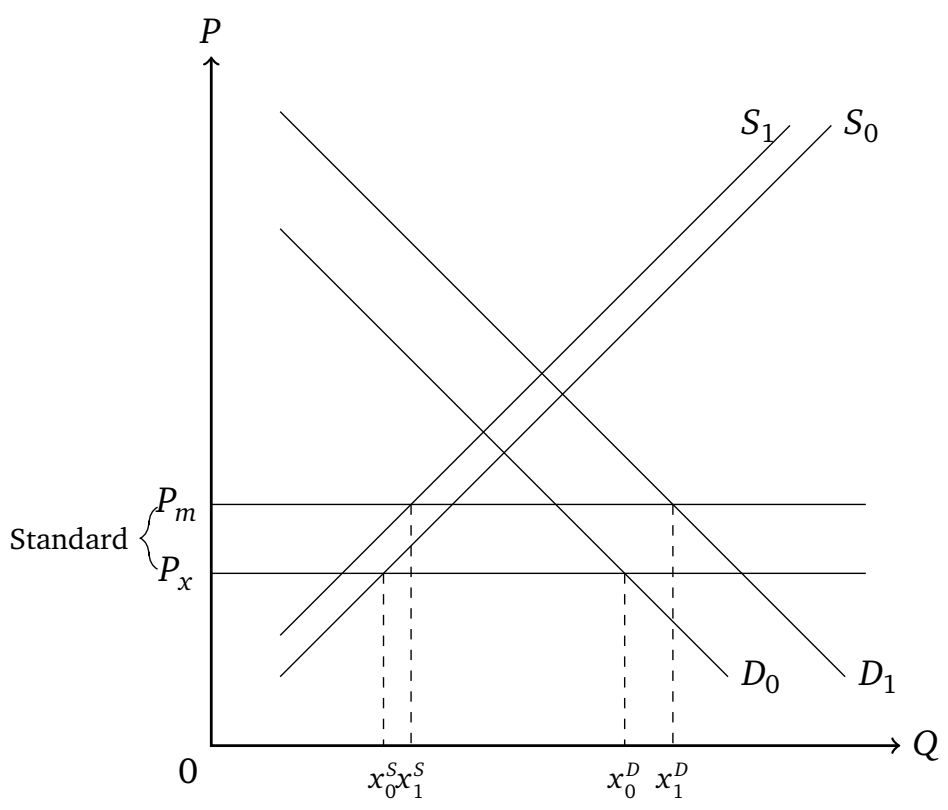

Source: adapted from Swinnen (2016)

voluntary certification (Figure 1.1). While these studies have tried to clarify the direction and size of their effects, the standards-trade effect remains ambiguous at worse or heterogeneous at best (see Table 2.1). The result is the almost unending "standards-as-catalysts or -barriers to trade" debate. This section provides concise theoretical justifications for the ambiguity of the standards-trade effect.

For one, standards shift both demand and supply curves and have different political economy implications. Take the case of a small open economy that introduces a standard (Figure 1.2). The cost-raising standard will shift the domestic supply curve from $S_{0}-S_{1}$ reflecting the increased cost of production. Since the standard addresses information asymmetries - situations where one party in a transaction has more information than the other - between producers and consumers, it also increases domestic demand from $D_{0}-D_{1}$. This improves consumer welfare as the gains from the outward shift of the demand curve are greater than the inward shift of the supply curve. Furthermore, under free trade - i.e., assuming that before the introduction of the standard at home, there was equivalence with standards at foreign - exports from foreign could enter the home country at $P_{x}$. The introduction of standards in the importing country raises the import competitive price to $P_{m}$. The difference, $P_{m}-P_{x}$, may reflect compliance cost pass-through to consumers in the importing country as higher prices, quality upgrading and signalling or a combination of the two effects.

At this point, let me emphasise that while the standards-trade effect may look similar to tariffs (e.g., raising import prices as in Figure 1.2), strict comparisons between the two are not valid. In a small open economy, the socially optimal tariff level is zero. This is not necessarily the case for standards. A call for zero standards ignores their potential consumer, producer or societal benefits. At home the optimal standard must consider the marginal gain in utility for consumers and the marginal cost for producers. Tariffs are by construction trade-reducing, but standards may also be marketcreating measures. The latter effect is depicted in Figure 1.2 where we see that the introduction of a standard increases domestic consumption $\left(x_{0}^{D}-x_{1}^{D}\right)$, domestic production $\left(x_{0}^{s}-x_{1}^{s}\right)$ and imports 
$\left(x_{0}^{S}-x_{0}^{D}\right.$ to $\left.x_{1}^{S}-x_{1}^{D}\right)$. A virtually identical approach can be used to show standards inducing a tradereducing effect. In any case, standards will always affect trade. The exception is when the standards effect on production exactly offsets the effects on consumption (Swinnen, 2016).

This dissertation aims at better understanding the country-level effects of standards on trade. Thanks to extensions of Krugman (1980)'s monopolistic competition model that incorporate firmheterogeneity (e.g., Chaney, 2008; Helpman et al., 2008), we acknowledge the different margins of trade. The changes in trade volumes we observe across countries or over time can be decomposed into an extensive margin (i.e., how much trade is because we have more products or exporters) and intensive margin (i.e., how much trade is due to higher volumes of existing products). In the neo-classical and Krugman models all export variations are on the intensive margin. More important, the different margins may respond differently to trade costs (Feenstra and Ma, 2014). The fixed cost component of a standard will affect mainly the extensive margin as increased production costs induce market exit for non-compliant firms. Theoretically, the effect on the intensive margin is $a$ priori ambiguous. Standards increase production costs and may reduce export volumes. But, the extra costs may be compensated by increased market access due to quality upgrading and/or more consumer information. To capture these differences, our analysis considers both margins of trade.

\subsubsection{Extensions to other welfare effects of standards}

The standards-trade effect is important, but so are their other welfare effects. For example, farm and household level studies report positive effects of standards on labour conditions (Schuster and Maertens, 2017) and reduced incidence of acute illnesses among farmers (Asfaw et al., 2010a). At the macro level, standards may affect welfare in ways that are not isomorphic to their effects on trade. For example, Disdier and Marette (2010) show that tighter standards on antibiotic residues in crustaceans improve social welfare but reduce the volume of trade. Yet, the large part of the empirical literature has focused attention on "the more simplistic issue of the trade effect" (Olper, 2016, pg. 293). Based on this premise, this dissertation considers not just the direct trade effects of standards but assesses other welfare effects, specifically (i) the corrective role of private standards in settings where institutions, as a proxy for public regulations, are weak and (ii) changes in product prices, product varieties available to consumers, and product quality upgrading.

There is theoretical and empirical evidence that domestic institutions and cross-country differences in institutional quality affect bilateral trade (e.g., Martínez-Zarzoso and Márquez-Ramos, 2019). In effect, while international trade remains important to integrate developing countries into GVCs, missing or weak institutions hamper their trade potential. What is certain, however, is that globally producers are embracing standards as quality signals to access high-value markets. To what extent do these market access provisions of standards hold for exporting countries with poor domestic institutions? Standards may have increased signalling effects among countries with extreme institutional quality differences or vice versa. Take for example, corruption; it erodes trust in public sector efforts to regulate the conduct of firms, thereby increasing the signalling value of private certifications. But corruption can also extend distrust to private standards and reduce their credibility and signalling value (Montiel et al., 2012). Yet, how gains from trade due to standards are realised in the context of institutional gaps is an empirical question that has received little attention in the literature. 
Standards are linked to food safety and quality. Yet public standards set by governments diverge substantially (see Table 4.1 for the case of MRLs). Since country-specific standards must be based on science, and public standards by construction do not discriminate against imports, it is difficult to distinguish genuine product quality concerns from disguised protectionist measures. But, do standards induce product quality upgrading? Unfortunately, this has been rarely studied in the agricultural trade literature. All we have are theoretical predictions (e.g., Gaigné and Larue, 2016) and anecdotal evidence (e.g., Beghin et al., 2015). We can excuse this lack of existing studies because the neoclassical and new-trade theories neglect the existence of product quality differences across countries. ${ }^{8}$ But recent extensions of the firm heterogeneity literature incorporate vertical quality differentiation across firms as key drivers of firms' export performance (Hallak, 2006; Crozet et al., 2012; Kugler and Verhoogen, 2011; Curzi and Olper, 2012). Insights from these models provide us with empirical evidence that successful exporters use higher-quality inputs and more skilled workers to produce higher-quality output that sell at higher prices. It is important to see the extent to which these apply to the agrifood sector. Indeed, agricultural markets have for long been the textbook case for perfect competition, but the proliferation of standards suggests otherwise. Standards specify a level of quality and define product characteristics and, as such, are typical features of differentiated product markets. The agrifood sector has shifted from an economy of quantities to one of qualities with producers in a position to select the quality, and not just the quantity, they produce (Hatanaka et al., 2006; Korinek et al., 2008). Hence, many agrifood markets cannot be studied with models of perfect competition because with standards, the axiom of homogeneous product is violated (Saitone and Sexton, 2010).

Standards may also affect welfare through their effects on industry structure. For instance, the theoretical model of Abel-Koch (2013) - who considers the economic effects of NTMs in a Melitz (2003) framework - predicts that standards decrease social welfare by reducing competition and product variety in the destination market imposing the standard. Due to the increased production costs, standards will induce market-exit for lower quality firms. Surviving exporters may exploit the reduced competition in this new market environment and pass on the extra costs of production to consumers as higher product prices. But there is a second possibility. By excluding low-quality exports, standards may limit the scope for product quality differentiation, but instead induce an increase in price competition. This will occur if mandatory compliance with the public standard leads firms that before the introduction of the standard were producing "low-quality" to improve their quality. In this case, the difference in quality between surviving firms reduces after the introduction of the standard. This will cause an increase in price competition and, as a consequence, a reduction of quality-adjusted prices. This mechanism is consistent with the theoretical model of Ronnen (1991). To verify the mechanism at play for public standards, this dissertation for the first time decomposes observed product price changes induced by MRLs into quality and quality-adjusted price components.

\footnotetext{
${ }^{8}$ It is important to mention here by way of digression that our understanding of international trade has changed a lot over time. In the neo-classical frameworks of the 19th century, countries trade because they are different. The 'newtrade' models of the 1980s introduced the now-obvious fact that trade is increasingly between similar countries, driven by economies of scale and consumers' love of variety. The 21st century 'new-new-trade' theory addresses the firm. This literature reminds us that it is not countries but firms that trade and though these firms are heterogeneous, they trade horizontally differentiated products. Recent extensions of the heterogeneous firms' literature contest the latter conclusion by showing that firms indeed trade goods of different quality (i.e., vertical differentiation).
} 


\subsection{Food standards and trade - the role of gravity}

"Gravity in trade is both fact and theory" (Carrére et al., 2019)

The goal of this dissertation is to better understand the country-level effects of trade costs, specifically food standards, on agricultural trade flows. In international economics, inferences on trade costs are mainly drawn from gravity equations linking observed trade flows to observable variables and unobservable trade costs (Anderson and Van Wincoop, 2004). The work presented in this thesis is empirical, but the analyses done within state-of-the-art structural gravity models are guided by sound economic principles. Gravity is distinguished by its parsimonious and tractable representation of economic interaction in a many-country world (Anderson, 2011). Here, I summarise the gravity model with a focus on the bits of theory and empirics relevant for the results presented in this thesis.

Gravity equations are basically expenditure equations that indicate how consumers allocate their spending across countries under the constraints of trade costs. But let us for expository reasons begin in a world free of trade costs, including standards-related costs. In this frictionless world, each good has the same price everywhere. We also assume that economic agents everywhere buy goods in the same proportions when faced with the same prices. In such a world, the natural benchmark prediction is

$$
X_{i j} / E_{j}=Y_{i} / Y
$$

where $X_{i j}$ is exports at destination prices from exporter $i$ to importer $j, E_{j}$ is expenditure in $j, Y_{i}$ is production in $i$ and $Y$ is world income. The implication of equation (1.1) is that the proportion of spending by $j$ on imports from $i$ is equal to the global proportion of spending on goods from $i$. We can easily infer trade frictions, if we impose market clearance. For goods this requires that sales from $i$, expenditures in $j$, and the sum of sales to all destinations must be equal, i.e., $\sum_{i} Y_{i}=\sum_{j} E_{j}=Y$. Multiplying both sides of equation (1.1) by $E_{j}$ yields predicted frictionless trade:

$$
X_{i j}=\frac{Y_{i} E_{j}}{Y}
$$

If we then take the ratio of observed trade $X_{i j}$ to predicted frictionless trade $Y_{i} E_{j} / Y$, we get the effect of trade frictions (e.g., food standards) along with random influences. This is a first attempt at deriving a theoretical gravity equation that is independent of the Newtonian idea of gravity. ${ }^{9}$

For a model that until the 21st century was disconnected from economic theory, several theoretical models now yield predictions that are close to gravity. ${ }^{10}$ In this thesis, I adopt the Armington-CES specification of Anderson and Van Wincoop (2003), specifically the product-specific specification

\footnotetext{
${ }^{9}$ Tinbergen (1962) applied the first gravity model of international trade. It was named gravity model because in its non-linear form, the model resembles Isaac Newton's Law of Universal Gravitation proposed in 1687. This was a rather practical approach that had no theoretical foundations in economics.

${ }^{10}$ The gravity model can be derived from a Ricardian structure with intermediate goods (Eaton and Kortum, 2002), Armington-CES model (Anderson and Van Wincoop, 2003), "new-new trade" theory with heterogeneous firms (Chaney, 2008; Helpman et al., 2008), "new trade" theory with monopolistic competition (Krugman, 1980) etc. Because the formal derivation of the gravity equation is now standard in the literature (see, e.g., Anderson and Van Wincoop, 2003; Baldwin and Taglioni, 2007; Yotov et al., 2016), I do not reproduce the derivation.
} 
in Anderson and Van Wincoop (2004). ${ }^{11}$ However, for simplicity in this section I derive the timeinvariant one-sector model of Anderson and Van Wincoop (2003), henceforth AvW. Two main assumptions underly the model. The first is the the Armington (1969) assumption that goods are differentiated by country of origin. ${ }^{12}$ Thus, the reason home consumers purchase foreign goods is because they are different from the ones produced at home. ${ }^{13}$ Second, consumer preferences are assumed identical and homothetic across countries and captured by a constant elasticity of substitution (CES) utility function. Solving the consumer optimisation problem and imposing market clearance yields the canonical AvW demand-side gravity equation:

$$
X_{i j}=\frac{Y_{i} E_{j}}{Y}\left(\frac{t_{i j}}{\Pi_{i} P_{j}}\right)^{1-\sigma}
$$

The right-hand side of equation (1.3) is a product of two ratios. The first ratio is the predicted trade flow under free trade (equation 1.2). However, observed economic interactions are far from this frictionless benchmark. As a key element in their model, AvW introduce and capture exogenous bilateral trade costs in the second ratio. The trade cost term is interpreted as the ratio of observed trade to frictionless trade, i.e., by comparing predicted and observed trade flows we obtain a measure of the trade effect of the trade cost term. The trade cost term consists of three components: (i) the numerator, $t_{i j}$, is the bilateral trade cost between $i$ and $j$ and contains our variable of interest. The denominator is made up of the structural terms (ii) $P_{j}$ and (iii) $\Pi_{i}$ which AvW call multilateral resistance. They measure the ease of market access for both the importer and the exporter. Controlling for $P_{j}$ and $\Pi_{i}$ is important to achieve precise estimates of our NTMs. Their omission can lead to wrong inferences. For instance, the trade impeding effects of standards found by Otsuki et al. (2001) disappear once controls for $P_{j}$ and $\Pi_{i}$ were introduced a decade later by Xiong and Beghin (2012).

In this dissertation, the interest lies in $t_{i j}$. This term enables us to show empirically how NTMs modify predicted frictionless trade (i.e., equation 1.2 or setting $t_{i j}=1 \forall_{i, j}$ in equation 1.3). As we see from equation (1.3), observed bilateral trade flows are lower the higher the trade cost $t_{i j}$ relative to $P_{j}$ and $\Pi_{i}$. We model $t_{i j}$ as a log-linear function of observed trade frictions. ${ }^{14} t_{i j}$ can be decomposed into 'natural' and 'unnatural' sources (Linnemann, 1966; Bergstrand and Egger, 2013). Natural trade costs refer to those incurred in most part by geography, e.g., the physical distance between countries and contiguity. Unnatural trade costs are mainly man-made policy decisions, e.g., trade agreements, tariffs, NTMs. The models estimated in this thesis account for both sources of trade costs, but the primary interest is on policy-related trade costs, specifically food standards. Compared to the frictionless world in equation (1.2), when a good is shipped from $i$ to $j$, the $t_{i j}$ s drive up the cost of each unit. As a result, in this more realistic setting, prices of goods differ across countries.

\footnotetext{
${ }^{11}$ One key assumption needed to generate a product-specific gravity equation is trade separability. Bilateral expenditures across countries at the aggregate and sectoral levels are separable from output and expenditure at the country level.

${ }^{12}$ Two goods of the same kind coming from different countries are imperfect substitutes, e.g., bananas from Colombia and bananas from Ecuador are distinct goods in the composite group bananas.

${ }^{13}$ Other motivations may exist for purchasing foreign goods, e.g., in a Ricardian world foreign goods will be purchased because they are produced more efficiently at foreign than at home.

14"While theory generally gives no guidance as to the appropriate functional form of the trade cost function, highly misleading results for trade barrier estimates arise when the wrong functional form is adopted" (Anderson and Van Wincoop, 2004, pg. 711). To ensure consistency with the gravity literature, we use the usual arbitrary log-linear specification of the trade cost function found in the gravity literature (see, e.g., Anderson and Van Wincoop, 2003, 2004; Emlinger et al., 2008; Yotov et al., 2016). Nevertheless, while this specification is very convenient it may be false.
} 


\subsection{Summary of essays}

\section{Essay 1: Does GlobalGAP certification promote agrifood exports?}

The GlobalGAP standard, one of the foremost private standards in the global agrifood sector, is emerging as a quasi-mandatory precondition to access various high-value markets, but has trade cost implications. Meeting GlobalGAP requirements involves passing several control points based on food safety, traceability, environmental sustainability and worker occupational health (GLOBALGAP, 2015). Yet, whether and to what extent GlobalGAP certification affects exports is an empirical question that has received only country/region-specific attention in the trade literature. Given that GlobalGAP has indeed become "global" with increasing importance for retailers even outside Europe, we provide the first ex-post empirical analysis of compliance with GlobalGAP on global bilateral trade flows.

This essay makes two new contributions to the literature. First, one major critic of the standards and trade literature is the lack of macro studies. This renders the generalisation of existing micro evidence from case studies problematic. This point is also corroborated by the authoritative review of the literature by John Beghin, Jo Swinnen and Miet Maertens (Beghin et al., 2015). For the first time, we contribute a multi-product and multi-country study that examines the effects of GlobalGAP standards on exports from all producing countries to all importing destinations. This allows us to draw more general conclusions. Even more important, this essay revisits how standards are measured in macro-level analyses. All existing studies - e.g., Vural and Akgüngör (2015), Ehrich and Mangelsdorf (2018) and Andersson (2018) - measure certification either as counts of certified firms, certified producers or certified land area in a country. These measures ignore the scale of certification within a country. Higher absolute counts of these measures do not always imply a higher concentration of certified production in a country's total production. Our second contribution to the broader private standards and trade literature is to propose the share of certified land area in the total harvest area of a country as a more appropriate measure. We argue that this isolates the effect of certification and rules out trade effects emerging from general growth trends in agricultural production.

We estimate structural gravity equations that account adequately for zero trade flows and zero certifications. ${ }^{15}$ Our results confirm a general trade enhancing effect of GlobalGAP certification on the probability of trading (i.e., the extensive margin) and the volume of exports conditional on trading (i.e., the intensive margin). The positive trade effects are driven more by increases in the area of certified farms, than from the entry of new certified farmers. However, the effect sizes are heterogeneous across apples, bananas and grapes. Once certified, the positive trade effects remain regardless of the development status of the exporting country. The trade effects are higher for exports to high-value EU and OECD markets but are substantial even for exports to markets outside these regions. Voluntary GlobalGAP certification may pose extra costs for producers, but it sustains market access.

\footnotetext{
${ }^{15}$ In the empirical analysis, we account for zero certifications using the approach by Battese (1997). While this approach is standard in the productivity literature and has also been used in the international aid literature, to the best of our knowledge this is the first application in the standards-trade literature. This means that unlike previous studies on GlobalGAP (Masood and Brümmer, 2014; Andersson, 2018) and other private standards (Ehrich and Mangelsdorf, 2018), we do not add an arbitrary small number to certification numbers before taking logs. Doing $\log (x+1)$ or some variant thereof has been the workhorse method to deal with zeroes in log-transformed variables since MaCurdy and Pencavel (1986). Over time, this approach has been criticised for introducing biases into the analysis. Our approach avoids this bias.
} 


\section{Essay 2: Exports and governance: the role of private voluntary agrifood standards}

Since Trefler (1995) introduced the idea of "missing trade", many studies have investigated why there is much less observed trade than in a predicted frictionless economy. One such identified constraint is the quality of domestic institutions. Bad institutions destroy international trade (Anderson and Marcouiller, 2002), but are a defining feature of many developing countries. Hence, this supply-side constraint further hinders the inclusion of developing countries into GVCs. In the Anderson and Marcouiller (2002) study, the tariff equivalent of poor Latin American institutions destroys about as much trade as their tariffs on average. Can the reduction of information asymmetry induced by standard-like NTMs play a corrective role in this regard? This question forms the core of the second essay where we examine whether and to what extent private voluntary standards offset bilateral institutional quality differences across countries and enhance trade. This research is well timed; the 2020 World Development Report (World Bank, 2020) emphasises that GVC linkages that depend on institutional quality are also particularly sticky, which calls for reputational mechanisms of cooperation that partly substitute for the absence of formal contracting. This chapter tests the extent to which GlobalGAP standards substitute for weak public institutions in producing countries.

This chapter extends the existing literature in two ways. First, it combines the concept of "institutional/governance distance" (Huchet-Bourdon and Cheptea, 2011; Álvarez et al., 2018) with that of "standards as catalysts to trade" (Swinnen, 2016) to develop a novel perspective of how voluntary standards create conditions that counter the trade-inhibiting effects of institutional distance. With growing research interest on the trade effects of voluntary standards, these findings are new. We are the first to consider their indirect trade effect from an institutional distance perspective. Second, using product level export data on apples, bananas, and grapes we investigate institutional distance and trade at the product level. Related studies consider aggregate (Álvarez et al., 2018; Martínez-Zarzoso and Márquez-Ramos, 2019) or sectoral trade flows; e.g., Huchet-Bourdon and Cheptea (2011). Even so, our findings generalise to the broader high-value agrifood sector.

Empirically, we estimate a structural gravity model on a sample of EU/EFTA imports from 134 countries between 2010 and 2015. We augment the model with a composite index of time-varying country-pair differences in the six dimensions of the World Governance Indicators ${ }^{16}$, which we call "governance distance", and its interaction with GlobalGAP standards to investigate the effect on trade flows. Our results show that while increasing governance distance hinders bilateral trade, the interaction of GlobalGAP standards and the governance distance is positively associated with exports, hence partially offsetting the direct trade-inhibiting effects of the latter. Certified countries see the trade-inhibiting effects of governance distance on their exports reduced by about $50 \%$, ceteris paribus. Put differently, when the quality of institutions differs widely between two countries, we argue and show empirical evidence that standards can act as (imperfect) substitute governance institutions. They level the playing field by placing geographically dispersed firms on a common ground in terms of managerial practices, business language and conflict-settling procedures. From a policy angle, voluntary certifications are viable means to improve exporting country reputations and increase trade even with differences in country-pair institutional quality.

\footnotetext{
${ }^{16}$ Our findings are robust to two other definitions of institutional quality using data from the Legatum Prosperity Index and the Economic Freedom of the World index.
} 


\section{Essay 3: Trade, price and quality upgrading effects of agrifood standards}

The third essay explores the existence and magnitude of any such quality-upgrading effect of imposing stricter standards on agrifood trade. The context is chemical use in crop production. In agriculture, chemical use is important to protect crops and enhance yields. But, depending on exposure levels, chemicals pose health risks. As such, most governments and multinational organisations set maximum residue limits (MRLs) to regulate their use. However, since chemical use is core to agricultural production, variations in regulations across countries will influence supply chains. With a steadily growing literature in trade and quality, none has ascertained the quality-upgrading effects of imposing stricter MRLs on trade flows. This essay contributes to filling this research gap by exploiting the bilateral difference in MRLs over the period 2005 - 2014 for 145 agrifood products and 59 countries.

This essay extends the existing literature in three ways. First, using MRL data to study the price and quality upgrading effects of standards improve the existing literature that only use counts of notifications (Curzi et al., 2020; Disdier et al., 2018; Movchan et al., 2019). MRLs are continuous measures of relative stringency that can be unambiguously ranked on a vertical scale. Hence they have a notion of strictness which allows comparability across countries. This "vertical" attribute of MRLs makes it more appropriate for use as a measure of quality. ${ }^{17}$ Second, public standards may be endogenous to trade volumes. A specific case is made for MRLs by Shingal et al. (2017). But, many empirical exercises carried out within the gravity framework ignore the problem. Following Baier and Bergstrand (2007), we address endogeneity concerns by including in our estimations a host of three-way fixed effects. Third, many countries in the South are tropical and suffer from severe pest and disease pressure. To the extent to which this is true, the average effects we estimate across all countries may hide interesting heterogeneous effects. As such, we explore how our estimates vary across different trade routes. There is limited evidence on trade route-specific effects of standards.

Empirically, we estimate different gravity-type models. We find that public standards are traderestrictive. They reduce trade at the extensive margin (i.e., the weighted count of traded varieties), the intensive margin (i.e., the market share of traded varieties in the total imports of the importer) and the value of exports conditional on trade. They also increase market exit rates. But, conditional on trading, standards lead to higher product prices. This holds even if we adjust prices for quality. However, we observe a rather small but statistically insignificant effect on product quality upgrading. ${ }^{18}$ The observed price effect is more a pure price increase (96\%) than a change in quality (4\%). Stricter standards, unlike higher tariffs, displace both non-compliant domestic firms and foreign exporters. This reduces competition in the imposing market, which successful firms exploit to exert some form of market power. Exploring the heterogeneity of these findings across different trade routes, we observe that the trade reducing effects and the price raising effects are pronounced for South-North trade but not exports to the South. Regulatory heterogeneity in terms of national MRLs disrupts trade (i.e., limited product varieties at higher prices) with null effects on product quality upgrading.

\footnotetext{
${ }^{17}$ If for example, two importing countries $j_{1}$ and $j_{2}$ set MRLs of 10 and $1 \mathrm{mg} \mathrm{kg}^{-1}$ respectively on a product-pesticide pair. Then a product with a residue count measured at the entry border of $3 \mathrm{mg} \mathrm{kg}^{-1}$ is considered high quality in $j_{1}$ but will be rejected in $j_{2}$ for being of low quality.

${ }^{18}$ Quality is estimated following Khandelwal et al. (2013) as the residual from a demand-side OLS regression that controls for product and country effects. The rationale behind this methodology is such that, if varieties of a good from countries $i_{1}$ and $i_{2}$ sell at the same price $p$, the country that offers a higher quality faces a higher demand from importing country $j$. We resort to this indirect, yet standard, approach because direct information on quality attributes are lacking.
} 


\title{
2 Does GlobalGAP certification promote agrifood exports?
}

\begin{abstract}
In global agricultural value-chains, private food standards are proliferating. Yet, their trade effects remain poorly understood. This paper assesses the effect of GlobalGAP certification on exports of apples, bananas and grapes. We estimate a structural gravity model using a global dataset of certified producers and the share of certified land area in total harvest area. While our results confirm GlobalGAP standards as catalysts to trade, we find that the trade-enhancing effect varies across products and destination markets. Furthermore, the trade effect is driven more by growth in the area of certified farms than by new certified producers.
\end{abstract}

JEL classification: F14, Q17, Q18

Keywords: agricultural trade, GlobalGAP, private food standards, gravity model

This chapter is published as: Fiankor, D-D. D, I. Flaschbarth, A. Masood and B. Brümmer (2020): Does GlobalGAP certification promote agricultural exports? European Review of Agricultural Economics, 47(1): 247-272.

Acknowledgements: We received much appreciated comments from Ehrich Malte, Nina Graßnick, Inmaculada MartínezZarzoso, participants of the European Trade Study Group Conference in Florence, Italy and three anonymous Referees of the European Review of Agricultural Economics.

Author contributions: This chapter builds on earlier work by A. Masood and B. Brümmer. Fiankor D-D. D. conceptualised the research design, analysed the data and wrote the paper. I. Flaschbarth and B. Brümmer revised the paper. 


\subsection{Introduction}

Standards are proliferating, both geographically and in terms of addressing new concerns (Swinnen, 2016). The agrifood sector, in particular, is prone to their increasing stringency. Food safety standards are prominent in the governance of global agricultural value chains, from farm to fork. Unlike de jure mandatory public standards, private standards are voluntary. However, the proliferation of private standards and the increasing market power of multinational retail chains and agribusiness firms means voluntary compliance is de facto mandatory to gain and maintain access to high-value markets (Henson and Humphrey, 2010).

Tariffs and quantitative restrictions on international trade are low, providing an impetus for retailers to diversify their product origins. Thus, besides the increasing consumer demand for food safety, the growing relevance of private food standards is due in part to efforts by retail chains to control entire production processes and ease supply chain management within increasingly globalised and competitive agrifood markets (Clarke, 2010). This way, they limit the associated risks of working with various spatially dispersed actors and activities in the supply chain (Dolan and Humphrey, 2000), ensure due diligence and protect their reputations (Subervie and Vagneron, 2013). Standards allow for product differentiation, decreasing consumer uncertainty and increasing demand (Vandemoortele and Deconinck, 2014). By adopting standards, producers also signal to retailers their commitments to quality attributes, such as safety, environmental sustainability and decent labour conditions (Goedhuys and Sleuwaegen, 2016).

Yet, the literature on how standards affect trade is inconclusive. High compliance costs may reduce trade flows (Shepherd and Wilson, 2013) from countries where farmers fail to get certified, but the associated improvement in information asymmetry and the reduced consumer search costs may enhance trade (Henson and Jaffee, 2008). Standards may have no trade effects (Schuster and Maertens, 2015), different short and long run trade effects (Maertens and Swinnen, 2009a) or favour developed country producers over their counterparts in developing countries (Xiong and Beghin, 2014; Ferro et al., 2015; Curzi et al., 2018) as the latter are usually standard takers. They may also benefit exporters with large trade volumes, but hinder exports from small trading partners (Anders and Caswell, 2009; Fernandes et al., 2019) since large exporters may find it more profitable to invest in compliance.

The heterogeneity of the standards-trade effect creates room for further and better empirical research (Beghin et al., 2015; Honda et al., 2015). In agricultural and food markets, private standards are ubiquitous, yet studies on public standards predominate the empirical literature (e.g., Anders and Caswell, 2009; Ferro et al., 2015). ${ }^{19}$ Indeed, part of the empirical difficulty is because data on private standards are often confidential and inaccessible. It is nevertheless important to analyse their trade effects because they are often more stringent than public standards (Colen et al., 2012). Understanding the heterogeneity of the private standards and trade effect will reveal important policy implications, e.g., for producers deciding between the choice of standards and destination markets (Andersson, 2018).

\footnotetext{
${ }^{19}$ Out of about 240 different standards listed in the International Trade Centre Standards Map database, about 190 are private (http://sustainabilitymap.org/standardidentify/). These may be established by firms (e.g., Tesco Nurture, and Nature's Choice), independent standard-setting bodies or NGOs (e.g., Fairtrade International, Rainforest Alliance, Marine Stewardship Council), and industry bodies or coalition of firms (e.g., BRC, IFS, GlobalGAP).
} 
In this paper, we focus on the GlobalGAP standard, one of the foremost private standards in the global agrifood sector. It is emerging as a quasi-mandatory precondition to access various highvalue markets. This has trade cost implications; meeting GlobalGAP requirements involve passing several control points based on food safety, traceability, environmental sustainability and worker occupational health (GLOBALGAP, 2015). These can be barriers to resource-constrained producers, influence adoption decisions (Lippe and Grote, 2017) and hinder market access. ${ }^{20}$ For example, to get certified, farms undergo detailed third-party audits of their documented procedures against GlobalGAP requirements. Control points include traceability (e.g., producers must guarantee products can be traced back to their farms, register exact planting and harvesting dates), record keeping (e.g., producers record all substances applied to crops, exact amounts, application dates), use of certified seed varieties and fertilisers, irrigation without contaminated water, and Integrated Pest Management (e.g., control pests in ecologically sensitive ways). Upon approval, a certificate is issued but subject to annual renewal. Hence, to choose compliance, the expected utility of producing the certified products (e.g., increased trade volumes) must be large enough to compensate producers for the extra costs involved. For retailers, the transaction costs of identifying farmers producing according to industry-accepted standards are also reduced.

However, whether and to what extent GlobalGAP certification affects exports is an empirical question that has received little attention in the agricultural trade literature. We provide the first ex-post empirical analysis of compliance with GlobalGAP on bilateral trade flows. Our study is novel in two ways. First, we question the generality of existing studies, which are all either country/region-specific, product-specific or use cross-sectional data (see also Beghin et al., 2015). These include studies on export vegetable production in Kenya (Asfaw et al., 2010b), lychees in Madagascar (Subervie and Vagneron, 2013), pineapple exports from Ghana (Kleemann et al., 2014), asparagus exporting firms in Peru (Schuster and Maertens, 2015), and EU banana (Masood and Brümmer, 2014) and fruit and vegetable imports (Andersson, 2018). We analyse the effects in a full multi-country and multi-sector (i.e., apples, bananas, and grapes) framework. Our second contribution is to the broader private standards and trade literature. To our knowledge, existing studies measure certification as the count of certified firms, land area or producers in a country (see, e.g., Herzfeld et al., 2011; Vural and Akgüngör, 2015; Ehrich and Mangelsdorf, 2018; Andersson, 2018). These ignore the scale of certification within a country, as higher counts of certified producers, firms or area may not always imply a higher concentration of certified production in a country's total production. We propose the share of certified land area in the total harvest area of a country as an additional measure. We argue that this adds valuable information in two ways: it (1) puts the increase of certification in proportion to the total increase in production and (2) allows for an interpretation of size effects, which can result from an increase in certified area without increases in the number of certified producers.

Empirically, we specify a gravity equation, account for zero trade flows, and address the potential endogeneity of certification. We hypothesise that GlobalGAP enhances trade if compliance is successful. The intuition behind this expectation is clear; certification reduces the transaction costs involved in importer-exporter relationships, and the certification process may serve as an important

\footnotetext{
${ }^{20}$ In some countries agricultural productivity is too low to bear the fixed entry and variable costs of certification, which may crowd them out of export markets. In this case, imposing standards may reduce trade flows.
} 
learning instrument for exporting countries (Goedhuys and Sleuwaegen, 2016) - who according to recent theoretical models (e.g., Chaney, 2008; Helpman et al., 2008) are the most productive and self-select into becoming exporters. These should facilitate market access. Nevertheless, this effect may vary by product, origin and destination market. Hence, our analysis considers both intensive and extensive margins and questions the heterogeneity of the effects according to characteristics of the origin and destination markets. In many cases, the findings support our hypothesis; GlobalGAP certifications may be extra costs for producers, but they sustain import demand.

The paper proceeds as follows. Section 2.2 provides some background information on the relationship between standards and trade, focusing on GlobalGAP. This is followed by a description of the data and the empirical strategy in Sections 2.3 and 2.4. We present and discuss the results in Section 2.5, and offer concluding remarks with policy implications in Section 2.6.

\subsection{Private food standards and trade}

\subsubsection{Empirical evidence}

We review and summarise the rather scant empirical literature related to the private food standards and agricultural trade nexus in Table 2.1. ${ }^{21}$ These studies use mainly country-level data (Mangelsdorf et al., 2012; Shepherd and Wilson, 2013; Vural and Akgüngör, 2015; Ehrich and Mangelsdorf, 2018), but the use of firm-level data is becoming prominent (Melo et al., 2014; Latouche and ChevassusLozza, 2015; Schuster and Maertens, 2015). Inferring from the table, while the empirical findings

Table 2.1: Summary of empirical studies on the trade effects of voluntary food standards

\begin{tabular}{|c|c|c|c|c|}
\hline Study & Trade flows & Standards & Products & Effect \\
\hline Ehrich and Mangelsdorf (2018) & $\begin{array}{l}\text { Bilateral trade } \\
\text { (87 countries) }\end{array}$ & IFS & Manufactured food products & + \\
\hline Latouche and Chevassus-Lozza (2015) & France - EU & IFS, BRC & Agrifood products & + \\
\hline Melo et al. (2014) & Chile - RoW & ChileGAP & Fresh fruits & + \\
\hline Andersson (2018) & RoW - EU-15 & GlobalGAP & Fruits and vegetables & + \\
\hline Masood and Brümmer (2014) & RoW - EU-27 & GlobalGAP & Banana & + \\
\hline Henson et al. (2011) & SSA - RoW & GlobalGAP & Fresh produce & + \\
\hline Schuster and Maertens (2015) & Peru - RoW & Multiple & Asparagus & $\bullet$ \\
\hline Mangelsdorf et al. (2012) & China - RoW & SAC & $\begin{array}{l}\text { Fish, Tea } \\
\text { Sugar, Vegetables } \\
\text { Meat, cereals, milk }\end{array}$ & $\begin{array}{l}- \\
+ \\
-\end{array}$ \\
\hline Vural and Akgüngör (2015) & $\begin{array}{l}24 \text { exporters - } \\
22 \text { importers }\end{array}$ & ISO 22000 & $\begin{array}{l}\text { Fresh fruits } \\
\text { Fresh vegetables }\end{array}$ & $\begin{array}{l}+ \\
+\end{array}$ \\
\hline Shepherd and Wilson (2013) & RoW - EU & CEN & $\begin{array}{l}\text { Dairy and eggs } \\
\text { Oil seeds } \\
\text { Cereals } \\
\text { Malt, starches, inulin } \\
\text { Fats and oils } \\
\text { Cereal preparations }\end{array}$ & $\begin{array}{l}+ \\
+ \\
- \\
- \\
- \\
-\end{array}$ \\
\hline
\end{tabular}

Notes: Standards are represented as CEN $=$ European Committee for Standardisation, IFS $=$ International Featured Standards, BRC $=$ British Retail Consortium standards, $\mathrm{SAC}=$ Standards Administration of the Peoples Republic of China. RoW means rest of the world. $\bullet$ : no statistically significant effects were found.

\footnotetext{
${ }^{21}$ For a detailed review of the effects of public standards on trade, see Honda et al. (2015).
} 
are mixed, positive trade effects dominate. Beyond the well established, positive and negative effects, some studies find no statistically significant effects. Our review indicates that the direction of the effect depends on the particular standard and/or product and/or country-pairs under study. A specific standard may have heterogeneous effects across products; e.g., for voluntary product standards in the EU food and agriculture market, Shepherd and Wilson (2013) find positive trade effects for dairy and egg products, negative effects for cereals and no statistically significant effects for fats and oils. Mangelsdorf et al. (2012) find that voluntary international standards in China hinder exports of fish and tea, but enhance exports of sugar and vegetables.

Table 2.1 also situates our study within the broader standards and trade literature; no previous study considers the effects of any private food standard on exports from all producing to all importing countries. This study is the first considering global bilateral trade flows. This is crucial because GlobalGAP has indeed become 'global', with increasing importance for retailers even outside Europe.

\subsubsection{The case of GlobalGAP standards}

In this section, we discuss the trade cost implications of GlobalGAP. Formally known as the Global Partnership for Good Agricultural Practices, GlobalGAP is the most widely used certification scheme in the global agrifood export sector. Over time, the number of certified producers and the area cultivated to fruits and vegetables has increased across all continents (Figure 2.1).

GlobalGAP is a process standard. It indicates at every stage of production - from soil management, plant protection to non-processed end product - how crops must be produced and handled. Developed within a business-to-business context, it assures retailers of product safety and does not signal quality directly to consumers. Producers may be better informed about their product attributes, but these are not always directly observable by buyers. To reduce the transaction cost-increasing effect of such information asymmetries, members of the Euro-Retailer Produce Working Group reacting to consumer concerns (e.g., product safety) and technical regulations (e.g., due diligence) harmonised their then different agrifood standards (van der Meulen, 2011) to form EurepGAP in 1997. To mark their global relevance they changed their name to GlobalGAP in 2007. The standard is

Figure 2.1: Development of GlobalGAP certified producers and land area by region

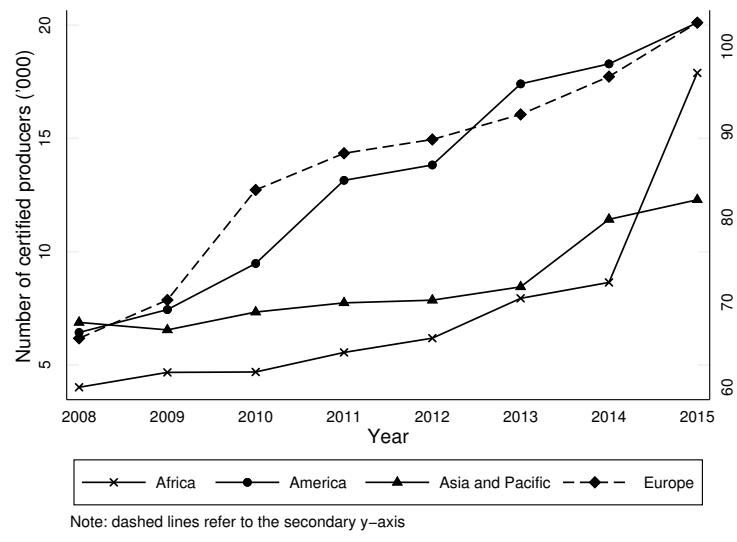

(a) Certified producers

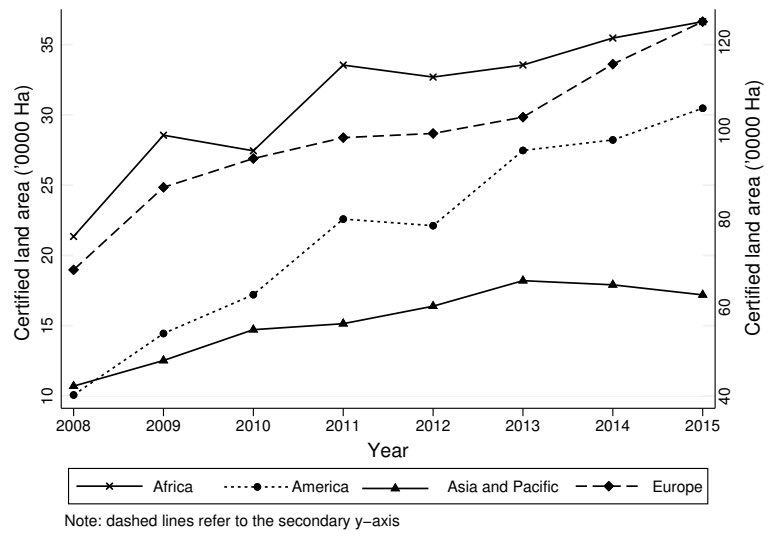

(b) Certified land area

Source: GlobalGAP data, own graph 
thus not proprietary to a single retailer, and product differentiation is a minor objective. For retailers, reduced transaction costs and improved supply chain management are motivations for requiring certification.

Granted that standards open up market access to participating producers, they also often imply the use of improved and more costly technology (Swinnen, 2016). That is, while retailers demand certification, the costs of compliance are at the expense of the producer. These costs - which can be recurring (e.g., annual certification renewals), non-recurring (e.g., upgrading infrastructure and facilities), tangible (e.g., establishing laboratory facilities) or intangible (e.g., opportunity costs) vary depending on the quality of existing domestic food safety regulations in the producing country (or specifically the farm). In countries with low domestic public standards, the initial cost of upgrading is higher if they need to implement new policies, processes, and installations. For countries with stringent domestic standards, producers already bear higher costs to comply. This allows them access to other markets with tight requirements at negligible or no extra costs (Drogué and DeMaria, 2012; Xiong and Beghin, 2014).

If compliance fails due to high setup and production costs, standards imposed by multinationals can hinder trade (Maertens and Swinnen, 2009a). For example, to be GlobalGAP certified, producers pay initial certification fees, annual registration fees (charged per product and per hectare) and the associated costs of implementing the standard. These are likely to be initial barriers to trade for farmers. To ease compliance, especially for producers in developing regions, GlobalGAP allows certification of farmers in groups. They also introduced the so-called localg.a.p. schemes ${ }^{22}$, which allow adapting existing domestic standards to GlobalGAP while maintaining international standards. There are also reported cases of technical and financial support from donors and trade facilitators (Subervie and Vagneron, 2013), in which case farmers do not have to bear the full cost of certification.

If compliance is successful, there are potential trade benefits. Standards reduce transaction costs by providing a common language within supply chains. This links increasingly demanding retailer requirements with increasing participation of distant suppliers and raises consumer confidence in product safety (Henson and Jaffee, 2008; Ferro et al., 2015). They lower coordination costs, and reduce information asymmetries and the cost of solving moral hazards for buyers facing heterogeneous suppliers (Russo et al., 2014). Standards help in reducing market failures; they allow retailers a common basis to compare products, and production subject to harmonised standards helps producers achieve economies of scale (Wilson, 2008). When standards are not harmonised, producers most likely face a wide divergence between their domestic and international food safety standards (Maertens and Swinnen, 2009a). By harmonising different agrifood standard requirements, GlobalGAP allows producers to export to different high-value markets without having to adopt country or retailer-specific production processes.

The GlobalGAP system provides a cost-effective way for retailers to identify farmers producing according to industry-accepted standards, i.e., those who are voluntarily certified. Hence, for producers, certification is a quality signalling mechanism or cost of doing business. For them, the mandatory

\footnotetext{
${ }^{22}$ The localg.a.p. program, seen as a cost-effective solution for emerging markets, serves as a stepping stone toward full GlobalGAP certification. It allows retailers and food service providers the chance to initiate food safety programs to prepare their supply base for eventual GlobalGAP certification. Examples include ChileGAP, ChinaGAP, KenyaGAP, MexicoGAP.
} 
initial investments and recurrent expenditures are nevertheless likely to result in increased productivity and/or enhanced product quality arising from other indirect trade effects of certification. Some studies find significant positive effects of GlobalGAP certification on firm performance, e.g., bettertrained employees (Colen et al., 2012) and reduced incidence of acute illnesses (Asfaw et al., 2010a). Following GlobalGAP protocols ensures better farm management, and increases exportable yields and sales volume. ${ }^{23}$

In summary, GlobalGAP certification harmonises agricultural practices across farms in different countries and signals product quality to retailers. These properties lower the transaction costs and information asymmetries involved in producer and retailer relationships and enhance international trade (Clougherty and Grajek, 2008). Given these mechanisms, we hypothesise that once certified, GlobalGAP standards have positive effects on trade.

\subsection{Data}

We use an Integrated Farm Assurance Standard (i.e., the GlobalGAP certificate) dataset supplied by the GlobalGAP Secretariat in Cologne, Germany. GlobalGAP offers 16 standards for three scopes: crops, livestock, and aquaculture. We limit our study to crops, specifically fruits and vegetables, where producers are mostly certified. There are about 150,000 certified fruit and vegetable producers in 120 countries covering about 3 million hectares of land area. We focus on apples, bananas and grapes, which together with potatoes constitute the top four GlobalGAP certified open field crops in terms of area (GLOBALGAP, 2012). ${ }^{24}$ We note that including only three crops limits our ability to draw general conclusions about trade effects for the entire agrifood sector. However, with these products, we include a major fraction of the overall certified crop sector - i.e., about $30 \%$ of certified fruits and vegetable producers - in our analysis. Furthermore, with multiple products, we can explore the heterogeneity of the trade effect, while assessing whether the trend remains independent of specific products. It also allows us to assess how the trade effects vary across income distributions; while developing countries dominate the export market for banana, the reverse is the case for apples and grapes (Table A2.1 of the appendix).

A bit more background on the different GlobalGAP certification schemes may help motivate our choice of target variables. There are four GlobalGAP certification options; of interest to our study are options one (where individual farmers apply for certification) and two (where a collection of farmers apply for group certification). The remaining options are the single producer and group certification benchmarked schemes. For each certified country, our dataset contains annual data on (1) the number of product-specific certificates issued and (2) the number of certified producers per product. Data on (1) aggregate both individual and group certificates and understates the actual number of farmers seeking certification. Group certifications help to achieve economies of scale, but variations in group size obscure the actual numbers of certified producers in a country. Taking mean values across countries, this effect is highest for bananas with eight times as many certified producers

\footnotetext{
${ }^{23}$ For instance, the GlobalGAP Chain of Custody certification ensures market agents handling certified products properly segregate certified and non-certified products in packing units (GLOBALGAP, 2015). In their study on GlobalGAP certified lychee producers in Madagascar, Subervie and Vagneron (2013) also find that local treatment plants provided separate sorting lines for certified and non-certified products. These guarantee certified, but not non-certified farmers, the opportunity to sell larger quantities.

${ }^{24}$ Due to data limitations, we cannot include potatoes in our analysis.
} 
Table 2.2: Overview of individual versus group certification per product (2010 - 2015)

\begin{tabular}{lrrrrrrr}
\hline & \multicolumn{1}{l}{ Mean } & & & \multicolumn{3}{c}{ Total (Millions) } \\
\cline { 2 - 3 } & \multicolumn{1}{c}{ Apples } & Bananas & Grapes & & Apples & Bananas & Grapes \\
\hline Number of certified producers & 239.39 & 72.08 & 85.29 & & 20.40 & 7.30 & 7.03 \\
Number of issued certificates & 71.49 & 8.30 & 26.78 & & 6.09 & 0.84 & 2.21 \\
Producers per certificate & 3.35 & 8.68 & 3.19 & & 3.35 & 8.68 & 3.19 \\
\hline
\end{tabular}

Source: GlobalGAP data, own calculations

as the number of certificates issued (Table 2.2). Certification-specific investments lead smallholder farmers, who predominate developing countries, to pursue group certifications (see, e.g., Mausch et al., 2009). To measure certification, we use the count of certified producers per product in our empirical analysis, as the number of certificates issued might understate the certification effect. Our dataset also contains data on GlobalGAP certified land area per product. ${ }^{25}$ Hence, we will also use the share of certified area in total harvest area as a comparative measure.

For exploratory purposes, Figure A2.1 of the appendix plots graphically in panel (a) the relationship between GlobalGAP certification and development (measured as per capita GDP) and, in panel (b) the relationship between certification and exports. The observed correlation is positive in both cases. In Table A2.2 of the Appenddix we explore detailed characteristics of selected certified countries with the highest shares of certified area per product. Interestingly, countries with high counts of certified producers do not always have large shares of their total harvest area certified. This justifies our approach of using both measures in the empirical analysis. Take the case of two banana-producing countries: Peru and Costa Rica. Over the study period, Peru, with 4010 certified producers, had only $56 \%$ of harvest area certified while Costa Rica, with 90 certified producers, had about $71 \%$ of harvest area certified. Production and exports are also higher in Costa Rica compared to Peru.

Our data series covers the period 2010 to 2015 and includes exports from 163 producing countries to 157 importing countries (see Table A2.3 of the Appendix). ${ }^{26}$ The dataset includes 91 appleproducing countries, 108 banana-producing countries, and 88 grape-producing countries. Out of these, 45 countries had at least one certified apple producer, 39 countries had at least one certified banana producer and 44 countries had at least one certified grape producer. We use trade data - from the United Nations Comtrade database via the World Integrated Trade Solution - at the six-digit level of the Harmonised System (HS)-2007 classification. It includes apples (HS080810 and HS081330), bananas (HS080300) ${ }^{27}$ and grapes (HS080610 and HS080620). Data on agricultural production and harvest area are from FAOSTAT of the Food and Agricultural Organisation. Country pair data on distance, colonial ties, common language, and contiguity are from the Centre d'Etudes Prospectives

\footnotetext{
${ }^{25}$ The number of hectares for countries or products with less than 10 producers is not provided by GlobalGAP. This, according to GlobalGAP is to ensure that it is not possible to identify individual producers. In such cases we calculate missing values for certified area by multiplying the average land size per certificate issued across countries in a year by the number of certificates issued in a country per year.

${ }^{26}$ We limit the bilateral trade data to six years to match the available GlobalGAP data.

${ }^{27}$ Banana trade flows recorded in the six-digit HS2007 classification includes plantains. But trade volumes are low compared to bananas, and should not alter our results. Since GlobalGAP certified area contains only bananas, the remaining banana-specific variables exclude plantains.
} 
et d'Informations Internationales, data on effectively applied tariffs are from the International Trade Centre, and data on regional trade agreements come from De Sousa (2012). See Appendix Table A2.4 for detailed summary statistics on all included variables.

\subsection{Empirical application}

To quantify the effect of GlobalGAP certification on global agrifood trade, we follow a consolidated tradition and use an augmented gravity equation. Hence, the gravity theory will guide our analysis and estimates. The gravity model has over the years developed into the preferred tool for trade policy analysis and is favoured among empirical researchers estimating the impact of standards on trade flows (Anders and Caswell, 2009; Ferro et al., 2015). Aside from its intuitive appeal, it has solid theoretical foundations, represents a realistic general equilibrium environment, and has good predictive power (Yotov et al., 2016). Taking the micro-founded specification of Anderson and Van Wincoop (2004) as our starting point, we estimate the following theory-consistent gravity model based on a constant elasticity of substitution demand in a general equilibrium structure:

$$
\ln X_{i j k t}=\ln E_{j t}+\ln Y_{i k t}-\ln Y_{k t}+\left(1-\sigma_{k}\right) \ln T_{i j k t}-\left(1-\sigma_{k}\right) \ln P_{j k t}-\left(1-\sigma_{k}\right) \ln \Pi_{i k t}+\varepsilon_{i j k t}
$$

where $\mathrm{X}_{i j k t}$ is trade flows (in current US dollars) of product $k$ from exporting country $i$ to importing country $j$ in year t. $\sigma_{k}$ is the intra-sectoral elasticity of substitution. $\mathrm{E}_{j t}$ is nominal GDP, which proxies the importing country's expenditure on product $k$. $\mathrm{Y}_{i k t}$ is the domestic production of $k$ in the exporting country. GDP is usually used as a proxy for the mass of exporting countries, but we consider sector-specific production as a better measure of the supply-side capacity in our model. This variable captures adequately the effect of domestic production of product $k$ on exports. We a priori expect that bigger producing countries will on average also export more. $Y_{k t}$ is aggregate world production for sector $k . P_{j k t}$ and $\Pi_{i k t}$ are the sectoral inward and outward multilateral resistance terms respectively. $\varepsilon_{i j k t}$ is the error term. Critical for our analysis is the trade cost term $T_{i j k t}$, which we define as the following log-linear function:

$$
T_{i j k t}=D_{i j}^{\beta_{1}} \tau_{i j k t}^{\beta_{2}} \text { GlobalGAP }_{i k t}^{\beta_{3}} \mathrm{O}_{i j k t} \exp \sum_{n=4}^{7} \beta_{n} \Omega_{i j t}
$$

$\mathrm{D}_{i j}$ is the bilateral distance between the capital cities of $i$ and $j$, and $\Omega_{i j}$ is a vector of traditional gravity covariates including dummies for common language (Language ${ }_{i j}$ ), colonial ties (Colony ${ }_{i j}$ ), sharing a common border (Contiguity ${ }_{i j}$ ), and membership of a regional trade agreement $\left(\mathrm{RTA}_{i j t}\right) \cdot \tau_{i j k t}$ is product-specific ad valorem tariffs defined as $\left(1+\right.$ Tariff $\left._{i j k t}\right)$. Following Emlinger et al. (2008) we include the variable $\mathrm{O}_{i j k t}$ to account for all remaining trade resistance terms. These include exchange rates, institutions, infrastructure, product-specific non-tariff measures imposed by the importing country (e.g., SPS, TBT, quantitative restrictions) and further unobservable time-varying country and product-specific variables.

It is important that the trade cost implications of GlobalGAP certification reflect in our empirical models. We augment the standard definition of $T_{i j k t}$ in equation (2.2) with our variable of interest, GlobalGAP $_{i k t}$. As we discuss in Section 2.2.2, GlobalGAP standards have trade cost implications. On the supply side, adjusting to new production procedures as per the requirements of the standard induces extra costs for producers. Besides, producing subject to a common benchmark may also 
lower their transaction costs. On the demand side, by reducing information asymmetries, GlobalGAP lowers the transaction costs for importers. Hence, we model GlobalGAP $i k t$ as trade costs that are proxied by their diffusion. Furthermore, it is imperative for our analysis that our measures capture adequately the certification effect on trade. As a first measure of certification, we follow the existing literature and use the count of certified producers of product $k$ in country $i$ in year $t$ (see, e.g., Herzfeld et al., 2011; Vural and Akgüngör, 2015; Ehrich and Mangelsdorf, 2018; Andersson, 2018). While this measure captures the certification effect (whether producers in country $i$ are certified or not), it also captures a size effect (whether there are many producers or many hectares of cropland area in country $i){ }^{28}$ We propose an alternative measure which focuses on the certification effect only. Using FAO data on total harvest area, we measure certification as the share of GlobalGAP certified land area in total harvest area of product $k .^{29}$ We use these two indicators separately to measure the diffusion of GlobalGAP standards in a country.

\subsubsection{Estimation issues and model specification}

Key to proper estimation of equation (2.1) is how we account for the unobservable multilateral resistance (MR) terms, accommodate zero trade flows and deal with the potential endogeneity of the standards-trade relationship. In this section, we address these estimation issues.

The MR terms account for the fact that trade flows between country pairs do not only depend on bilateral trade costs but trade costs prevailing with all their other trading partners (Anderson and Van Wincoop, 2003), i.e., the effects of $T_{i j k t}$ should be measured against $P_{j k t}$ and $\Pi_{i k t}$. Hence, failing to account for these third-country effects means inaccurately predicting how GlobalGAP standards affect bilateral trade flows. The general strategy employed in the literature is to proxy these theoretical constructs using country fixed effects (Baldwin and Taglioni, 2007). In our empirical setting, these proxies must be time and product varying. However, GlobalGAP ${ }_{i k t}$ in equation (2.2) is time varying only in the exporter-product dimension, and so collinear with the outward MR term, $\Pi_{i k t}$. To overcome this identification challenge, we use instead importer-product-time $\left(\gamma_{j k t}\right)$, exporter-time $\left(\phi_{i t}\right)$ and product-time $\left(\psi_{k t}\right)$ fixed effects. ${ }^{30}$

There are two potential sources of endogeneity in our empirical setting: omitted variable biases and simultaneity of the standards-trade effect. By incorporating a series of fixed effects (i.e., $\gamma_{j k t}, \phi_{i t}$, and $\psi_{k t}$ ) into our estimation equations, we account for the remaining unobservable trade resistance terms (i.e., $\mathrm{O}_{i j k t}$ in equation 2.2) whose omission may lead to endogeneity in the standards-trade relationship. Second, while certification will affect trade, the intensity of existing trade is also likely to enhance the decision to seek certification. To deal with this potential reverse causality bias, we use a one-year lag of GlobalGAP certification. This is because while past and present certification status are highly correlated, we do not expect past certifications to influence current trade flows (see,

\footnotetext{
${ }^{28}$ We thank an anonymous reviewer for pointing out this distinction.

${ }^{29}$ For some years, Austria, Belgium, Chile, Greece, Italy, New Zealand and the United Arab Emirates had values $>1$. In these cases, we replaced them by the value of 1 . Dropping these 2,335 observations or replacing them with the mean values do not affect our results quantitatively.

${ }^{30}$ While, the $\gamma_{j k t}$ term accounts for annual importer-product-specific effects it misses out on seasonal variations within a year. Hence, e.g., for the EU's import regime for fruits and vegetables, our analysis accounts for yearly variations, but not intra-annual seasonal and price stabilisation effects such as zero-tariff quota regimes and the entry price scheme. Analysing these specific policies goes beyond the scope of this study. For a more detailed discussion see Cioffi and dell'Aquila (2004), Cioffi et al. (2011), and Santeramo and Cioffi (2012).
} 
e.g., Shepherd and Wilson, 2013; Ferro et al., 2015; Andersson, 2018). Nevertheless, as a robustness check, we also estimate instrumental variable regressions.

Since we study product specific agricultural trade flows at the HS6 digit level, zeroes dominate our bilateral trade dataset. It is impossible to account for informative zero trade flows if we log-transform the dependent variable as in equation (2.1). Common practices employed to deal with zeroes in trade data, e.g., truncation and censoring, are arbitrary and without strong theoretical or empirical justification and can distort results significantly (Haq et al., 2012). So, we eliminate uninformative zeroes by limiting our exporter sample to only producing countries, and then use more appropriate estimation techniques to deal with all remaining zeroes. ${ }^{31}$ Another potential source of bias in our setting is the inherent heteroskedasticity of trade data. Using the Poisson pseudo-maximumlikelihood (PPML) estimator, we simultaneously account for zero trade flows and heteroskedasticity (Santos Silva and Tenreyro, 2006). The estimator's log-linear objective function allows us to specify the gravity equation in its multiplicative form without log-transforming the dependent variable.

Combining equations (2.1) and (2.2), and taking into account the estimation issues discussed above, we specify the PPML estimation equation as:

$$
\begin{aligned}
\mathrm{X}_{i j k t} & =\exp \left[\gamma_{j k t}+\phi_{i t}+\psi_{k t}+\beta_{0}+\beta_{1} \ln \text { GlobalGAP }_{i k t-1}+\beta_{2} \ln \mathrm{Y}_{i k t}+\beta_{3} \ln \mathrm{D}_{i j}+\sum_{n=4}^{6} \beta_{n} \Omega_{i j}\right. \\
& \left.+\beta_{7} \mathrm{RTA}_{i j t}+\beta_{8} \ln \left(1+\operatorname{Tariff}_{i j k t}\right)+\beta_{9} \mathrm{NoGAP}_{i k t-1}\right]+\varepsilon_{i j k t}
\end{aligned}
$$

Similar variable definitions hold as in equations (2.1) and (2.2). In all estimation equations, our variable of interest is GlobalGAP $i k t-1$. To account for producing countries with zero certifications, we add a constant value of 1 to GlobalGAP $i k t-1$ for those cases with zero values before taking logarithms, and also include a 'no certification' dummy (i.e., NoGAP ${ }_{i k t-1}$ ) which takes the value of 1 when the country has no GlobalGAP certification and 0 otherwise (Battese, 1997).$^{32}$ In this way, we allow for different slopes between exporters with GlobalGAP certification and those without any GlobalGAP certification. If the slope coefficient is indifferent across certified and non-certified countries, we will expect a statistically insignificant NoGAP ${ }_{i k t-1}$ variable. For our results to be in line with our hypothesis, we expect a positive coefficient for the GlobalGAP variable (i.e., $\left[\partial X_{i j k t} / \partial \mathrm{GlobalGAP}_{i k t-1}\right]>0$ ).

To account for possible product heterogeneity, we estimate a second specification in which we interact dummies for the different products (i.e., apples, bananas and grapes) with the GlobalGAP $i k t-1$

\footnotetext{
${ }^{31}$ It is intuitive to assume that countries that are not producing, e.g., due to climatic or biological reasons, are either not exporting or only re-exporting. Re-exporters are not interesting for our study because GlobalGAP certification is a farm level process standard. We identify producing countries using the FAO dataset on production quantities. All remaining zeroes are informative for our study and dropping them may bias our findings.

${ }^{32}$ In principle, this means that we define our variable of interest in equation (2.3) as $\left[\beta_{1} \ln \left(\mathrm{GlobalGAP}_{i k t-1}+\right.\right.$ $\left.\left.\operatorname{NoGAP}_{i k t-1}\right)+\beta_{9} \operatorname{NoGAP}_{i k t-1}\right]$. Where NoGAP $i k t-1=1$ if GlobalGAP $i k t-1=0$ and NoGAP $i k t-1=0$ if GlobalGAP $i k t-1=1$. The NoGAP dummy serves as a slope shifter depending on the certification status of the exporting country.
} 
variable. The resulting estimation equation is:

$$
\begin{aligned}
\mathrm{X}_{i j k t} & =\exp \left[\gamma_{j k t}+\phi_{i t}+\psi_{k t}+\beta_{0}+\alpha_{1} \ln \text { GlobalGAP }_{i k t-1} \times \text { Apple }+\alpha_{2} \ln \text { GlobalGAP }_{i k t-1} \times \text { Banana }^{5}\right. \\
& +\alpha_{3} \ln \text { GlobalGAP }_{i k t-1} \times \text { Grape }+\beta_{1} \ln Y_{i k t}+\beta_{2} \ln \mathrm{D}_{i j}+\sum_{n=3}^{5} \beta_{n} \Omega_{i j}+\beta_{6} \mathrm{RTA}_{i j t} \\
& \left.+\beta_{7} \ln \left(1+\text { Tariff }_{i j k t}\right)+\beta_{8} \mathrm{NoGAP}_{i k t-1}\right]+\varepsilon_{i j k t}
\end{aligned}
$$

We go a step further in the analysis and assess specifically to what extent the trade effect of certification differs depending on the income status of the exporting country. Here, we are interested in whether the exporting country's development status influences the effectiveness of the certification effect on trade. In developed countries with well-functioning institutions to enforce food safety, the trade effects of certification may be less relevant. The reverse may be the case for developing countries, who will then enjoy an even larger trade effect of certification. To assess if this is the case, we split our certification variable into two; one for developing countries - which we define to include all those not listed as high income in the World Bank income classifications - and the other for developed countries (equation 2.5).

$$
\begin{aligned}
\mathrm{X}_{i j k t} & =\exp \left[\gamma_{j k t}+\phi_{i t}+\psi_{k t}+\beta_{0}+\omega_{1} \ln \text { GlobalGAP }_{i k t-1} \times \text { Developing }+\omega_{2} \ln \text { GlobalGAP }_{i k t-1} \times\right. \text { Developed } \\
& \left.+\beta_{1} \ln \mathrm{Y}_{i k t}+\beta_{2} \ln \mathrm{D}_{i j}+\sum_{n=3}^{5} \beta_{n} \Omega_{i j}+\beta_{6} \mathrm{RTA}_{i j t}+\beta_{7} \ln \left(1+\text { Tariff }_{i j k t}\right)+\beta_{8} \mathrm{NoGAP}_{i k t-1}\right]+\varepsilon_{i j k t}
\end{aligned}
$$

Finally, to check the robustness of our results to the choice of estimation technique, we use the Heckman selection model. It accounts for zero trade flows in a two-step procedure. Our benchmark specification assesses the intensive margin of trade (i.e., the volume of export conditional on trading), thus, though the Heckman procedure is not robust to heteroskedastic errors and model misspecification (Ferro et al., 2015), it has an additional benefit for our empirical setting. It allows us to distinguish the effect of GlobalGAP standards on the extensive margin of trade (i.e., the probability of trading). In the first stage (i.e., the extensive margin), we estimate a probit equation on whether country pairs in our sample engage in bilateral trade for product $k$ or not. From the parameter estimates in the first stage, we compute the inverse Mill's ratio $\left(\lambda_{i j k t}\right)$ for each country pair which captures selection bias in the residual of the gravity equation. In the second stage, we include $\lambda_{i j k t}$ as an extra explanatory variable and estimate the expected values of trade flows conditional on trade using ordinary least squares. Robust identification in the Heckman model requires an exclusion variable that affects the extensive but not the intensive margin; we use common religion $\left(\right.$ Religion $\left._{i j}\right)$ as the exclusion restriction (Helpman et al., 2008). The underlying idea is that fixed trade costs, here proxied by the religion dummy, affects the probability to export but not the volume of exports. ${ }^{33}$ Indeed, similar religions, like similar cultures, may reduce trade costs, but the complexities inherent in international trading relationships, the potential for costly errors, and other related costs may be large enough to reduce the number of transactions it generates (Cipollina and Salvatici, 2010).

\footnotetext{
${ }^{33}$ This choice is also justified as including Religion ${ }_{i j}$ in equation 2.3 yields statistically insignificant results, i.e., common religion has no effect on trade at the intensive margin. The results are available upon request from the authors.
} 


\subsection{Results and discussion}

Table 2.3 reports the results of our benchmark estimations in equation (2.3). The columns differ only in the choice of GlobalGAP measure: (1) the number of certified producers, and (2) the ratio of certified land area to total harvest area. The overall fit of the estimations is consistent with theoretical priors. All the standard gravity variables have their expected signs and are statistically significant at conventional levels. The magnitudes of the coefficient estimates are readily comparable to those in the gravity literature (see Head and Mayer, 2014). Domestic production in the exporting country, speaking a common language, sharing a common border, past colonial ties and regional trade agreements are trade enhancing while bilateral distance and tariffs hinder bilateral trade. In line with the gravity theory, the estimated trade elasticity of our distance measure is close to unity. The tariff coefficient suggests that a one percent decrease in the ad valorem tariff, on average, induces an increase in trade of $0.4 \% .^{34}$

The estimated parameters on the GlobalGAP variables, considering the difference in certification measures, show a positive and statistically significant effect of certification on exports in both model estimations. In column (1), the estimated elasticity of trade to a one percent increase in the number of certified producers is 0.33 . In column (2), the estimated elasticity is higher; a one percent increase in the share of GlobalGAP certified land area in total harvest area increases bilateral trade by $0.45 \%$,

Table 2.3: GlobalGAP certification and agrifood exports: baseline results

\begin{tabular}{lcc}
\hline & Certified producer & Certified area/Harvest area \\
\cline { 2 - 3 } & $(1)$ & $(2)$ \\
\hline Log GlobalGAP $_{i k t-1}$ & $0.334^{* * *}$ & $0.449^{* * *}$ \\
& $(0.044)$ & $(0.047)$ \\
Log Production $_{i k t}$ & $0.277^{* * *}$ & $0.538^{* * *}$ \\
& $(0.075)$ & $(0.068)$ \\
Log Distance & $i j$ & $-1.221^{* * *}$ \\
& $(0.103)$ & $(0.101)$ \\
Language $_{i j}$ & $0.429^{* *}$ & $0.436^{* *}$ \\
Contiguity $_{i j}$ & $(0.167)$ & $(0.171)$ \\
& $0.414^{* *}$ & $0.422^{* *}$ \\
Colony $_{i j}$ & $(0.190)$ & $(0.188)$ \\
RTA $_{i j t}$ & $0.483^{* *}$ & $0.462^{*}$ \\
Log $^{*}\left(1+\right.$ Tariff $\left._{i j k t}\right)$ & $(0.239)$ & $(0.240)$ \\
NoGAP $_{i k t-1}$ & $0.866^{* * *}$ & $0.873^{* * *}$ \\
& $(0.166)$ & $(0.166)$ \\
Observations & $-0.378^{* * *}$ & $-0.362^{* * *}$ \\
\hline
\end{tabular}

Notes: Robust country-pair-product clustered standard errors in parentheses. ***, **, * denote significance at 1\%, 5\% and 10\% respectively. Importer-product-time, exporter-time and product-time fixed effects included in all regressions. Intercepts included but not reported.

\footnotetext{
${ }^{34}$ Giving a structural interpretation to the tariff coefficient in equation (2.1), we can infer the elasticity of substitution (i.e., $\beta_{8}=1-\sigma_{k}$ ). As theory predicts, the elasticity of substitution is positive and greater than 1 .
} 
ceteris paribus. The difference in coefficient estimates of the two certification measures is in part because average land holdings per producers differ across countries (Table A2.2). We note that an increase in the certified area per country includes an increase in the certified area of already certified farms, but also from newly certified farms. This makes it difficult to fully disentangle the land size effect from the effect of an increase in certified producers. However, the much lower coefficient of the latter compared to the former points to the dominance of the size effect, i.e., the trade effect from a percentage change in certified area is larger than from a percentage change in the number of certified producers. ${ }^{35}$ This finding suggests that once producers gain access to export markets through certification, they expand their production. Furthermore, the $\mathrm{NoGAP}_{i k t-1}$ variable captures the fact that non-certified producing countries have on average lower exports compared to their certified counterparts.

Table 2.4 reports the product-specific estimates. Overall, GlobalGAP enhances bilateral trade, but the magnitude of the trade effect is heterogeneous across products. ${ }^{36}$ This is driven in part by differences in the market structure of the different products. For example, the trade-enhancing effects are economically substantial for all three products but comparatively small for bananas. This is because developed countries dominate apple and grape production, with a rather dispersed market structure; hence, the relatively high trade effect of GlobalGAP certification reflects the high competition among producers for market share. On the other hand, banana production is concentrated in developing countries. ${ }^{37}$ Hence, the relatively low effect for banana may arise from a particular characteristic of the sector, i.e., the historic presence of well-established banana plantations (e.g., Dole, Chiquita,

Table 2.4: GlobalGAP certification and agrifood exports: product specific results

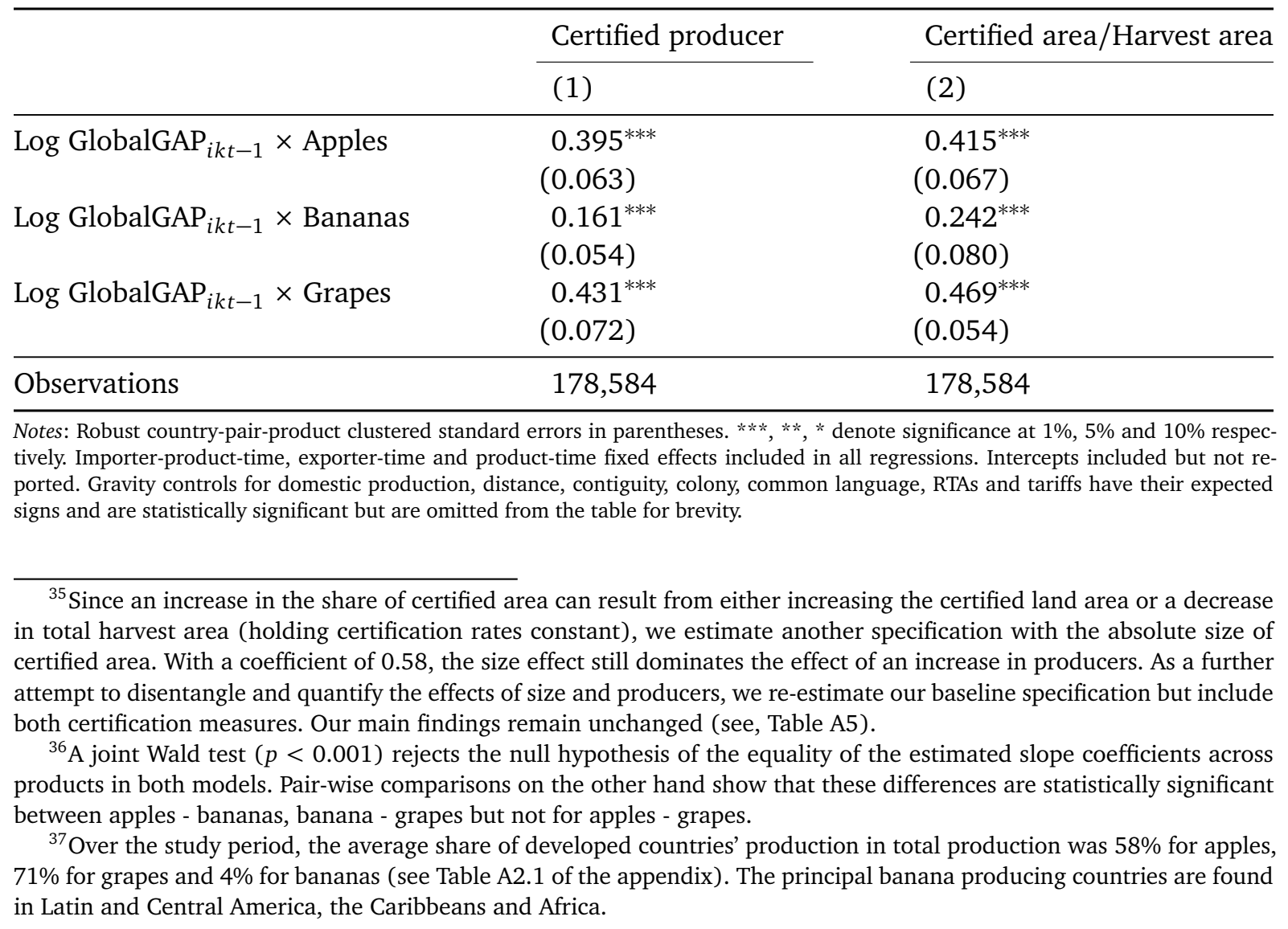


Fyffes, Del Monte, Compagnie fruitiere) that are often vertically integrated, and have always structured the supply to the world market (UNCTAD, 2016). They often times have their own production units in producer countries, and develop quality standards internal to the firm. Thus, GlobalGAP certification may not have made a huge difference in their export volumes. The perishability of the products may also explain the differences in the trade elasticity of certification we observe across products. While all three products are perishable, grapes especially have little protective coating, are prone to surface injuries and impact bruising and thus have shorter post-harvest lives. Since the demand for all three products is higher in developed countries, GlobalGAP signals product quality and gives certified producers a competitive edge in exports over their non-certified counterparts. For all products, bilateral trade responds more positively to increases in certified area than to increases in the number of certified producers. This is consistent with our baseline findings.

\subsubsection{Differences in trade effects by development status}

To gain further insights into the effect of certification on exports, we focus attention on the development level of the exporting country. The results - interpreted as the extent to which GlobalGAP certification affects trade depending on whether a country is developed or developing - reported in Table 2.5 confirm a general trade enhancing effect of GlobalGAP certification for both developed and developing countries.

The findings for developing countries are compelling. In column (1), the magnitudes of the trade effects are bigger than for developed countries. This supports our prior argument that the certification-trade effect is larger for developing countries. This is because, for retailers, the transaction cost reducing effect of certification is more pronounced in their dealings with developing country producers. Obviously, information asymmetry and missing institutions to enforce food safety standards are more conspicuous in developing countries. This supports the findings by Andersson (2018) who find a larger certification-trade effect for low-income compared to high-income exporting countries. In column (2), however, the standard-trade effect for developing countries is comparable in magnitude to the effect for developed countries. Indeed the hypothesis that the two have the same coefficient (i.e., $\omega_{1}=\omega_{2}$ in equation (2.5)) cannot be rejected with a $\chi^{2}$ value of 2.40 .

Table 2.5: GlobalGAP certification and agrifood exports: by income group

\begin{tabular}{|c|c|c|}
\hline & Certified producer & Certified area/Harvest area \\
\hline & (1) & (2) \\
\hline $\log _{\text {GlobalGAP }}{ }_{i k t-1} \times$ Developing $_{i}$ & $\begin{array}{l}0.417^{* * *} \\
(0.060)\end{array}$ & $\begin{array}{l}0.343^{* * *} \\
(0.078)\end{array}$ \\
\hline Log GlobalGAP $_{i k t-1} \times$ Developed $_{i}$ & $\begin{array}{l}0.259^{* * *} \\
(0.066)\end{array}$ & $\begin{array}{l}0.472^{* * *} \\
(0.050)\end{array}$ \\
\hline Observations & 178,584 & 178,584 \\
\hline
\end{tabular}

Notes: Robust country-pair-product clustered standard errors in parentheses. $* * *, * *, *$ denote significance at $1 \%$, $5 \%$ and $10 \%$ respectively. Importer-product-time, exporter-time and product-time fixed effects included in all regressions. Intercepts included but not reported. All gravity controls have their expected signs and are statistically significant but are omitted from the table for brevity. Developed countries are defined as high-income countries. Middle and low-income countries are defined as developing countries. 


\subsubsection{The effect on the extensive margin of trade}

Next, we discuss the effects of GlobalGAP on the extensive trade margin, i.e., the probability of exporting. Because probits are nonlinear, we report marginal effects of the first-stage estimates of the Heckman sample selection model in columns (1) and (3) of Table 2.6. ${ }^{38}$ The coefficient estimate of $\lambda_{i j k t}$ which measures selection effects is statistically significant; omitting zero trade observations would bias our estimates. The exclusion restriction, i.e., sharing a common religion, performs considerably well. It has a statistically significant and positive effect in the selection equation and is exogenous to the outcome equation. The estimated marginal effects of the different certification measures are positive and statistically significant. GlobalGAP certification increases the probability of exporting by $2 \%$. Effects of this magnitude are consistent with recent empirical evidence, e.g., Andersson (2018) find that increases in the number of GlobalGAP certified producers or certificates in a country increases the probability of EU-15 imports of fruits and vegetables by $6 \%$. Our results imply that the probability of new trade relationships is positively influenced by certification.

Table 2.6: GlobalGAP certification and agrifood exports: Heckman model

\begin{tabular}{|c|c|c|c|c|}
\hline & \multicolumn{2}{|l|}{ Producers } & \multicolumn{2}{|c|}{ Certified area/Harvest area } \\
\hline & $\operatorname{Pr}\left(X_{i j k t}>0\right)$ & $\ln \left(X_{i j k t}\right)$ & $\operatorname{Pr}\left(X_{i j k t}>0\right)$ & $\ln \left(X_{i j k t}\right)$ \\
\hline & (1) & $(2)$ & (3) & (4) \\
\hline $\log _{\text {GlobalGAP }}{ }_{i k t-1}$ & $\begin{array}{l}0.017^{* * *} \\
(0.001)\end{array}$ & $\begin{array}{l}0.523^{* * * *} \\
(0.028)\end{array}$ & $\begin{array}{l}0.016^{* * *} \\
(0.001)\end{array}$ & $\begin{array}{l}0.507 * * * \\
(0.025)\end{array}$ \\
\hline Religion $_{i j}$ & $\begin{array}{l}0.025^{* * * *} \\
(0.003)\end{array}$ & & $\begin{array}{l}0.025^{* * * *} \\
(0.003)\end{array}$ & \\
\hline $\operatorname{IMR}\left(\lambda_{i j k t}\right)$ & & $\begin{array}{l}0.918^{* * * *} \\
(0.009)\end{array}$ & & $\begin{array}{l}0.921^{* * *} \\
(0.009)\end{array}$ \\
\hline Observations & 178,584 & 25,185 & 178,584 & 25,185 \\
\hline
\end{tabular}

Notes: Robust country-pair-product clustered standard errors in parentheses. $* * *, * * *$ denote significance at $1 \%, 5 \%$ and $10 \%$ respectively. Columns (1) and (3) refer to the first stage Probit (i.e., the extensive margin) and columns (2) and (4) are the OLS stage (i.e., the intensive margin) of the Heckman regression. Importer-product-time, exporter-time and product-time fixed effects included in all regressions. Intercepts included but not reported. All gravity controls have their expected signs and are statistically significant but are omitted from the table for brevity. IMR is the inverse Mills ratio.

\subsubsection{Destination market heterogeneity}

In this section, we explore the consistency of our findings across different destination markets. We define two markets, 'high-value' and 'low-value', depending on their abilities to enforce strict food safety standards. The use of food safety standards as a mandatory market access requirement may be more evident in high-value markets. Hence, our first destination market segment focuses on exports to the EU and high-income OECD countries. The market for non-certified GlobalGAP products is limited in many of these countries (see Colen et al. (2012) and Andersson (2018) for the case of the EU). GlobalGAP, being a retailer-led industry standard, may also be required more by countries with a higher concentration of supermarket chains. Using data on modern grocery distributions within countries, our second market segment focuses on importing countries with a concentration of domestic supermarkets above the mean across all countries (i.e., 32\%). ${ }^{39}$

\footnotetext{
${ }^{38}$ The coefficient estimates from both stages of the Heckman model are available at ERAE online (Table A6).

${ }^{39}$ The data on modern grocery distributions was retrieved from www.planetretail.com.
} 
Table 2.7: GlobalGAP certification and agrifood exports: destination market heterogeneity

\begin{tabular}{|c|c|c|c|c|}
\hline & \multicolumn{2}{|c|}{ EU \& OECD imports } & \multicolumn{2}{|c|}{ Modern Grocery Distribution } \\
\hline & (1) & $(2)$ & (3) & (4) \\
\hline Log GlobalGAP $_{i k t-1} \times$ High-value $_{j}$ & $\begin{array}{l}0.321 * * * \\
(0.048)\end{array}$ & $\begin{array}{l}0.481 * * * \\
(0.051)\end{array}$ & $\begin{array}{l}0.359 * * * \\
(0.046)\end{array}$ & $\begin{array}{l}0.482 * * * \\
(0.047)\end{array}$ \\
\hline Log GlobalGAP $_{i k t-1} \times$ Low-value $_{j}$ & $\begin{array}{l}0.353^{* * *} \\
(0.049)\end{array}$ & $\begin{array}{l}0.384^{* * * *} \\
(0.056)\end{array}$ & $\begin{array}{l}0.259^{* * *} \\
(0.048)\end{array}$ & $\begin{array}{l}0.316^{* * * *} \\
(0.055)\end{array}$ \\
\hline Observations & 178,584 & 178,584 & 178,584 & 178,584 \\
\hline
\end{tabular}

Notes: Robust country-pair-product clustered standard errors in parentheses. $* * *$, ** * denote significance at 1\%, 5\% and 10\% respectively. Importer-product-time, exporter-time and product-time fixed effects included in all regressions. Intercepts included but not reported. All gravity controls have their expected signs and are statistically significant but are omitted from the table for brevity. The measure of GlobalGAP standard: columns (1) and (3) use the number of certified producers and column (2) and (4) use the share of certified land area in total harvest area.

In both cases, the positive trade effects of GlobalGAP certification remains (Table 2.7). The estimated GlobalGAP coefficients are statistically different across the two groups, except for column (1). The trade effects are larger for exports to the 'high-value' markets. This confirms that there exist significant destination market heterogeneities regarding the use of certification. However, we also find a clear positive and significant trade-effect for the so-called 'low-value' markets, which we interpret as evidence of a growing demand for certified produce even in developing countries. This points to an increasing demand for certified produce that goes beyond the large multinational retailers and agribusiness companies. Many developing countries are experiencing a supermarket revolution (Qaim, 2017), with increasing numbers of smaller retail conglomerates which are emulating the global trend of certification.

\subsubsection{Robustness checks}

Finally, we conduct two robustness checks to confirm our main findings in Table 2.3. To rule out endogeneity bias in our baseline model specification, we run two-stage least squares estimations ${ }^{40}$, instrumenting for GlobalGAP $i k t-1 \cdot{ }^{41}$ The results available in the Appendix (Table A2.7) are similar to our benchmark specification with all the coefficients retaining their expected sign and statistical significance. The magnitudes of the GlobalGAP coefficients remain close to those in our benchmark specification. Also, as we observe in Figure (2.1), the spread of certification across regions is uneven; the number of certified producers and area cultivated remains higher in Europe, especially within the EU. To see if this drives our results, we use a sample that excludes EU exports. The results show this is not the case; our positive coefficients remain for GlobalGAP, but with slightly higher trade effects. ${ }^{42}$ This means that non-EU exporters experience a more than average trade effect of certification.

\footnotetext{
${ }^{40}$ Our attempts to estimate an instrumental variable Poisson model — using both ivpoisson or ivppml — generally failed to converge due to the large number of fixed effects involved.

${ }^{41}$ We use as an instrument for certification in apple producing countries the certification in grape producing countries, and vice versa. This is because apple and grape producing farms are located mainly in regions with similar climatic and soil conditions. This is not the case for bananas which are produced mainly in the tropics, hence we use banana certifications in neighbouring countries as an instrument. To justify the validity of these instruments, we argue following Ehrich and Mangelsdorf (2018) that countries cannot self-select themselves into becoming neighbours, hence there are no arguments why compliance with a standard in neighbouring countries should influence directly exports of a country. Neither will we expect that certification to one product affects directly exports of another product. Yet, these certification variables are in themselves strongly correlated with each other and satisfy the relevance condition.

${ }^{42}$ The results are available upon request from the authors.
} 


\subsection{Conclusion}

How private food standards and their associated certification schemes affect bilateral trade flows remain largely ambiguous. We provide further insights using the case of GlobalGAP standards. The study is novel in two ways. First, we question the generality of existing studies because of their country or product-specific approaches and contribute the first multi-country and multi-product study. Second, using the share of certified area in total harvest area as an additional measure of certification, we deviate from the existing literature - which uses counts of certified producers, production area, or firms (Vural and Akgüngör, 2015; Ehrich and Mangelsdorf, 2018; Andersson, 2018). We argue that the scale of production under certification is an overlooked consideration in the existing literature, but adds valuable information because it isolates the effect of certification and rules out trade effects emerging from general growth trends in agricultural production.

The results of our gravity estimations confirm a general trade enhancing effect of GlobalGAP certification at both intensive and extensive margins of trade. Thus, while voluntary certification may pose extra costs for producers, they also sustain import demand. These findings are robust to the different certification measures, controls for endogeneity, and remain stable across different model specifications and sub-samples. The positive trade effects are driven more by increases in the area of certified farms, than from the entry of new certified producers. However, the effect sizes are heterogeneous. By product, the trade effect is lowest for bananas. Once certified, the positive trade effects remain regardless of the development status of the exporting country. However, we find a more pronounced trade effect if the number of certified producers increases in developing countries. High transaction costs, typical for many developing countries, are major barriers to trade. Certification can serve as a substitute for a lack of well-functioning institutions to enforce food safety and to overcome information asymmetries (Fiankor et al., 2019b). Unsurprisingly, the trade effects are higher for exports to high-value EU and OECD markets but interestingly are substantial even for exports to markets outside these regions.

In general, our findings are consistent with the 'standards-as-catalyst' strand of the standards literature. The positive trade effects coincide with micro-level findings that the returns on GlobalGAP investments are considerable in terms of export growth (Henson et al., 2011) and affect positively the quantities sold on international markets (Subervie and Vagneron, 2013), but differ from findings that private standards do not enhance trade (Schuster and Maertens, 2015). At the macro-level, it complements the findings that GlobalGAP certifications enhance EU fruit and vegetable imports (Masood and Brümmer, 2014; Andersson, 2018). But, our study is the first to reveal the described important heterogeneities at a global level. Our findings also support those found in the literature for other voluntary standards in the agrifood sector, such as the IFS, BRC and ISO standards (Latouche and Chevassus-Lozza, 2015; Vural and Akgüngör, 2015; Ehrich and Mangelsdorf, 2018).

Given that voluntary GlobalGAP certification is fast becoming a de facto mandatory global standard, yet promotes agrifood exports, policies should aim at facilitating private standard adoption. This is especially relevant in developing countries for two reasons: (1) the transaction cost reducing effect of private standards has the potential to increase trade volumes even more than in developed countries, and (2) GlobalGAP also increases the probability to enter export markets - a finding most relevant for the more marginalised developing countries. A necessary precondition for high 
certification rates is the modernisation of export-oriented sectors. Public sector technical and financial support may help producers, especially those in developing countries, overcome the initial costs of certification. Furthermore, enhancing good governance and a country's institutional quality can lead to value-chain upgrading, and thereby higher certification rates (Herzfeld et al., 2011). Another policy implication relates to the dominance of the size effect over the trade effect of additional certified farmers. To reverse this trend that large certified farms experience export growth, while new market entrants contribute disproportionately less, policies should specifically target smaller producers. This is particularly relevant in a development context, e.g., in the banana sector where it would lead to more inclusive growth as gains from trade would then be more evenly distributed. However, since apples and grapes are produced mainly in developed countries, our findings also suggest that certification plays a major role in gaining and retaining global market shares even for developed country producers.

One caveat inherent in our empirical analysis - and all the literature that has employed the gravity approach - is that public trade databases have no distinction between certified and noncertified commodity trade flows. As HS codes have been introduced for certified organic products, we recommend the same for products under private sustainability standards. This would lead to a clearer identification of the trade effects of private standards distinct from increased trade due to other structural changes in the agricultural sector. To enhance our country-level findings, firm-level data would allow the analysis of entry and exit dynamics of certification, help to better identify barriers to certification, and how firms react individually to food safety standards. Further research could also explore possible nonlinearities in the certification and trade effect using more flexible semi/non-parametric model specifications. 


\subsection{Appendix}

Table A2.1: Average production and imports (2010 - 2015)

\begin{tabular}{llllllll}
\hline & \multicolumn{3}{l}{ Developed countries } & & \multicolumn{3}{c}{ Developing countries } \\
\cline { 2 - 3 } & Apple & Banana & Grapes & & Apple & Banana & Grapes \\
\hline Production ('000 Tonnes) & 555 & 43 & 1118 & & $403^{*}$ & 1160 & 459 \\
Share in total & 0.58 & 0.04 & 0.71 & & 0.42 & 0.96 & 0.29 \\
\hline Imports ('000 USD) & 735 & 1544 & 1393 & & 342 & 245 & 255 \\
Share in total & 0.68 & 0.86 & 0.85 & & 0.32 & 0.14 & 0.15 \\
\hline
\end{tabular}

Source: FAO and UNComtrade data, own calculations. Developed countries are defined as high income countries, whiles middle and low income countries constitute developing countries. ${ }^{*}$ The figure for apple production in developing countries excludes China - the largest producer and consumer of apples.

Figure A2.1: GDP per capita, exports and spread of GlobalGAP certification (2010 - 2015)

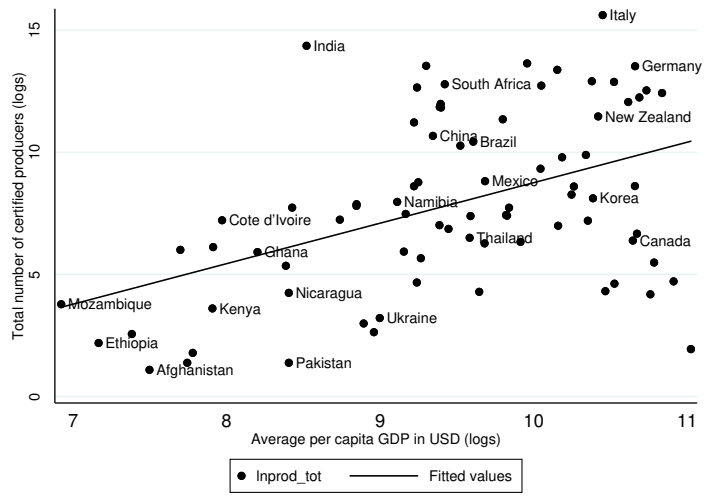

(a) Certification and GDP per capita

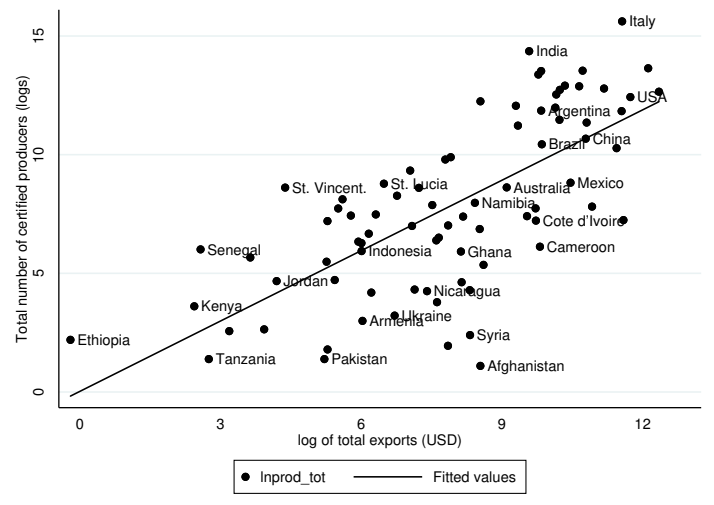

(b) Certification and exports

Source: GlobalGAP, UNComtrade and, World Bank data, own graph 
Table A2.2: Characteristics of selected certified countries (2010 - 2015)

\begin{tabular}{|c|c|c|c|c|c|}
\hline & \multicolumn{2}{|l|}{ GlobalGAP certified } & \multirow[b]{2}{*}{$\begin{array}{l}\text { Exports } \\
\text { ('000 USD) }\end{array}$} & \multirow[b]{2}{*}{$\begin{array}{l}\text { Production } \\
\text { ('000 Tonnes) }\end{array}$} & \multirow[b]{2}{*}{$\begin{array}{l}\text { Harvest area } \\
\text { (Hectares) }\end{array}$} \\
\hline & $\begin{array}{l}\text { Share in harvest area } \\
(\%)\end{array}$ & Producers & & & \\
\hline \multicolumn{6}{|l|}{ Apple } \\
\hline New Zealand & 0.92 & 243 & 2949 & 434 & 8762 \\
\hline Chile & 0.91 & 726 & 5417 & 1675 & 36114 \\
\hline Belgium & 0.84 & 622 & 969 & 271 & 7275 \\
\hline South Africa & 0.83 & 317 & 2224 & 821 & 22559 \\
\hline The Netherlands & 0.82 & 772 & 1426 & 339 & 8042 \\
\hline Italy & 0.56 & 11877 & 5682 & 2295 & 55698 \\
\hline France & 0.37 & 708 & 4259 & 1721 & 42796 \\
\hline Israel & 0.36 & 21 & 146 & 109 & 2751 \\
\hline Slovenia & 0.34 & 27 & 84 & 98 & 2642 \\
\hline Czech Republic & 0.30 & 44 & 119 & 118 & 8992 \\
\hline USA & 0.25 & 482 & 5812 & 4533 & 131491 \\
\hline \multicolumn{6}{|l|}{ Bananas } \\
\hline Costa Rica & 0.71 & 90 & 9905 & 2257 & 42543 \\
\hline Peru & 0.56 & 4010 & 1078 & 184 & 6736 \\
\hline Colombia & 0.51 & 477 & 11022 & 1967 & 77797 \\
\hline Dominican Republic & 0.44 & 919 & 2684 & 1018 & 28087 \\
\hline Cote d'Ivoire & 0.43 & 10 & 1774 & 324 & 7428 \\
\hline South Africa & 0.39 & 20 & 52 & 414 & 7692 \\
\hline Honduras & 0.38 & 19 & 1761 & 798 & 22932 \\
\hline Ecuador & 0.30 & 748 & 24413 & 7053 & 195803 \\
\hline Guatemala & 0.23 & 15 & 5865 & 3158 & 69074 \\
\hline Saint Lucia & 0.23 & 327 & 69 & 11 & 1124 \\
\hline \multicolumn{6}{|l|}{ Grapes } \\
\hline Peru & 0.42 & 92 & 3712 & 414 & 20508 \\
\hline Namibia & 0.24 & 13 & 483 & 23 & 5828 \\
\hline Chile & 0.23 & 768 & 14010 & 2432 & 196854 \\
\hline Mexico & 0.20 & 25 & 2698 & 337 & 27389 \\
\hline South Africa & 0.18 & 353 & 5296 & 1867 & 113976 \\
\hline Israel & 0.13 & 85 & 68 & 77 & 7613 \\
\hline Egypt & 0.09 & 205 & 1193 & 1463 & 68543 \\
\hline India & 0.07 & 3341 & 1305 & 2001 & 115023 \\
\hline Brazil & 0.06 & 104 & 1090 & 1459 & 80280 \\
\hline Greece & 0.05 & 1276 & 1424 & 693 & 79556 \\
\hline
\end{tabular}


Table A2.3: List of importing and exporting countries

$\overline{\text { Afghanistan*, Angola, Albania, Algeria, Antigua and Barbuda }^{\dagger}, \text { Argentina, Armenia, Aruba }^{\dagger}, \text { Aus- }}$ tralia, Austria, Azerbaijan, Barbados*, Burundi, Brunei Darussalam ${ }^{\dagger}$, Belgium, Benin, Bangladesh, Bulgaria, Bahrain, Bahamas, Bosnia and Herzegovina, Botswana ${ }^{\dagger}$, Belarus, Belize*, Bermuda, Bolivia, Brazil, British Virgin Islands*, Barbados, Bhutan, Burkina Faso ${ }^{\dagger}$, Cabo Verde, Cambodia, Canada, Central African Republic, Chile, China, Cote d'Ivoire, Cameroon, DR Congo*, Congo*, Cook Islands*, Colombia, Comoros*, Croatia, Costa Rica, Cuba*, Cyprus, Czech Republic, Dominica*, Denmark, Dominican Republic, Ecuador, Egypt, Equatorial Guinea*, Estonia, Ethiopia, Finland, Fiji, France, Gabon*, Gambia*, Germany, Georgia, Ghana, Guinea*, Greece, Grenada*, Greenland $^{\dagger}$, Guatemala, Guyana, Hong Kong ${ }^{\dagger}$, Honduras, Haiti*, Hungary, Iceland ${ }^{\dagger}$, Indonesia, India, Ireland, Iran, Iraq*, Israel, Italy, Jamaica, Jordan, Japan, Kazakhstan, Kenya, Kyrgyzstan, Kiribati*, Republic of Korea, Kuwait, Laos, Lebanon, Libya*, Lithuania, Luxembourg, Latvia, Macao ${ }^{\dagger}$, Morocco, Moldova ${ }^{\dagger}$, Madagascar*, Mexico, Macedonia, Mali, Malta, Mozambique, Montserrat, Mauritius, Mauritania ${ }^{\dagger}$, Malawi, Malaysia, Mongolia ${ }^{\dagger}$, Montserrat, Myanmar ${ }^{\dagger}$, Namibia, New Caledonia, Nicaragua, Netherlands, Norway, Nepal, New Zealand, Niger ${ }^{\dagger}$, Nigeria ${ }^{\dagger}$, Oman, Palestine ${ }^{\dagger}$, Pakistan, Panama, Peru, Philippines*, Papua New Guinea, Palau ${ }^{\dagger}$, Poland, D.P.R. Korea*, Portugal, Paraguay, French Polynesia, Qatar, Romania, Russian Federation, Rwanda, Saint Lucia, Samoa, Saudi Arabia, South Africa, Sudan, Senegal, Singapore ${ }^{\dagger}$, Sierra Leone*, El Salvador, Saint Kitts and Nevis ${ }^{\dagger}$, Sao Tome and Principe ${ }^{\dagger}$, Somalia*, Serbia/Montenegro, Spain, Suriname*, Slovakia, Slovenia, Sweden, Swaziland*, Seychelles, Sri Lanka ${ }^{\dagger}$, Switzerland, Syria, Togo*, Thailand, Tajikistan*, Turkmenistan*, Tonga, Trinidad and Tobago, Tunisia, Turks and Caicos Islands ${ }^{\dagger}$, Turkey, Tanzania, Uganda, United Arab Emirates, United Kingdom, Ukraine, Uruguay, USA, Uzbekistan*, Saint Vincent and the Grenadines, Venezuela*, Viet Nam, Yemen, Zambia, Zimbabwe

$*$ means the country is only an exporter and ${ }^{\dagger}$ means the country is only an importer

Table A2.4: Summary statistics of variables used in the gravity equation

\begin{tabular}{|c|c|c|c|c|c|c|}
\hline Variable & Mean & Std. Dev. & Min. & Max. & $\mathrm{N}$ & Unit \\
\hline Contiguity & 0.02 & 0.14 & & & 267006 & \\
\hline Language & 0.13 & 0.34 & & & 267006 & \\
\hline Colony & 0.01 & 0.12 & & & 267006 & \\
\hline Religion & 0.13 & 0.33 & & & 267006 & \\
\hline RTA & 0.18 & 0.38 & & & 267006 & \\
\hline Certified area/Harvest area & 0.06 & 0.18 & & & 267006 & \\
\hline Certified Producers & 130.00 & 808.00 & 0 & 12678.00 & 267006 & \\
\hline Certified area & 1908.00 & 6755.00 & 0 & 64862.00 & 267006 & Hectares \\
\hline Harvest area & 61115.00 & 180274.00 & 0 & 2328300.00 & 267006 & Hectares \\
\hline Distance & 7726.00 & 4542.00 & 60 & 19904.00 & 267006 & Kilometers \\
\hline Tariff & 7.66 & 13.23 & 0 & 181.62 & 267006 & Percentages \\
\hline Trade & 645.00 & 11426.00 & 0 & 9693086.00 & 267006 & 1000 USD \\
\hline Production Exporter & 0.92 & 3.20 & 0 & 42.61 & 267006 & Million tonnes \\
\hline
\end{tabular}


Table A2.5: GlobalGAP certification and agrifood exports

(1)

\begin{tabular}{|c|c|}
\hline Log GlobalGAP ${ }_{i k t-1}^{\text {Producers }}$ & $\begin{array}{c}0.144^{* * *} \\
(0.051)\end{array}$ \\
\hline Log GlobalGAP ${ }_{i k t-1}^{\text {Hectares }}$ & $\begin{array}{l}0.343^{* * *} \\
(0.056)\end{array}$ \\
\hline $\log _{\text {Production }_{i k t}}$ & $\begin{array}{c}0.466^{* * *} \\
(0.071)\end{array}$ \\
\hline Log Distance $_{i j}$ & $\begin{array}{c}-1.237^{* * *} \\
(0.102)\end{array}$ \\
\hline Language $_{i j}$ & $\begin{array}{c}0.437^{* * *} \\
(0.169)\end{array}$ \\
\hline Contiguity $_{i j}$ & $\begin{array}{l}0.416 * * * \\
(0.186)\end{array}$ \\
\hline Colony $_{i j}$ & $\begin{array}{l}0.481^{* * *} \\
(0.236)\end{array}$ \\
\hline $\mathrm{RTA}_{i j t}$ & $\begin{array}{l}0.867^{* * *} \\
(0.166)\end{array}$ \\
\hline $\log \left(1+\operatorname{Tariff}_{i j k t}\right)$ & $\begin{array}{c}-0.352^{* * *} \\
(0.078)\end{array}$ \\
\hline No $\mathrm{GAP}_{i k t-1}$ & $\begin{array}{c}-3.783^{* * *} \\
(0.481)\end{array}$ \\
\hline
\end{tabular}

Observations

178,584

Notes: Robust country-pair-product clustered standard errors in parentheses. $* * *, * *, *$ denote significance at $1 \%, 5 \%$ and $10 \%$ respectively. Importer-product-time, exporter-time and product-time fixed effects included in all regressions. Intercepts included but not reported. All gravity controls have their expected signs and are statistically significant but are omitted from the table for brevity. 
Table A2.6: Results of the Heckman Two-Step Estimation

\begin{tabular}{|c|c|c|c|c|}
\hline & \multicolumn{2}{|l|}{ Producers } & \multicolumn{2}{|c|}{ Certified area/Harvest area } \\
\hline & $\operatorname{Pr}\left(X_{i j k t}>0\right)$ & $\ln \left(X_{i j k t}\right)$ & $\operatorname{Pr}\left(X_{i j k t}>0\right)$ & $\ln \left(X_{i j k t}\right)$ \\
\hline & (1) & (2) & (3) & (4) \\
\hline $\log _{\text {GlobalGAP }}{ }_{i k t-1}$ & $\begin{array}{l}0.161 * * * \\
(0.008)\end{array}$ & $\begin{array}{l}0.523 * * * \\
(0.028)\end{array}$ & $\begin{array}{l}0.144 * * * \\
(0.007)\end{array}$ & $\begin{array}{l}0.507 * * * \\
(0.025)\end{array}$ \\
\hline $\log _{\text {Production }_{i k t}}$ & $\begin{array}{l}0.102 * * * \\
(0.007)\end{array}$ & $\begin{array}{l}0.187 * * * \\
(0.023)\end{array}$ & $\begin{array}{l}0.157 * * * \\
(0.007)\end{array}$ & $\begin{array}{l}0.409 * * * \\
(0.023)\end{array}$ \\
\hline $\log _{\text {Distance }_{i j}}$ & $\begin{array}{l}-0.616 * * * \\
(0.017)\end{array}$ & $\begin{array}{l}-1.402 * * * \\
(0.059)\end{array}$ & $\begin{array}{l}-0.611^{* * * *} \\
(0.017)\end{array}$ & $\begin{array}{l}-1.413^{* * *} \\
(0.059)\end{array}$ \\
\hline Language $_{i j}$ & $\begin{array}{l}0.403 * * * \\
(0.034)\end{array}$ & $\begin{array}{l}0.724 * * * \\
(0.112)\end{array}$ & $\begin{array}{l}0.407 * * * \\
(0.034)\end{array}$ & $\begin{array}{l}0.721 \% * * \\
(0.111)\end{array}$ \\
\hline Contiguity $_{i j}$ & $\begin{array}{l}0.510 * * * \\
(0.058)\end{array}$ & $\begin{array}{l}1.232 * * * \\
(0.131)\end{array}$ & $\begin{array}{l}0.521 * * * \\
(0.058)\end{array}$ & $\begin{array}{l}1.240 * * * * \\
(0.131)\end{array}$ \\
\hline Colony $_{i j}$ & $\begin{array}{l}0.461 * * * \\
(0.063)\end{array}$ & $\begin{array}{l}0.824 * * * \\
(0.165)\end{array}$ & $\begin{array}{l}0.455 * * * \\
(0.064)\end{array}$ & $\begin{array}{l}0.854 * * * * \\
(0.164)\end{array}$ \\
\hline $\mathrm{RTA}_{i j t}$ & $\begin{array}{l}0.263 * * * \\
(0.030)\end{array}$ & $\begin{array}{l}0.697 * * * \\
(0.099)\end{array}$ & $\begin{array}{l}0.264 * * * \\
(0.030)\end{array}$ & $\begin{array}{l}0.738 * * * * \\
(0.099)\end{array}$ \\
\hline $\log \left(1+\right.$ Tariff $\left._{i j k t}\right)$ & $\begin{array}{l}-0.201 * * * \\
(0.014)\end{array}$ & $\begin{array}{c}-0.515 * * * \\
(0.050)\end{array}$ & $\begin{array}{l}-0.198 * * * \\
(0.015)\end{array}$ & $\begin{array}{c}-0.507 * * * \\
(0.051)\end{array}$ \\
\hline $\operatorname{NoGAP}_{i k t-1}$ & $\begin{array}{l}-0.355 * * * \\
(0.038)\end{array}$ & $\begin{array}{c}-1.405^{* * *} \\
(0.136)\end{array}$ & $\begin{array}{l}-1.281^{* * *} \\
(0.040)\end{array}$ & $\begin{array}{l}-4.485^{* * *} \\
(0.144)\end{array}$ \\
\hline Religion $_{i j}$ & $\begin{array}{l}0.229 * * * \\
(0.030)\end{array}$ & & $\begin{array}{l}0.228 * * * \\
(0.030)\end{array}$ & \\
\hline 3 Observations & 178,584 & 25,185 & 178,584 & 25,185 \\
\hline
\end{tabular}

Notes: Robust country-pair-product clustered standard errors in parentheses. $* * *, * *, *$ denote significance at $1 \%$, 5\% and $10 \%$ respectively. Importer-product-time, exporter-time and product-time fixed effects included in all regressions. Intercepts included but not reported. Measure of GlobalGAP standard: columns (1) - (2) use number of certified producers and column (3) - (4) use certified land area. 
Table A2.7: GlobalGAP certification and agrifood exports: IV regressions

\begin{tabular}{|c|c|c|c|c|}
\hline & \multicolumn{2}{|l|}{ Producers } & \multicolumn{2}{|c|}{ Certified area/Harvest area } \\
\hline & First stage & IV (2SLS) & First stage & IV (2SLS) \\
\hline & (1) & $(2)$ & (3) & (4) \\
\hline Log GlobalGAP ${ }_{i k t-1}$ & $\begin{array}{l}0.938^{* * *} \\
(0.004)\end{array}$ & $\begin{array}{l}0.432^{* * *} \\
(0.027)\end{array}$ & $\begin{array}{l}0.781^{* * *} \\
(0.010)\end{array}$ & $\begin{array}{l}0.407^{* * *} \\
(0.031)\end{array}$ \\
\hline Log Production $_{i k t}$ & $\begin{array}{c}-0.008 \\
(0.005)\end{array}$ & $\begin{array}{l}0.138^{* * *} \\
(0.023)\end{array}$ & $\begin{array}{c}-0.043^{* * *} \\
(0.008)\end{array}$ & $\begin{array}{l}0.332^{* * *} \\
(0.022)\end{array}$ \\
\hline Log Distance $_{i j}$ & $\begin{array}{l}0.017^{\text {*** }} \\
(0.006)\end{array}$ & $\begin{array}{c}-1.126^{* * *} \\
(0.057)\end{array}$ & $\begin{array}{l}0.030^{* * *} \\
(0.011)\end{array}$ & $\begin{array}{c}-1.121^{* * *} \\
(0.056)\end{array}$ \\
\hline Language $_{i j}$ & $\begin{array}{c}0.002 \\
(0.012)\end{array}$ & $\begin{array}{l}0.532^{* * *} \\
(0.114)\end{array}$ & $\begin{array}{r}-0.022 \\
(0.021)\end{array}$ & $\begin{array}{l}0.515^{* * *} \\
(0.113)\end{array}$ \\
\hline Contiguity $_{i j}$ & $\begin{array}{c}0.009 \\
(0.013)\end{array}$ & $\begin{array}{l}1.128^{* * *} \\
(0.133)\end{array}$ & $\begin{array}{c}0.014 \\
(0.027)\end{array}$ & $\begin{array}{l}1.130^{* * *} \\
(0.132)\end{array}$ \\
\hline Colony $_{i j}$ & $\begin{array}{r}-0.002 \\
(0.015)\end{array}$ & $\begin{array}{l}0.605^{* * *} \\
(0.166)\end{array}$ & $\begin{array}{r}-0.027 \\
(0.029)\end{array}$ & $\begin{array}{l}0.620^{* * *} \\
(0.164)\end{array}$ \\
\hline $\mathrm{RTA}_{i j t}$ & $\begin{array}{c}-0.039^{* * *} \\
(0.011)\end{array}$ & $\begin{array}{l}0.573^{* * *} \\
(0.100)\end{array}$ & $\begin{array}{c}-0.051^{* * *} \\
(0.018)\end{array}$ & $\begin{array}{l}0.600^{* * *} \\
(0.101)\end{array}$ \\
\hline $\log \left(1+\operatorname{Tariff}_{i j k t}\right)$ & $\begin{array}{c}-0.032^{* * *} \\
(0.006)\end{array}$ & $\begin{array}{c}-0.431^{* * *} \\
(0.051)\end{array}$ & $\begin{array}{c}-0.043^{* * *} \\
(0.011)\end{array}$ & $\begin{array}{c}-0.425^{* * *} \\
(0.052)\end{array}$ \\
\hline NoGAP $_{i k t-1}$ & $\begin{array}{c}0.010 \\
(0.024) \\
\end{array}$ & $\begin{array}{c}-1.384^{* * *} \\
(0.132)\end{array}$ & $\begin{array}{l}1.658^{* * *} \\
(0.053)\end{array}$ & $\begin{array}{c}-3.760^{* * *} \\
(0.146)\end{array}$ \\
\hline $\begin{array}{l}\text { Observations } \\
\text { Underidentification } \\
\text { Weak identification }\end{array}$ & 25,185 & $\begin{array}{l}25,185 \\
1480.322 \\
52588.63\end{array}$ & 25,185 & $\begin{array}{l}25,185 \\
1388.341 \\
6566.972\end{array}$ \\
\hline
\end{tabular}

Notes: Robust country-pair-product clustered standard errors in parentheses. ***, **, * denote significance at $1 \%$, 5\% and $10 \%$ respectively. Importer-product-time, exporter-time and product-time fixed effects included in all regressions. Intercepts included but not reported. 2SLS is two-stage least squares estimation. We use GlobalGAP certifications for apple as instruments for grape and vice versa. We instrument for banana, using banana certifications in neighbouring countries. Underidentification and weak identification tests are Kleibergen-Paap rk LM statistic and Cragg-Donald Wald F statistic, respectively. 
This page intentionally left blank 


\title{
3 Exports and governance: the role of private voluntary agrifood standards
}

\begin{abstract}
The empirical evidence that institutional differences across countries affect bilateral trade is robust. The crucial question remains how countries can enhance trade amid these differences. In this paper, we measure the degree to which governance and institutions differ between countries as "governance distance". Using a sample of EU/EFTA imports, we examine how adopting private agrifood safety standards modify the effect of governance distance on exports of fruits and vegetables, in particular apples, bananas and grapes within a structural gravity framework. Our results show that while increasing governance distance hinders bilateral trade, the interaction of standards and the governance distance is positively associated with exports, hence partially offsetting the direct trade-inhibiting effects of the latter. GlobalGAP certified countries see the trade-inhibiting effects of governance distance on their exports reduced by about 50\%, ceteris paribus.
\end{abstract}

JEL classification: F14, L15, Q17, Q18

Keywords: Agricultural trade, GlobalGAP, Private food standards, Gravity model, Institutional quality

This chapter is published as Fiankor D-D. D, I. Martínez-Zarzoso and B. Brümmer (2019). Exports and governance: the role of private voluntary agrifood standards. Agricultural Economics: 50(3), 341-352.

Acknowledgements: We acknowledge comments from Stephan von Cramon-Taubadel, Hengrong Luo, two referees of the journal Agricultural Economics and participants of the 20th Göttingen workshop on International Economic Relations, and the 30th International Conference of Agricultural Economists in Vancouver.

Author contributions: Fiankor D-D. D. came up with the research idea, conceptualised it, analysed the data and wrote the paper. All authors revised the papers. 


\subsection{Introduction}

The question whether or not domestic institutions or institutional quality differences between countries affect bilateral trade flows has been examined extensively in the international trade (see, e.g., Anderson and Marcouiller, 2002; de Groot et al., 2004; Berden et al., 2014; Martínez-Zarzoso and Márquez-Ramos, 2019; Álvarez et al., 2018) and agricultural trade literature (see, e.g., Bojnec and Fertô, 2009; Olper and Raimondi, 2009; Huchet-Bourdon and Cheptea, 2011; de Mendonça et al., 2014). These studies provide robust evidence that answers this question generally in the affirmative. In effect, while international trade remains important to integrate developing countries into the global economy, missing or weak institutions will complicate international trade for their domestic firms (Goedhuys and Sleuwaegen, 2016).

An equally important question, but one which has received much less attention, is how countries overcome these institutional quality differences (Dimitrova et al., 2017). This is especially important for developing countries because they are dominated by small- and medium-scale producers who need to work around this institutional void (Goedhuys and Sleuwaegen, 2016). This paper makes an empirical contribution to the literature by examining the role of private voluntary standards for fruits and vegetables as alternative governance mechanisms to bridge the bilateral institutional or governance distance. ${ }^{43}$ Thus, it is not another paper that shows that institutions matter for trade; but a discussion of one way to increase trade in the presence of institutional differences.

Voluntary standards and product certifications have proliferated, becoming almost a universal phenomenon (Busch, 2011; Swinnen, 2016). Producers, in both developed and developing countries, are embracing certifications as quality signalling mechanisms to access high-value markets. To what extent do these market access provisions hold for exporting countries with poor domestic institutions? Voluntary product certifications may have increased signalling effects among countries with extreme institutional quality differences or the effectiveness of certification may be dampened under extreme institutional quality differences. ${ }^{44}$ This is an empirical question that to our knowledge has not been studied in the agricultural trade literature. In fact, relatively little attention has been devoted to the role of voluntary standards in the context of institutional gaps. ${ }^{45}$ This is nevertheless, essential. The increasing use of third-party audited standards to govern agrifood trade is an attempt by retailers to normalise agribusiness practices across countries (Ouma, 2010). The result, as we will argue, is that private standards counteract the trade-inhibiting effect of the institutional distance between countries.

We study this in the context of business-to-business relationships in the agrifood sector. Specifically, the case of producers targeting markets in the European Union (EU) and the European Free Trade Area (EFTA). This is important because the agrifood sector is particularly subject to quality standards, but constitutes a significant share of total exports in many developing countries. The EU/EFTA, a major export destination for many developing countries (Scoppola et al., 2018) and a market with strict food safety regulations (Kareem et al., 2018), provides a good setting for our study.

\footnotetext{
${ }^{43}$ We use the terms "institutional distance" and "governance distance" interchangeably in this paper.

${ }^{44}$ Corruption erodes trust in government efforts to regulate the conduct of firms, thereby increasing the signalling value of private certifications, however, widespread corruption can also extend distrust to private certification systems and reduce their credibility and signalling value (see, e.g., Montiel et al., 2012).

${ }^{45}$ One exception is Goedhuys and Sleuwaegen (2016).
} 
We focus on GlobalGAP, which is possibly the most widely used agrifood standard globally. Retailers in many developed countries seek to protect their integrity and reputation by demonstrating "due diligence" from food safety scandals (Lockie et al., 2015). Retail-driven process standards in general, but GlobalGAP standards, in particular, provide them one such guarantee. GlobalGAP standards are subordinate to state legislation whenever the requirements of the state exceed those of the standard. Hence, they act as de facto institutions enforcing food safety and quality whenever public regulations are weak or missing.

Our contributions to the literature are as follows. First, we combine the concept of "institutional distance"(Huchet-Bourdon and Cheptea, 2011; Dimitrova et al., 2017; Álvarez et al., 2018) with that of "standards as barriers or catalysts to trade" (Anders and Caswell, 2009; Swinnen, 2016) to develop a novel perspective of how voluntary standards create conditions that counter the trade-inhibiting effects of institutional distance. With growing research interest on the trade effects of voluntary standards, we should highlight that our findings are new. We are the first to consider their indirect trade effect from an institutional distance perspective. Second, using product level export data at the six digits-level of the Harmonised System Classification - on apples (HS 080810 and HS 081330), bananas (HS 080300), and grapes (HS 080610 and HS 080620), we formally investigate institutional distance and trade at the product level. Related studies consider aggregate or sectoral trade flows; e.g., Álvarez et al. (2018) and Martínez-Zarzoso and Márquez-Ramos (2019) study how institutions affect total bilateral trade flows, while Huchet-Bourdon and Cheptea (2011) consider the agrifood sector by summing up data on all products listed under HS06. Hence, these studies do not exploit the product dimension of their datasets. Moreover, to test the generality of our findings to the broader high-value agrifood sector, we use aggregate GlobalGAP-certified fruits and vegetable production in a country as a robustness check.

Empirically, we estimate a structural gravity model on a sample of EU/EFTA imports from 134 countries between 2010 and 2015. We augment the model with a composite index of time-varying country-pair differences in the six dimensions of the World Governance Indicators (WGI), which we call "governance distance", and its interaction with GlobalGAP standards to investigate the effect on trade flows. Our results confirm a trade impeding effect of governance distance on exports, mitigated by the interaction between governance distance and GlobalGAP, which has a trade-enhancing effect. Thus, conditional on certification the trade impeding effect of bilateral governance distance is reduced. These findings are robust to the product-specific analysis of apples, bananas, and grapes but also the aggregate fruits and vegetable sector, and to different measures of institutional quality. From a policy angle, voluntary certifications are viable means to improve exporting country reputations and increase trade even with differences in country-pair institutional quality.

The rest of the paper is structured as follows. Section 2 discusses conceptual issues related to institutional distance and private food standards. Section 3 deals with the empirical specification of the gravity model and the econometric issues. Section 4 describes the data and develops an index of time-varying bilateral institutional quality differences. Section 5 presents and discusses the estimation results and Section 6 concludes. 


\subsection{Conceptual discussion and hypotheses}

We test two research questions in our empirical setting: (1) the extent to which bilateral governance distance affects trade flows and (2) the role of voluntary standards as a means to bridge these gaps. In this section, we conceptualise different pathways that may moderate the effects.

\subsubsection{Governance and exports}

International trade involves multiple countries that usually have different institutional environments, e.g., democracies tend to have better institutions regarding consumer and food safety regulations, and provisions for their legal enforcement (Yu, 2010). Thus, the relationship between firms in different countries is naturally subject to multiple difficulties. An exhaustive literature has established their trade cost implications (e.g., Felbermayr and Toubal, 2010). Martínez-Zarzoso and Márquez-Ramos (2019) conceptualise these costs implications in three channels. First, good governance facilitates contracts and long-term agreements between firms in different countries. If institutional effectiveness is similar in both countries, traders can easily use and operate in each other's institutional environments. This reduces adjustment costs arising from natural unfamiliarity with international partners and lowers the insecurity related to transaction contingencies. The implication is that countries with similar ethical business environments will tend to trade more bilaterally (Horsewood and Voicu, 2012). As argued by Li and Samsell (2009) the time and cost of learning new rules and regulations are minimal for countries with similar domestic institutions. Second, good governance promotes investments and productivity improvements (see, e.g., Bojnec et al., 2014). Finally, good governance decreases uncertainty by increasing transparency, comparability and trust. This improves importers' trust in exporters (Yu, 2010) and reduces the transaction costs and costs associated with the risks of trading. The reverse is also true; for exporting countries with weak institutions, importers will have little or no trust in their products. This will increase trade costs and reduce their exports.

The empirical evidence is conclusive; poor institutional quality hinders exports by increasing trade costs. We review the empirical literature related to agrifood trade. ${ }^{46}$ Inferring from a microfounded gravity equation, Olper and Raimondi (2009) is one of the earliest studies to highlight the trade cost effect of institutions in the food industry. This is followed by Huchet-Bourdon and Cheptea (2011) who show that for the 11 founding members of the European Monetary Union, trade in agricultural products is sensitive to the quality and similarity of institutions. Bojnec and Fertő (2012) investigate how EU enlargement and quality of governance improves the size and duration of their agro-food trade. To generate a measure of governance and institutions, they apply a principal component analysis to the WGIs. They find that good institutions improve food exports and duration in each of the EU market segments. Estimating a gravity model, Bojnec et al. (2014) show that the quality of institutions in both exporting and importing countries enhance bilateral agro-food trade for the BRIC countries. de Mendonça et al. (2014) show that issues such as property rights, quality of rural employment and adoption of national and international norms in agricultural activity are essential to enlarge trade flows between countries.

\footnotetext{
${ }^{46}$ We refer the interested reader to Martínez-Zarzoso and Márquez-Ramos (2019) who review the general trade literature that study governance as a first-order determinant of bilateral trade flows.
} 
Premised on this discussion we hypothesise that increasing bilateral governance distance has a negative effect on agrifood trade ceteris paribus, i.e., the farther away countries are from each other in terms of their institutional quality, the less trade we will observe.

\subsubsection{Voluntary food standards as private governance institutions}

In many instances, retailers in developed countries ("the North") import their agricultural and food products from developing countries ("the South"). But, institutions and the ability to enforce strict food safety regulations in the North are better than in the South (Levchenko, 2007). Consider the case of the EU/EFTA; according to the EU Food Law (Regulation EC No 178/2002), where any food which is unsafe is part of a batch, it shall be presumed that all the food in that batch is also unsafe. It is the responsibility of retailers in the EU to ensure that banned substances are not applied or present on their imports from third countries. Retailers stand the risk of damaging their reputation and losing out financially if the quality of their imports is compromised.

Ensuring due diligence increases the transaction costs for retailers, especially where they cannot trust domestic institutions in the producing countries to ensure high standards. Export-oriented producers and firms operating in institutionally weak countries face difficulties in this regard, as buyers tend to infer the quality of their products partly from the generally poor reputation of their home countries' institutions (Montiel et al., 2012). As Hudson and Jones (2003) point out, because perceptions of quality have become associated with the level of development in the country of origin, developing countries find it especially difficult to signal quality to buyers. They are disproportionately hampered by information asymmetries and negative reputation effects (Goedhuys and Sleuwaegen, 2013) which necessitates signalling quality to their international partners through other means. For example, Dimitrova et al. (2017) find that when the differences in country-pair quality of institutions increase, uncertainty about exchanges heightens, and importers tend to rely more on an exporter's reputation for its people as a reassurance that exporting firms will be honest in their dealings. In other words, the more bilaterally distant the formal institutional environments between countries, the more beneficial the use of informal arrangements (Abdi and Aulakh, 2012).

Our point of departure is the argument that voluntary certification by exporters to a standard that is accepted in the importing country improves exporting country reputations thereby reducing the trade-impeding effect of the bilateral governance distance between the two countries. This effect is moderated through the transaction cost reducing effect of the standard for retailers in the importing country. When the quality of institutions differs widely between two countries, we argue that standards can act as surrogate governance institutions. They level the playing field by placing geographically dispersed firms on a common ground in terms of managerial practices, business language and conflict-settling procedures (Hudson and Jones, 2003; Goedhuys and Sleuwaegen, 2016). This will reduce the effects of the bilateral institutional distance across countries engaged in bilateral trade. In agricultural trade, importers can in many cases only judge the final product. In the presence of increasing bilateral governance distance, information asymmetries are pronounced and signalling quality becomes even more important. With bounded rationality, importers will look for proxies to assess product quality. Exporters that can provide quality assurance, e.g., via certification, gain a competitive edge (Cao and Prakash, 2011). 
As traceability requirements (e.g., article 18.2 of the EU Food Law) ${ }^{47}$ get stricter, retailers are increasingly interested in the guarantee that not only the final products but also the production processes meet the required standards. The surge in the number of retailer-led standards, e.g., GlobalGAP, International Featured Standards, British Retail Consortium standards is, therefore, not surprising. The case of GlobalGAP standards is particularly interesting because it is fast becoming quasimandatory to assess high-value markets despite being legally voluntary. As a business-to-business standard, GlobalGAP certification resembles an attempt by retailers to enforce a system where individual farmers' skills are benchmarked against each other. This provides a mechanism for retailers to identify producers, regardless of country of origin, producing according to industry accepted standards, i.e., those who can signal quality through the possession of a certificate of conformity. This enhances the scopes of importers to gauge the quality performance of their suppliers and ensures the inclusion of distant suppliers (Ouma, 2010).

In the process, this reduces the transaction costs for retailers dealing with producers scattered across various countries, who may have different food safety standards and different abilities to enforce them. By outsourcing both the knowledge acquisition and the technical expertise required for design and ex-post monitoring of the standard, GlobalGAP allows both for a reduction in the costs of monitoring food safety standards at the farm level and ensuring that they comply with EU public regulations (Maze, 2017). However, it also induces extra costs for the producing party, which some have interpreted as the increasing power of retailers to pass on food safety risks through their supply chains (Lockie et al., 2013). For producers, GlobalGAP has "major" and "minor" musts that should be met along each stage of the production chain before certification is granted. ${ }^{48}$ But, the harmonisation of production processes across farms overrides to some extent the institutional quality differences between high-value importing countries and suppliers, especially from countries with weak domestic food safety regulations. Hence, producers who bear the costs and comply, nevertheless, may achieve a competitive advantage.

In summary, supply chain governance via GlobalGAP standards is an attempt to normalise spatially dispersed farming practices across countries (Ouma, 2010). Certification provides a shared frame of reference for both parties and increases importers' trust in products irrespective of the country of origin. By increasing the visibility of actions of actors on the supply-side (i.e., producers and suppliers) to actors on the demand-side (i.e., retailers and importers) of the value chain, standards enable the maintenance of trust in distant relationships (Lockie et al., 2015). Based on these arguments, we hypothesise that by reducing the transaction costs for retailers, private voluntary food certifications offset the trade-inhibiting effect of the bilateral governance distance between countries.

\footnotetext{
${ }^{47}$ The regulation states that "food and feed business operators shall be able to identify any person from whom they have been supplied with a food, a feed, a food-producing animal, or any substance intended to be, or expected to be, incorporated into a food or feed"

48 "Major" control points of GlobalGAP include traceability (e.g., producers must guarantee that the product can be traced back to the farm by registering exact planting and harvesting dates), record keeping (e.g., producers are required to keep records on all substances applied to crops, exact amounts, and application dates), varieties and fertilisers (e.g., only certified/authorised seed varieties and fertilisers may be used; inorganic and organic fertilisers have to be stored separately from crops and seeds), irrigation (e.g., without contaminated water), Integrated Pest Management (e.g., pests must be dealt with in ecologically sensitive ways, crops must be treated with pesticides punctually if affected, and producers must ensure a minimum time between spraying and harvesting), harvesting and produce handling (e.g., hygienic treatment of harvested produce must be ensured).
} 


\subsection{Empirical application}

To test our hypotheses we estimate a structural gravity model of international trade. The gravity model describes one of the most stable relationships in economics: "interaction between large economic clusters is stronger than between smaller ones, and nearby clusters attract each other more than faroff ones" (van Bergeijk and Brakman, 2010, p. 1). It has become the workhorse model for trade policy analysis. Our modelling approach is similar to Tadesse and White (2010) and Dimitrova et al. (2017) who assess the pro-export effect of immigrants on cultural distance, and the relationship between bilateral country reputation and export volume, respectively. Following Anderson and Van Wincoop (2003), our augmented gravity model assumes a constant elasticity of substitution $(\sigma)$ and product differentiation by place of origin. In addition, prices differ among locations due to asymmetric bilateral trade costs. In its log-log reduced form, the structural gravity model is specified as:

$$
\ln X_{i j k t}=\ln E_{j t}+\ln Y_{i k t}-\ln Y_{k t}+\left(1-\sigma_{k}\right) \ln \tau_{i j k t}-\left(1-\sigma_{k}\right) \ln P_{j k t}-\left(1-\sigma_{k}\right) \ln \Pi_{i k t}+\varepsilon_{i j k t}
$$

where $X_{i j k t}$ is exports of product $k$ from exporting country $i$ to importing country $j$ in year $t . \mathrm{E}_{j t}$ is nominal GDP, which proxies the import demand of $j$ in $t . Y_{i k t}$ is the level of domestic production in $i . Y_{k t}$ is aggregate world production and $P_{j k t}$ and $\Pi_{i k t}$ are the inward and outward multilateral resistance terms respectively. $\varepsilon_{i j k t}$ is the error term, which we cluster by product and country-pair. $\tau_{i j k t}$ are trade costs, which we define as the following multiplicative log-linear function:

$$
\begin{aligned}
\ln \tau_{i j k t} & =\gamma_{1} \ln \text { Distance }_{i j}+\gamma_{2} \text { GovDist }_{i j t}+\gamma_{3} \text { GlobalGAP }_{i k t}+\gamma_{4} \text { GovDist }_{i j t} \times \text { GlobalGAP }_{i k t} \\
& +\gamma_{5} \text { RTA }_{i j t}+\gamma_{6} \ln \left(1+\text { Tariff }_{i j k t}\right)+\sum_{n=7}^{9} \gamma_{n} \theta_{i j}
\end{aligned}
$$

As we highlight in the conceptual discussion, institutional quality differences between countries affect trade costs. Simultaneously, compliance with retailer-led standards like GlobalGAP are costs of doing business - that may, or may not, enhance profitability through improved market access (Lockie et al., 2015) - especially for producers targeting high-value export markets. Thus, we argue that the effects of both institutional quality differences and GlobalGAP certification on trade is via the trade cost channel. We augment the trade cost component of our model with GovDist ${ }_{i j t}$ which proxies institutional quality differences between country pairs and a dummy variable, GlobalGAP ${ }_{i k t}$, which is our measure of the certification status of the exporting country. GovDist ${ }_{i j t} \times$ GlobalGAP $_{i k t}$ is the interaction of the two variables. Distance ${ }_{i j}$ is the bilateral distance between country-pairs, RTA ${ }_{i j t}$ is a dummy that denotes membership in a regional trade agreement, and Tariff ${ }_{i j k t}$ is product-specific ad valorem tariff. $\theta_{i j}$ is a vector of time-invariant traditional gravity covariates including dummies for sharing a common language, colonial ties, and a common border.

For estimation purposes, we introduce the trade cost component, $\tau_{i j k t}$ into equation (3.1) and specify a standard augmented gravity model in its log-linear form as:

$$
\begin{aligned}
\ln \mathrm{X}_{i j k t} & =\alpha_{t}+\psi_{i}+\rho_{j}+\phi_{k}+\beta_{0}+\beta_{1} \ln \text { Production }_{i k t}+\beta_{2} \ln _{\text {GDP }}+\beta_{3} \ln \text { Distance }_{i j} \\
& +\beta_{4} \text { GovDist }_{i j t-1}+\beta_{5} \text { GlobalGAP }_{i k t-1}+\beta_{6} \text { GovDist }_{i j t-1} \times \text { GlobalGAP }_{i k t-1} \\
& +\beta_{7} \text { RTA }_{i j t}+\beta_{8} \ln \left(1+\text { Tariff }_{i j k t}\right)+\sum_{n=9}^{11} \beta_{n} \theta_{i j}+\varepsilon_{i j k t}
\end{aligned}
$$


where $\alpha_{t}, \psi_{i}, \rho_{j}$, and $\phi_{k}$ are year, exporter, importer, and product fixed effects, respectively. Production $_{i k t}$ is the domestic production of product $k$ in the exporting country and GDP ${ }_{j t}$ is the Gross Domestic Product of the importing country. These variables measure the supply-side capacity of the exporting country and the demand-side capacity of the importing countries, respectively. All other variables remain as defined in equation (3.2). To deal with the potential endogeneity of institutions and certifications due to reverse causality, we use a one year-lag of both variables (see, e.g., Dimitrova et al., 2017; Álvarez et al., 2018).

The model as specified in equation (3.3) is at best atheoretical because it does not account fully for the theoretical multilateral resistance terms $\mathrm{P}_{j k t}$ and $\Pi_{i k t}$ in equation (3.1) (Anderson and Van Wincoop, 2003) - which in our sectoral panel data setting should be time and product varying (Baldwin and Taglioni, 2007). What this means is that the country fixed effects in equation (3.3) must vary with product and time. To that effect, our theoretically specified ordinary least squares (OLS) model is:

$$
\begin{aligned}
\ln \mathrm{X}_{i j k t} & =\psi_{i k t}+\lambda_{j k t}+\beta_{0}+\beta_{1}{\text { ln } \text { Distance }_{i j}+\beta_{2} \text { Language }_{i j}+\beta_{3} \text { Colony }_{i j}+\beta_{4} \text { Contiguity }_{i j}} \\
& +\beta_{5} \text { GovDist }_{i j t-1}+\beta_{6} \text { GovDist }_{i j t-1} \times \text { GlobalGAP }_{i k t-1}+\beta_{7} \text { RTA }_{i j t} \\
& +\beta_{8} \ln \left(1+\text { Tariff }_{i j k t}\right)+\varepsilon_{i j k t}
\end{aligned}
$$

where $\psi_{i k t}$ and $\lambda_{j k t}$ are the exporter-product-time and importer-product-time fixed effects respectively. Apart from being consistent with the gravity theory, the inclusion of these terms account for the size terms (i.e., $\mathrm{GDP}_{j t}$ and Production $_{i k t}$ ) and the certification measure (GlobalGAP $\left.i k t\right) .{ }^{49}$ They also account for unobservable variables that have the country-product-time dimension (e.g., non-tariff measures, infrastructure, domestic institutions), thus mitigating any further omitted variable biases that may lead to endogeneity in our model specification. Furthermore, the specification in equations (3.3) and (3.4) requires log transforming the dependent variable. This may result in significant loss of information in micro-settings like agrifood trade where zero valued trade flows are ubiquitous. Since we estimate our gravity model at the disaggregated six-digit level, the issue of zeroes is even more pronounced. Indeed, $81 \%$ of our observed trade flows are zeroes. As an alternative to the OLS specification, we adopt the Poisson pseudo-maximum-likelihood (PPML) estimator (Santos Silva and Tenreyro, 2006, 2011) in equation (3.5). The estimator's log-linear objective function allows us to specify the gravity equation in its multiplicative form without log-transforming the dependent variable, and is consistent under heteroskedasticity:

$$
\begin{aligned}
\mathrm{X}_{i j k t} & =\exp \left[\psi_{i k t}+\lambda_{j k t}+\beta_{0}+\beta_{1} \text { ln Distance }_{i j}+\beta_{2} \text { Language }_{i j}+\beta_{3} \text { Colony }_{i j}+\beta_{4} \text { Contiguity }_{i j}\right. \\
& \left.+\beta_{5} \text { GovDist }_{i j t-1}+\beta_{6} \text { GovDist }_{i j t-1} \times \text { GlobalGAP }_{i k t-1}+\beta_{7} \text { RTA }_{i j t}+\beta_{8} \ln \left(1+\text { Tariff }_{i j k t}\right)\right] \\
& +\varepsilon_{i j k t}
\end{aligned}
$$

Similar variable definitions hold as in equation (3.2). Our hypotheses are confirmed when the coefficient on the governance distance measure is negative (i.e., $\beta_{5}<0$ ), but we expect a positive

\footnotetext{
${ }^{49}$ We do not include the main effect for GlobalGAP $i k t$ in equations (3.4) and (3.5) because they are accounted for by the exporter-product-time specific effects.
} 
coefficient on the interaction term (i.e., $\beta_{6}>0$ ).

\subsection{Data}

Growing interest in studying the quality of governance institutions has given rise to quantitative governance indicators from different sources. These include data from the International Country Risk Guide rating systems, Freedom House, Transparency International's Corruption Perception Index, and the World Bank's WGIs (Arndt and Oman, 2006). But, the WGIs are the most comprehensive institutional indicators currently available for many countries (Arndt and Oman, 2006; Lio and Liu, 2008; Huchet-Bourdon and Cheptea, 2011; Berden et al., 2014; Álvarez et al., 2018). Hence, we calculate our governance distance measure using data on the WGIs. The WGIs are composed of six indicators (Table 3.1) ${ }^{50}$ that are based on several hundreds of variables obtained from 31 underlying data sources reporting the perceptions of governance of a large number of survey respondents, and expert assessments of non-governmental organisations, commercial business information providers, and public sector organisations worldwide (Kaufmann et al., 2011).

Each of these indicators, measured in units ranging from -2.5 (worst) to 2.5 (best), represents a different dimension of governance in a country which can potentially affect trade. Since our interest is in how these measures vary across country-pairs, we transform the country-varying WGIs into country-pair varying variables using an index defined in equation (3.6). There is an added advantage to this approach; it respects the structural properties of the gravity model by allowing estimates with the proper set of country-time fixed effects. Recent work that has followed this approach include Martínez-Zarzoso and Márquez-Ramos (2019) and Álvarez et al. (2018). Their approaches yield indices that vary bilaterally over time across each of the individual WGIs. We, on the other hand, are interested in a composite measure of bilateral and time-varying institutional quality. Following Kogut and Singh (1988), Abdi and Aulakh (2012), and Dimitrova et al. (2017), and introducing the time dimension $t$ of our dataset, we calculate the bilateral governance distance between country pairs as the standardised difference between the importing and exporting country scores on each of the six

Table 3.1: Brief description of the components of the Worldwide Governance Indicators

1. Voice and Accountability: the extent to which a country's citizens are able to participate in selecting their government, as well as freedom of expression, association, and a free media.

2. Government Effectiveness: the quality of public services, the civil service and the degree of its independence from political pressures, the quality of policy formulation and implementation, and the credibility of the government's commitment to such policies.

3. Control of Corruption: the extent to which public power is exercised for private gain, including both petty and grand forms of corruption, as well as the state by elites and private interests.

4. Regulatory Quality: the ability of the government to formulate and implement sound policies and regulations that permit and promote private sector development.

5. Political stability: captures perceptions of the likelihood that the government will be destabilised or overthrown by unconstitutional or violent means.

6. Rule of Law: the extent to which agents have confidence in and abide by the rules of society, and in particular the quality of contract enforcement, property rights, the police, and the courts, as well as the likelihood of crime and violence.

Source: Kaufmann et al. (2011).

\footnotetext{
${ }^{50}$ These variables are more or less standard in the literature and are not discussed in details here. We refer the interested reader to de Groot et al. (2004), Arndt and Oman (2006), and Berden et al. (2014).
} 
WGIs:

$$
\text { GovDist }_{i j t}=\sum_{n=1}^{6}\left[\mathrm{WGI}_{j n t}-\mathrm{WGI}_{i n t}\right]^{2} / 6 V_{n t}
$$

where GovDist ${ }_{i j t}$ is the bilateral governance distance between exporter $i$ and importer $j$ in year $t$, $\mathrm{WGI}_{j n t}$ and $\mathrm{WGI}_{i n t}$ are the values for the $\mathrm{n}^{\text {th }}$ WGI indicator for $i$ and $j$, respectively, and $\mathrm{V}_{k t}$ is the variance of the $\mathrm{k}^{\text {th }}$ WGI indicator across all countries in the dataset. The indicator is minimised at zero for countries with similar institutional qualities and maximised for countries that are institutionally furthest apart. In our sample, the average ranges from 0.014 (i.e., the Netherlands - Canada) to 17.69 (i.e., Finland - Somalia). Using the case of Germany as an importing country, Figure (3.1) shows the average bilateral governance distance over the period 2010 to 2015. The darker regions, i.e., countries in Africa and the Middle East, imply large institutional quality differences with Germany. Countries with the lowest governance gaps include other countries in the EU, EFTA, the United States, Canada, Chile, Japan and Australia.

Figure 3.1: Bilateral governance distance: 2010 - 2015 (using Germany as the importer)

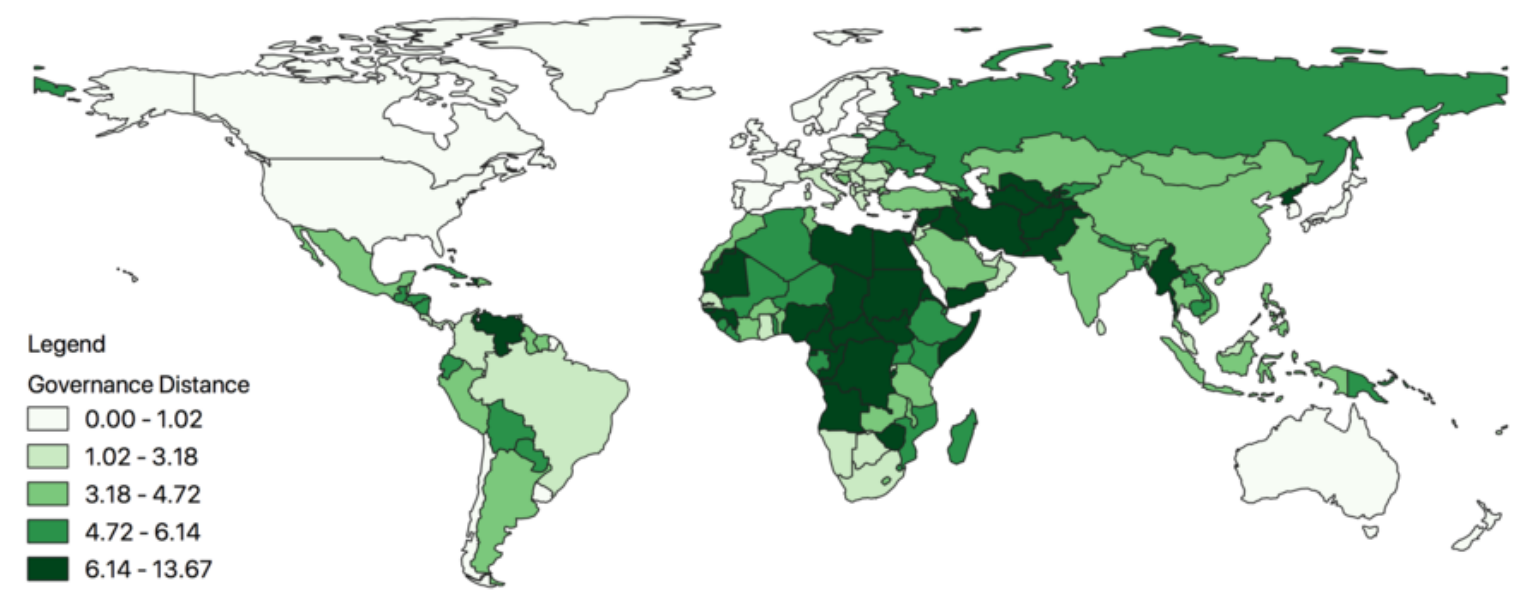

Source: World Bank WGI dataset, authors' own map.

To test the second hypothesis we use GlobalGAP certifications as our preferred private voluntary standard. We premise this on the observation that GlobalGAP has become the most widely applied retailer-led quality assurance scheme for agrifood production since its inception in $1997 .{ }^{51}$ As we show in Table 3.2, the number of producers seeking certification has increased over time. The choice of GlobalGAP also makes the EU and EFTA ideal export destinations because GlobalGAP is considered a minimum requirement to access their agrifood markets. In 2007, in an attempt to mark their global relevance they effected a name change from EUREPGAP to GlobalGAP. Hence, while GlobalGAP still wields a growing global influence, we expect their effects to be stronger for exports targeting the EU and EFTA. The dataset was provided by the GlobalGAP Secretariat in Cologne, Germany.

\footnotetext{
${ }^{51}$ In international agri-food trade, private standards are, ubiquitous nevertheless, GlobalGAP standards are more widespread, e.g. Mohammed and Zheng (2017) show that for the 131 countries they study, the number of GlobalGAP certified sites is normally several times larger than that certified to other private standards (i.e. BRC, FSSC 22000, ISO 22000, PrimusGFS, SQF).
} 
Table 3.2: Total number of GlobalGAP certified producers per year ('000)

\begin{tabular}{lllll}
\hline Year & Apples & Bananas & Grapes & Fruits and vegetables \\
\hline 2010 & 3302 & 565 & 898 & 16750 \\
2011 & 2913 & 995 & 1039 & 18270 \\
2012 & 3264 & 1099 & 1032 & 18743 \\
2013 & 3530 & 1521 & 1114 & 20164 \\
2014 & 3699 & 1540 & 1370 & 21623 \\
2015 & 3696 & 1576 & 1577 & 24493 \\
\hline
\end{tabular}

Source: GlobalGAP data

GlobalGAP certifies both crops, livestock, and aquaculture. We limit our study to the fruit and vegetable crops sector, specifically, apples, bananas and grapes, given their relative importance among certified products. Together with potatoes, these products are the most GlobalGAP certified open field crops by area (GLOBALGAP, 2012), representing more than 30\% of all GlobalGAP certified fruits and vegetable production (Table 3.2). Moreover, to test the generality of our findings to the broader high-value agrifood sector, we use aggregate GlobalGAP certified fruits and vegetable production in a country as a robustness check. Unlike the product-specific data on apples, bananas, and grapes, this dataset does not allow us to identify the specific crops certified within a country. It aggregates data on all products that can be certified within the GlobalGAP sub-scope 'Fruits and Vegetables'.

Our dataset covers exports from 134 non-EU/EFTA countries to 31 EU/EFTA countries over the period 2010 to 2015. We omit re-exports from non-producing countries. To match the available product-specific GlobalGAP data, our set of exporters is limited to apple, banana and grape producing countries (Table A3.1). Over the study period, 25 exporting countries had at least one certified apple producer, 36 exporting countries had at least one certified banana producer and 30 exporting countries had at least one certified grape producer. Hence, for each of these countries, the GlobalGAP ${ }_{i k t}$ dummy takes the value of 1 .

The remaining gravity model data come from different sources. The bilateral trade data on fresh and dried apples (HS 080810 and 081330), fresh and dried bananas (HS 080300) ${ }^{52}$ and, fresh and dried grapes (HS 080610 and 080620) comes from the United Nations Comtrade database and is downloaded at the six-digit HS2007 level. ${ }^{53}$ Data on distance, colonial ties, common language, and contiguity are from the Centre d'Etudes Prospectives et d'Informations Internationales. Data on effectively applied tariffs are from the International Trade Centre, and data on regional trade agreements are from De Sousa (2012). Detailed summary statistics on all included variables are presented in Table A3.2.

\subsection{Results and discussion}

\subsubsection{Main results}

To allow for comparison across model specifications and to conclude whether our variables of interest can be estimated reliably regardless of the estimation procedure, we present and discuss the results

\footnotetext{
${ }^{52}$ Banana trade flows recorded in the six-digit HS2007 classification includes plantains. But trade volumes are low compared to bananas, and should not alter our results.

${ }^{53}$ We limit the bilateral trade data to six years to match the available product-specific GlobalGAP data.
} 
of both the OLS and PPML models. ${ }^{54}$

Table 3.3 reports the estimated coefficients in equations (3.4) and (3.5). In many cases, consistent with the literature the estimates of the PPML model are smaller than in the OLS specification (Santos Silva and Tenreyro, 2006). The signs and magnitudes of the traditional gravity control variables are all consistent with the gravity literature. Bilateral distance and tariffs decrease trade, but linguistic similarity, and countries that share a common border, past colonial ties or are members of a trade agreement are more likely to trade than otherwise. The coefficient estimates on the Tariff and RTA variables are not always statistically significant across our model specifications. This is not surprising because the sample of importing countries contains EU and EFTA countries and therefore there is little variation in the RTA and tariff variables.

In support of our first hypothesis, the coefficient estimate on our governance dissimilarity measure, GovDist ${ }_{i j t-1}$, is negative and statistically significant at any conventional level in both model specifications. Thus, with increasing bilateral governance distance, bilateral trade decreases. This implies that for retailers in the EU and EFTA, when deciding where to source their agrifood products, they prefer countries with institutional qualities similar to those existing in the EU and EFTA.

Next, we test the effect on the interaction of governance distance and GlobalGAP standards. We enter the interaction term GovDist ${ }_{i j t-1} \times$ GlobalGAP $_{i k t-1}$, and the constitutive terms of the interaction into the models in columns (2) and (4). The GlobalGAP $i k t-1$ terms are omitted from the tables as they are accounted for by the exporter-product-time fixed effects. In support of our hypothesis, the coefficient estimate on the interaction term is positive and statistically significant. Hence, the more distant the governance gap between country pairs, the more effective the use of certification.

Based on these findings, we assess the differential effect of bilateral governance distance on trade flows depending on the GlobalGAP certification status of the exporting country. From equations (3.4) and (3.5), the effect for certified countries includes the direct effect of the governance gap proxy and the coefficient on the interaction term (i.e., $\hat{\beta}_{5}+\hat{\beta}_{6} \times$ GlobalGAP $_{i k t-1}$ ). Thus, empirically based on our a priori expectation, a negative governance gap effect becomes less negative if the interaction term is positive. Specifically, for non-certified countries, the effects on trade are the direct GovDist $_{i j t-1}$ effects (i.e., -0.599 in column 2 and -0.450 in column 4 ). For certified countries, the trade-inhibiting effect of governance distance is about half the magnitude for non-certified countries (i.e., -0.296 in column 2 and -0.185 in column 4 ).

Our results imply that even though bilateral governance distance has a trade impeding effect on trade flows, the negative effects are smaller for certified compared to non-certified countries. This suggests that product certification, which signals product quality, is important in enhancing exports even for country pairs with big differences in institutional quality. This is because where public food safety regulations are missing or, when available, institutions to enforce them are weak, the GlobalGAP standard provides the retailer with an instrument to manage their risks (Lockie et al., 2013). However, because the coefficient on the interaction term is smaller in magnitude than the direct effect of GovDist ${ }_{i j t-1}$ (i.e., $\left|\beta_{6}\right|<\left|\beta_{5}\right|$ ), the GlobalGAP certification effect is not sufficiently large to completely eliminate the negative trade effects of governance distance.

\footnotetext{
${ }^{54}$ To deal with the high-dimensional fixed effects in our model specifications, we use the user-written commands reghdfe (Correia, 2016) and poi2hdfe (Guimaraes and Portugal, 2010) in Stata.
} 
Table 3.3: The effect of private food safety standard and governance distance on product-level exports

\begin{tabular}{|c|c|c|c|c|}
\hline \multirow[b]{2}{*}{ Dependent variable } & \multicolumn{2}{|l|}{ OLS } & \multicolumn{2}{|l|}{ PPML } \\
\hline & $\begin{array}{l}(1) \\
\ln X_{i j k t}\end{array}$ & $\begin{array}{l}(2) \\
\ln X_{i j k t}\end{array}$ & $\begin{array}{l}(3) \\
X_{i j k t}\end{array}$ & $\begin{array}{l}(4) \\
X_{i j k t}\end{array}$ \\
\hline Log Distance ${ }_{i j}$ & $\begin{array}{l}-1.916^{* * *} \\
(0.246)\end{array}$ & $\begin{array}{l}-1.947^{* * *} \\
(0.243)\end{array}$ & $\begin{array}{l}-1.359^{* *} \\
(0.658)\end{array}$ & $\begin{array}{c}-1.409^{* *} \\
(0.664)\end{array}$ \\
\hline Language $_{i j}$ & $\begin{array}{c}0.082 \\
(0.265)\end{array}$ & $\begin{array}{c}0.084 \\
(0.266)\end{array}$ & $\begin{array}{c}0.394^{*} \\
(0.234)\end{array}$ & $\begin{array}{c}0.400^{*} \\
(0.236)\end{array}$ \\
\hline Colony $_{i j}$ & $\begin{array}{c}0.395 \\
(0.270)\end{array}$ & $\begin{array}{c}0.390 \\
(0.270)\end{array}$ & $\begin{array}{l}0.675^{* * *} \\
(0.196)\end{array}$ & $\begin{array}{l}0.674^{* * *} \\
(0.196)\end{array}$ \\
\hline Contiguity $_{i j}$ & $\begin{array}{l}1.066^{* *} \\
(0.481)\end{array}$ & $\begin{array}{l}1.077^{* *} \\
(0.465)\end{array}$ & $\begin{array}{c}1.982^{*} \\
(1.177)\end{array}$ & $\begin{array}{c}1.886 \\
(1.150)\end{array}$ \\
\hline $\mathrm{RTA}_{i j t}$ & $\begin{array}{l}0.994^{* *} \\
(0.412)\end{array}$ & $\begin{array}{l}1.066^{* *} \\
(0.418)\end{array}$ & $\begin{array}{c}0.043 \\
(0.229)\end{array}$ & $\begin{array}{c}0.026 \\
(0.230)\end{array}$ \\
\hline $\log \left(1+\operatorname{Tariff}_{i j k t}\right)$ & $\begin{array}{c}-0.102 \\
(0.163)\end{array}$ & $\begin{array}{c}-0.111 \\
(0.164)\end{array}$ & $\begin{array}{l}-0.167 \\
(0.108)\end{array}$ & $\begin{array}{c}-0.173 \\
(0.108)\end{array}$ \\
\hline GovDist $_{i j t-1}$ & $\begin{array}{l}-0.458^{* * *} \\
(0.076)\end{array}$ & $\begin{array}{l}-0.599^{* * *} \\
(0.082)\end{array}$ & $\begin{array}{r}-0.216^{*} \\
(0.112)\end{array}$ & $\begin{array}{c}-0.450^{* * *} \\
(0.123)\end{array}$ \\
\hline GovDist $_{i j t-1} \times$ GlobalGAP $_{i k t-1}$ & & $\begin{array}{l}0.303^{* * *} \\
(0.080)\end{array}$ & & $\begin{array}{c}0.265^{* *} \\
(0.119)\end{array}$ \\
\hline Observations & 6,272 & 6,272 & 23,192 & 23,192 \\
\hline
\end{tabular}

Notes: Robust country-pair-product clustered standard errors in parentheses. $* * * * *, *$ denote significance at $1 \%, 5 \%$ and $10 \%$ respectively. Importer-product-time and exporter-product-time fixed effects included in all regressions. Intercepts included but not reported.

To put the findings in perspective, we use the results of the PPML specification. For the average effect in column (3), all else remaining equal, a one standard deviation increase in the bilateral governance gap index $(=2.740)$, decreases trade flows by about $60 \% .{ }^{55}$ This effect approximately corresponds to a change in GovDist ${ }_{i j t}$ from Austria - USA $(=0.12)$ to that of Austria - Turkey $(=2.86)$, Germany - Australia $(=0.03)$ to that of Germany - Albania $(=3.09)$, or from Sweden Ghana $(=3.33)$ to that of Sweden - Guatemala $(=6.18)$. Thus, if the institutional distance between Austria - Turkey, Germany - Albania, and Sweden - Ghana decreases by one standard deviation, apple exports from Turkey to Austria, grape exports from Albania to Germany and banana exports from Guatemala to Sweden will increase by $60 \%$. For the conditional effects in column (4), the trade reducing effect of a one standard deviation increase in the governance distance measure is $124 \%$ for non-certified countries but decreases to about $51 \%$ for certified producing countries.

To gain further insights into the analysis, we disaggregate the composite governance distance index into its individual components and assess how each of them influences trade and interacts with GlobalGAP standards. In the spirit of Álvarez et al. (2018) we enter the six different components; Voice and Accountability $\left(\mathrm{VA}_{i j t}\right)$, Political Stability $\left(\mathrm{PS}_{i j t}\right)$, Rule of Law $\left(\mathrm{RL}_{i j t}\right)$, Control of Corruption $\left(\mathrm{CC}_{i j t}\right)$, Government Effectiveness $\left(\mathrm{GE}_{i j t}\right)$, and Regulatory Quality $\left(\mathrm{RQ}_{i j t}\right)$ individually into the model specifications. For brevity, the results of the analysis presented in the appendix (Table A3) show only variables related to the governance measures. ${ }^{56}$ The results naturally vary by indicator,

\footnotetext{
${ }^{55} 2.740 \times 0.217=0.595$.

${ }^{56} \mathrm{The}$ full table of results are available upon request from the authors.
} 
but the main finding of a negative effect of institutional distance on trade and a positive interaction effect with GlobalGAP standards is robust for each indicator; confirming our main findings. ${ }^{57}$

We also explore the heterogeneity of the effect across products and the development level of the certified exporting country. We define two levels of development based on the World Bank's income classification: "developing" (all countries listed as middle and low income) and "developed" (all countries listed as high income). The results of the analysis presented in columns (1) and (2) of Table 3.4 show that our findings are driven by developing country exports. The statistically non-significant findings for developed countries are in line with recent empirical findings that the GlobalGAP certification-trade effect is larger for developing countries compared to developed countries (Andersson, 2018; Fiankor et al., 2019a). By products, the positive effect of GlobalGAP certification on the bilateral governance distance is economically substantial for grapes and apples, but remain small for bananas. The results for banana, reflect in part the special nature of the banana export market, especially in the EU, where they are considered sensitive products and have often been regulated by specific import regimes. Given the low level of banana production in the EU/EFTA, and the reputation especially of the EU as the number one banana consumption market globally, it appears that other bilateral trade policies aside certification are shaping the banana import market,

Table 3.4: The effect of private food safety standard and governance distance on product-level exports: income level and product heterogeneities

\begin{tabular}{|c|c|c|c|c|}
\hline \multirow[b]{4}{*}{ Dependent variable } & \multicolumn{2}{|c|}{ By income level } & \multicolumn{2}{|c|}{ By product } \\
\hline & OLS & PPML & OLS & PPML \\
\hline & (1) & (2) & (3) & (4) \\
\hline & $\ln X_{i j k t}$ & $X_{i j k t}$ & $\ln X_{i j k t}$ & $X_{i j k t}$ \\
\hline GovDist $_{i j t-1}$ & $\begin{array}{c}-0.573^{* * *} \\
(0.083)\end{array}$ & $\begin{array}{c}-0.456^{* * *} \\
(0.125)\end{array}$ & $\begin{array}{l}-0.605^{* * *} \\
(0.081)\end{array}$ & $\begin{array}{c}-0.425^{* * *} \\
(0.115)\end{array}$ \\
\hline GovDist $_{i j t-1} \times$ GlobalGAP $_{i k t-1}^{\text {Developing }}$ & $\begin{array}{l}0.323^{* * *} \\
(0.081)\end{array}$ & $\begin{array}{c}0.265^{* *} \\
(0.119)\end{array}$ & & \\
\hline GovDist $_{i j t-1} \times$ GlobalGAP $_{i k t-1}^{\text {Developed }}$ & $\begin{array}{c}-0.097 \\
(0.284)\end{array}$ & $\begin{array}{c}0.493 \\
(0.320)\end{array}$ & & \\
\hline GovDist $_{i j t-1} \times$ GlobalGAP $_{i k t-1}^{\text {Apple }}$ & & & $\begin{array}{l}0.337^{* * *} \\
(0.130)\end{array}$ & $\begin{array}{c}0.362^{* *} \\
(0.156)\end{array}$ \\
\hline GovDist $_{i j t-1} \times$ GlobalGAP $_{i k t-1}^{\text {Banana }}$ & & & $\begin{array}{c}-0.002 \\
(0.129)\end{array}$ & $\begin{array}{c}0.143 \\
(0.182)\end{array}$ \\
\hline GovDist $_{i j t-1} \times$ GlobalGAP $_{i k t-1}^{\text {Grape }}$ & & & $\begin{array}{l}0.502^{* * *} \\
(0.122)\end{array}$ & $\begin{array}{c}0.386^{* * *} \\
(0.127)\end{array}$ \\
\hline Observations & 6,272 & 23,192 & 6,272 & 23,192 \\
\hline
\end{tabular}

Notes: Robust country-pair-product clustered standard errors in parentheses. $* * *, * *, *$ denote significance at $1 \%, 5 \%$ and $10 \%$ respectively. Importer-product-time and exporter-product-time fixed effects included in all regressions. All standard gravity controls have their expected signs but are omitted from the table for brevity. Intercepts included but not reported.

\footnotetext{
${ }^{57}$ This also shows that we do not lose valuable information by aggregating the separate measures into a one-dimensional indicator. Moreover, the coefficients of $\mathrm{RL}_{i j t-1} \times \mathrm{GlobalGAP}_{i k t-1}$ and $\mathrm{RQ}_{i j t-1} \times \mathrm{GlobalGAP}_{i k t-1}$ are not statistically significant in the PPML model. Regulatory quality $\left(\mathrm{RQ}_{i j t}\right)$ and rule of law $\left(\mathrm{RL}_{i j t}\right)$ are related to the implementation of regulations and policies and their enforcement. These aspects of governance may be less relevant for exporting firms trying to signal quality via certification than issues concerning the quality of public services (part of Government Effectiveness), or some forms of corruption; all of which are closely related to "behind the border" trade barriers affecting trade flows.
} 
for example, the EU's preferential trade agreements and long-standing banana relations with the African Caribbean and Pacific countries, and recent bilateral trade agreements with banana-producing Latin American countries. The historic presence of well-established banana plantations (e.g., Dole, Chiquita, Fyffes, Del Monte, Compagnie Fruitiere) that have always structured the supply to the world market (UNCTAD, 2016) may also explain the findings for banana. These vertically integrated firms often have their own production units in producer countries, and develop quality standards internal to the firm. Competing voluntary certification schemes for banana are also becoming popular. While GlobalGAP still certifies the largest banana area globally, Fairtrade, Organic and Rainforest Alliance/SAN certified banana area increased by almost $60 \%, 18 \%$ and, $28 \%$, respectively since 2008 (Lernoud et al., 2015). Given the importance of banana in the EU, bananas certified to other standards may be just as important as GlobalGAP.

\subsubsection{Robustness checks}

In this section, we conduct a series of robustness checks to confirm the reliability of our findings. For comparative purposes, we extend the analysis to include all producing countries as exporters and all importing destinations (Table 3.5). This sample includes bilateral trade flows between 163 producing countries and 157 importing countries (see Table A2.3). All estimated coefficients remain consistent with the gravity theory. In the OLS case, the coefficients on colonial ties and common language become statistically significant compared to the estimates in Table 3.3. Moreover, membership of a trade

Table 3.5: Robustness check: bilateral product-level trade between all countries

\begin{tabular}{|c|c|c|c|c|}
\hline \multirow[b]{2}{*}{ Dependent variable } & \multicolumn{2}{|l|}{ OLS } & \multicolumn{2}{|l|}{ PPML } \\
\hline & $\begin{array}{l}(1) \\
\ln X_{i j k t}\end{array}$ & $\begin{array}{l}(2) \\
\ln X_{i j k t}\end{array}$ & $\begin{array}{l}(3) \\
X_{i j k t}\end{array}$ & $\begin{array}{l}\text { (4) } \\
X_{i j k t} \\
\end{array}$ \\
\hline Log Distance $_{i j}$ & $\begin{array}{c}-1.284^{* * *} \\
(0.058)\end{array}$ & $\begin{array}{c}-1.279^{* * *} \\
(0.057)\end{array}$ & $\begin{array}{c}-1.477^{* * *} \\
(0.112)\end{array}$ & $\begin{array}{c}-1.476^{* * *} \\
(0.112)\end{array}$ \\
\hline Language $_{i j}$ & $\begin{array}{l}0.466^{* * *} \\
(0.113)\end{array}$ & $\begin{array}{l}0.471^{* * *} \\
(0.113)\end{array}$ & $\begin{array}{c}0.324^{* *} \\
(0.160)\end{array}$ & $\begin{array}{c}0.323^{* *} \\
(0.160)\end{array}$ \\
\hline Colony $_{i j}$ & $\begin{array}{l}0.691^{* * *} \\
(0.160)\end{array}$ & $\begin{array}{l}0.681^{* * *} \\
(0.160)\end{array}$ & $\begin{array}{l}0.681^{* * *} \\
(0.237)\end{array}$ & $\begin{array}{c}0.678^{* * *} \\
(0.237)\end{array}$ \\
\hline Contiguity $_{i j}$ & $\begin{array}{l}0.899^{* * *} \\
(0.132)\end{array}$ & $\begin{array}{l}0.908^{* * *} \\
(0.132)\end{array}$ & $\begin{array}{c}-0.099 \\
(0.200)\end{array}$ & $\begin{array}{c}-0.099 \\
(0.200)\end{array}$ \\
\hline $\mathrm{RTA}_{i j t}$ & $\begin{array}{l}0.546^{* * *} \\
(0.098)\end{array}$ & $\begin{array}{l}0.511^{* * *} \\
(0.099)\end{array}$ & $\begin{array}{l}0.791^{* * *} \\
(0.160)\end{array}$ & $\begin{array}{l}0.787^{* * *} \\
(0.161)\end{array}$ \\
\hline $\log \left(1+\operatorname{Tariff}_{i j k t}\right)$ & $\begin{array}{c}-0.422^{* * *} \\
(0.052)\end{array}$ & $\begin{array}{c}-0.428^{* * *} \\
(0.052)\end{array}$ & $\begin{array}{c}-0.304^{* * *} \\
(0.082)\end{array}$ & $\begin{array}{c}-0.302^{* * *} \\
(0.082)\end{array}$ \\
\hline GovDist $_{i j t-1}$ & $\begin{array}{c}-0.067^{* * *} \\
(0.020)\end{array}$ & $\begin{array}{c}-0.164^{* * *} \\
(0.029)\end{array}$ & $\begin{array}{c}-0.128^{* * *} \\
(0.033)\end{array}$ & $\begin{array}{c}-0.172^{* * *} \\
(0.051)\end{array}$ \\
\hline GovDist $_{i j t-1} \times$ GlobalGAP $_{i k t-1}$ & & $\begin{array}{l}0.152^{* * *} \\
(0.035)\end{array}$ & & $\begin{array}{c}0.050 \\
(0.061)\end{array}$ \\
\hline Observations & 24,726 & 24,726 & 163,990 & 163,990 \\
\hline
\end{tabular}

Notes: Robust country-pair-product clustered standard errors in parentheses. $* * *, * *, *$ denote significance at $1 \%$, $5 \%$ and $10 \%$ respectively. Importer-product-time and exporter-product-time fixed effects included in all regressions. Intercepts included but not reported. 
agreement increases trade by about $70 \%{ }^{58}$, while a $10 \%$ increase in bilateral tariffs decreases trade by $42 \%$ in column (1). Focusing on our variables of interest, the trade inhibiting effect of bilateral governance distance and the pro-export effect of the interaction term remains robust. The magnitudes are nevertheless smaller than in our main specification and the coefficient on the interaction term is statistically insignificant in the PPML specification in column (4). This latter finding is due to the significant heterogeneity in the sample of importers and the fact that for some developing country importers certification may not be that important as for importers in developed countries. ${ }^{59}$

As further checks of the generality of our findings, we extend our analysis to all GlobalGAP certified fruits and vegetables. Hence this part of the analysis reestimates our baseline specification, but considers an aggregate of products listed under HSO7 (i.e., edible vegetables, and certain roots and tubers), HSO8 (i.e., edible fruits and nuts) and the spices listed in HS09. ${ }^{60}$ To ensure theoretical consistency, we control for the multilateral resistance terms using importer-time and exporter-time fixed effects. The findings reported in Table 3.6 confirm our main findings. Hence, our product-level findings in Table 3.3 can be extended to the broader agrifood sector.

Table 3.6: The effect of private food safety standard and governance distance on exports of all fruits and vegetables

\begin{tabular}{lcc}
\hline & OLS & PPML \\
\cline { 2 - 3 } & $(1)$ & $(2)$ \\
Dependent variable & $\ln X_{i j t}$ & $X_{i j t}$ \\
\hline Log Distance $_{i j}$ & $-1.851^{* * *}$ & $-1.249^{* * *}$ \\
& $(0.155)$ & $(0.161)$ \\
Language $_{i j}$ & $0.710^{* * *}$ & -0.044 \\
Colony $_{i j}$ & $(0.154)$ & $(0.258)$ \\
Contiguity $_{i j}$ & $0.715^{* * *}$ & $0.782^{* * *}$ \\
& $(0.176)$ & $(0.207)$ \\
RTA $_{i j t}$ & $0.952^{* * *}$ & -0.205 \\
& $(0.294)$ & $(0.495)$ \\
Log $\left(1+\right.$ Tariff $\left._{i j k t}\right)$ & $0.395^{* *}$ & 0.117 \\
& $(0.190)$ & $(0.146)$ \\
GovDist $_{i j t-1}$ & 0.099 & 0.105 \\
& $(0.090)$ & $(0.073)$ \\
GovDist $_{i j t-1} \times$ GlobalGAP $_{i k t-1}$ & $-0.328^{* * *}$ & $-0.189^{* * *}$ \\
& $(0.049)$ & $(0.066)$ \\
Observations & $0.193^{* * *}$ & $0.170^{* * *}$ \\
\hline
\end{tabular}

Notes: The dependent variable is aggregate exports of fruits and vegetables from country $i$ to country $j$. Robust country-pair-product clustered standard errors in parentheses. $* * *, * *, *$ denote significance at $1 \%, 5 \%$ and $10 \%$ respectively. Intercepts included but not reported. Importer-time and exporter-time fixed effects included in all regressions.

\footnotetext{
${ }^{58}$ Dummy variables are interpreted as $[\exp (\beta)-1] \times 100 \%$.

${ }^{59}$ To test this empirically, we estimate equations (3.4) and (3.5) splitting the sample between two importer groups: EU/EFTA and non-EU/EFTA. The interaction term remains statistically insignificant and economically small in magnitude for non-EU/EFTA importers. The results are available upon request from the authors.

${ }^{60}$ In this dataset, it is not possible to identify the number of product $k$ specific producers in country $i$. It aggregates data on all products that can be certified within the GlobalGAP sub-scope 'Fruits and Vegetables'.
} 
As another exercise, we re-estimate the product-level specifications, but use instead of a GlobalGAP certification dummy, the number of certified producers in each exporting country. The results presented in Table A3.4 of the appendix are consistent with our previous findings and confirm our main hypotheses. However, the coefficient on the interaction term is statistically significant in the OLS but not the PPML model. A possible reason for this finding is that retailers in the importing countries care mainly about the certification status of the exporting countries rather than how widespread the standard is within the country.

Finally, to see how sensitive our findings are to the choice of institutional quality measure, we use data from two other sources: (1) the Legatum Prosperity Index (Lind, 2014) - sub-indices include legal and political environment, physical property rights and intellectual property rights - and (2) the Economic Freedom of the World index (Murphy and Lawson, 2018) - sub-indices include size of government, legal system and property rights, sound money, freedom to trade internationally and regulations. The results represented in the Appendix (Table A3.5) show that our hypotheses are confirmed regardless of the measure of institution we use.

\subsection{Conclusion}

Much of the existing literature has shown that governance and institutions are important drivers of trade and economic growth. Similarities in governance and institutional quality measures across countries enhance bilateral trade flows. Hence, retailers in countries with good institutions will choose to source their products from countries with similar or better domestic institutions. Aside from the reputational damage associated with potential food scares, institutional dissimilarities also impose significant costs for trade. Hence, the more dissimilar country-pairs the less trade will be observed. Much less attention has, however, been paid to how exporting countries in low-quality institutional regimes can overcome these differences. This paper evaluates first, the effect of bilateral differences in governance and related institutions across countries on agrifood trade. Retailers, especially in high-value markets such as the EU and EFTA, are increasingly becoming concerned about traceability, quality of production processes and final products. Thus, second, we argue that private food standards and certifications act as surrogate institutions that help to overcome these differences at the country level. We are not aware of any existing studies that test this hypothesis empirically in the agricultural trade literature.

Empirically, our gravity model estimates confirm the trade reducing effect of bilateral governance distance on trade flows. But in addition, we also find that the trade impeding effects vary depending on whether the exporting country is certified to GlobalGAP standards or not. For certified exporting countries, the trade impeding effects are much lower compared to their non-certified counterparts, especially for importers located in the EU and EFTA markets. Hence, we show that certification exerts a pro-export effect that partially offsets the trade-inhibiting effects of bilateral governance distance at the country level. Our findings are robust to the product-specific analysis of apples, bananas, and grapes but also the aggregate fruits and vegetable sector, and to different measures of institutional quality.

These findings have important policy implications. For export-oriented producers and firms targeting high-value markets but are located in countries with low quality of existing domestic public 
institutions, getting certified to a standard that is accepted in the importing country can help overcome the negative reputation effects associated with their geographical locations. Undoubtedly, certification in itself is not enough to overcome the total bilateral governance distance at the country level. Nevertheless, it is a viable alternative to reduce trade costs and enhance trade. We leave for further research the evaluation of the effect of private standards on exports from developing to developed countries using firm-level data. 


\subsection{Appendix}

Table A3.1: List of countries: non EU/EFTA exports to the EU/EFTA

\begin{tabular}{ll}
\hline Country groups & Members \\
\hline Importers & Austria, Belgium, Bulgaria, Cyprus, Czech Republic, Denmark, Estonia, Finland, France, \\
& Germany, Greece, Hungary, Ireland, Italy, Latvia, Lithuania, Luxembourg, Malta, the \\
& Netherlands, Poland, Portugal, Romania, Slovak Republic, Slovenia, Spain, Sweden, \\
& United Kingdom, Liechtenstein, Norway, Switzerland, Iceland \\
Exporters & Afghanistan, Angola, Albania, Algeria, Argentina, Armenia, Australia, Azerbaijan, Bu- \\
& rundi, Benin, Bangladesh, Bahrain, Bahamas, Barbados, Belarus, Belize, Bermuda, \\
& Bhutan, Bolivia, Bosnia and Herzegovina, Brazil, British Virgin Islands, Central African \\
& Republic, Canada, Chile, China, Cote d'Ivoire, Cameroon, Cape Verde, Congo, Cook \\
& Islands, Colombia, Comoros, Costa Rica, Croatia, Cuba, Democratic Republic of \\
& the Congo, Dominica, Dominican Republic, Ecuador, Egypt, El Salvador, Ethiopia, \\
& Equatorial Guinea, Fiji, French Polynesia, Gabon, Georgia, Ghana, Guinea, Grenada, \\
& Guatemala, Guyana, Honduras, Haiti, India, Indonesia, Iran, Iraq, Israel, Jamaica, Jor- \\
& dan, Japan, Kazakhstan, Kenya, Kyrgyzstan, Cambodia, Kiribati, South Korea, Kuwait, \\
& Laos, Lebanon, Libya, Morocco, Moldova, Madagascar, Mexico, Macedonia, Mali, \\
& Mozambique, Montserrat, Mauritius, Malawi, Malaysia, Namibia, New Caledonia, \\
& Nicaragua, Nepal, New Zealand, Oman, Pakistan, Panama, Peru, Philippines, Papua \\
& New Guinea, North Korea, Paraguay, Qatar, Russia, Rwanda, Saint Lucia, Saint Vincent \\
& and Grenadines, Samoa, Saudi Arabia, Sudan, Senegal, Sierra Leone, Somalia, Serbia, \\
& Suriname, Swaziland, Seychelles, South Africa, Syria, Togo, Thailand, Tajikistan, Turk- \\
& menistan, Tonga, Trinidad and Tobago, Tunisia, Turkey, Tanzania, Uganda, Ukraine, \\
& United Arab Emirates, Uruguay, USA, Venezuela, Viet Nam, Yemen, Zambia, Zimbabwe \\
\hline
\end{tabular}

Table A3.2: Summary statistics

\begin{tabular}{|c|c|c|c|c|c|}
\hline Variable & Mean & Std. Dev. & Min. & Max. & $\mathrm{N}$ \\
\hline Contiguity $_{i j}$ & 0.007 & 0.085 & & & 41580 \\
\hline Language $_{i j}$ & 0.054 & 0.226 & & & 41580 \\
\hline Colony $_{i j}$ & 0.030 & 0.170 & & & 41580 \\
\hline GlobalGAP $_{i k t}$ & 0.308 & 0.462 & & & 41580 \\
\hline $\mathrm{VA}_{i j t}$ & 3.213 & 3.018 & 0 & 16.014 & 40860 \\
\hline $\mathrm{PS}_{i j t}$ & 2.701 & 3.259 & 0 & 21.547 & 40710 \\
\hline $\mathrm{RL}_{i j t}$ & 3.655 & 3.177 & 0 & 20.976 & 40860 \\
\hline $\mathrm{CC}_{i j t}$ & 3.550 & 3.462 & 0 & 17.606 & 40860 \\
\hline $\mathrm{GE}_{i j t}$ & 3.407 & 3.185 & 0 & 23.69 & 40860 \\
\hline $\mathrm{RQ}_{i j t}$ & 3.321 & 3.198 & 0 & 20.679 & 40860 \\
\hline GovDist $_{i j t}$ & 3.305 & 2.740 & 0.002 & 18.544 & 40710 \\
\hline GlobalGAP producers & 64 & 395 & 0 & 6523 & 41580 \\
\hline$X_{i j k t}$ (in 1000 USD) & 1290.818 & 13274.385 & 0 & 640772.5 & 41580 \\
\hline Distance $_{i j}$ & 6771.094 & 3813.855 & 117.345 & 19586.18 & 41580 \\
\hline
\end{tabular}




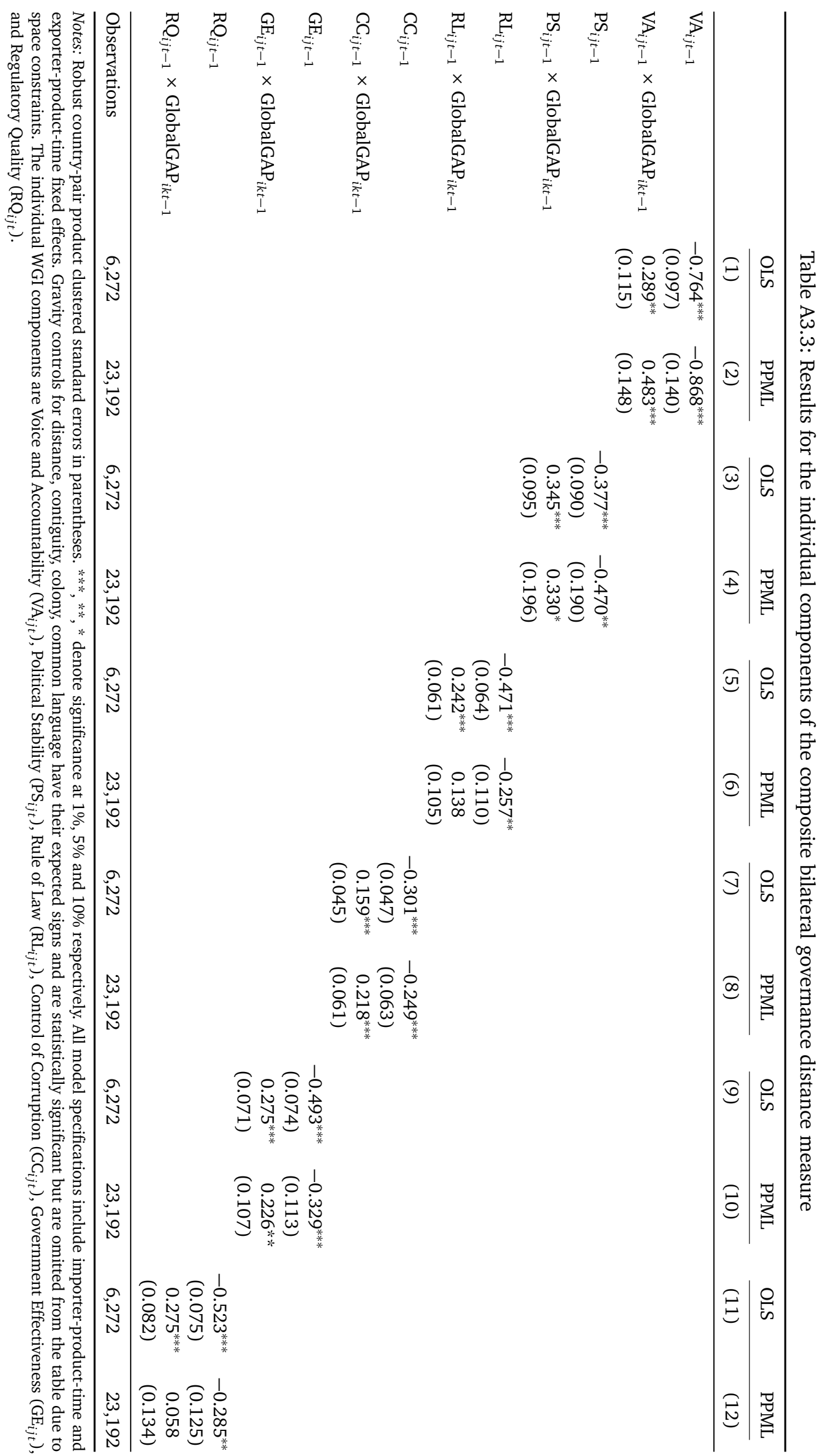


Table A3.4: Measure of certification: number of certified farmers

\begin{tabular}{|c|c|c|}
\hline & OLS & PPML \\
\hline Dependent variable & $\begin{array}{l}(1) \\
\ln X_{i j t}\end{array}$ & $\begin{array}{l}(2) \\
X_{i j t}\end{array}$ \\
\hline $\log _{\text {Distance }}$ ij $_{1}$ & $\begin{array}{l}-1.812^{* * *} \\
(0.241)\end{array}$ & $\begin{array}{c}-1.144^{*} \\
(0.641)\end{array}$ \\
\hline Language $_{i j}$ & $\begin{array}{c}0.124 \\
(0.262)\end{array}$ & $\begin{array}{r}0.448^{*} \\
(0.231)\end{array}$ \\
\hline Colony $_{i j}$ & $\begin{array}{c}0.388 \\
(0.264)\end{array}$ & $\begin{array}{l}0.650^{* * *} \\
(0.197)\end{array}$ \\
\hline Contiguity $_{i j}$ & $\begin{array}{l}0.997^{* *} \\
(0.446)\end{array}$ & $\begin{array}{c}2.097^{*} \\
(1.126)\end{array}$ \\
\hline $\mathrm{RTA}_{i j t}$ & $\begin{array}{l}1.026^{* *} \\
(0.402)\end{array}$ & $\begin{array}{c}-0.035 \\
(0.230)\end{array}$ \\
\hline $\log \left(1+\operatorname{Tariff}_{i j k t}\right)$ & $\begin{array}{c}-0.105 \\
(0.155)\end{array}$ & $\begin{array}{c}-0.168 \\
(0.106)\end{array}$ \\
\hline GovDist $_{i j t-1}$ & $\begin{array}{l}-0.667^{* * *} \\
(0.081)\end{array}$ & $\begin{array}{c}-0.356^{* * *} \\
(0.122)\end{array}$ \\
\hline GovDist $_{i j t-1} \times$ GlobalGAP $_{i k t-1}$ & $\begin{array}{l}0.099^{* * *} \\
(0.014)\end{array}$ & $\begin{array}{c}0.030 \\
(0.019)\end{array}$ \\
\hline Observations & 6,272 & 23,192 \\
\hline
\end{tabular}

Notes: Robust country-pair-product clustered standard errors in parentheses. ${ }^{* * *}, * *, *$ denote significance at $1 \%, 5 \%$ and $10 \%$ respectively. Intercepts included but not reported. 


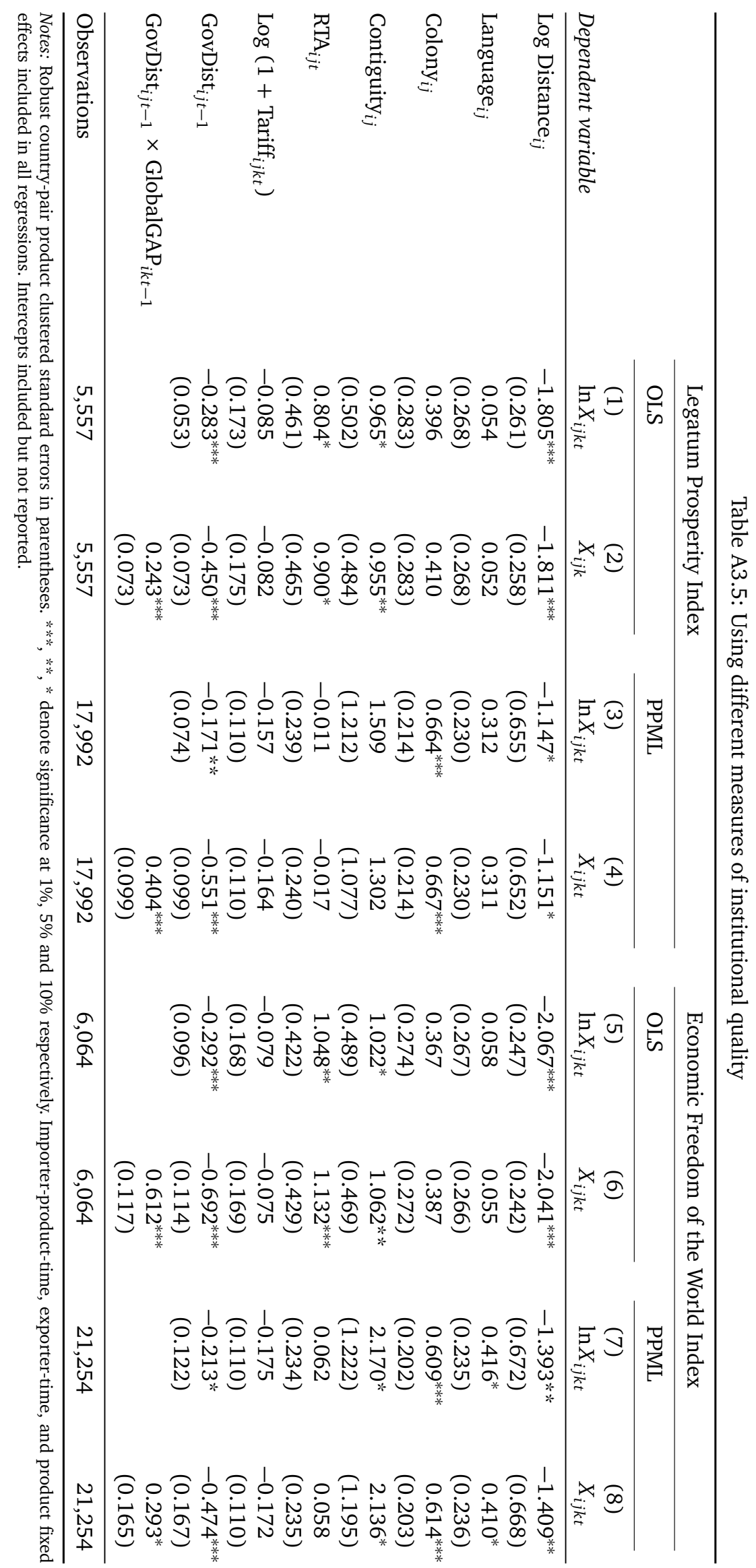




\title{
$4 \mid$ Trade, price and quality upgrading effects of agrifood standards
}

\begin{abstract}
Since chemical use is core to agricultural production, cross-country differences in chemical-related regulations will influence supply chain structures. This paper assesses how this regulatory heterogeneity affects the trade, pricing and quality upgrading strategies of trading partners. Exploiting the bilateral difference in maximum residue limits over the period 2005 - 2014 for 145 agrifood products across 59 countries, we show that differences in public regulations are trade-restrictive. However, conditional on trading, they increase product prices — even when we adjust prices for quality with null effects on estimated product quality. These effects are pronounced for South-North trade but not exports to the South.
\end{abstract}

JEL classification: F14, Q17, Q18

Keywords: agricultural trade, trade margins, maximum residue limits, quality, unit values

This chapter is joint work with Daniele Curzi and Alessandro Olper. The manuscript was submitted to the European Review of Agricultural Economics in October 2019. A revised version has been submitted to the journal.

Acknowledgements: We acknowledge comments from Bernhard Brümmer, Xiaohua Yu, Inmaculada Martínez-Zarzoso, Mahmoud Ahmed, and participants of the Department of Environmental Science and Policy Seminar - University of Milano, Italy and the 6th African Conference of Agricultural Economists in Abuja, Nigeria.

Author contributions: Fiankor D-D.D conceptualised the idea, carried out the analysis and wrote the paper. Curzi D. and A. Olper provided research guidance and revised the paper. 


\subsection{Introduction}

How standards affect bilateral trade flows is topical in the agricultural trade literature. This is because as many countries have reduced their use of tariffs and other quantitative restrictions, standard-like non-tariff measures (NTMs) have become important alternative trade policy measures. ${ }^{61}$ Food safety standards shape agricultural trade flows and determine who is successful in many export markets. As a result, they are often seen as non-tariff barriers (NTBs) to trade, with different political economy implications (Swinnen, 2016).

Unlike tariffs, that operate as a pure tax on imports, standards affect both imports and domestic production. ${ }^{62}$ Hence, theoretically, standards can have positive (negative) effects on trade depending on whether the demand-enhancing effect, if any, dominates (falls short of) the trade-cost effect (Xiong and Beghin, 2014). The empirical results mainly depict them as either catalysts or barriers to trade (Disdier et al., 2008; Maertens and Swinnen, 2009b; Disdier and Marette, 2010; Drogué and DeMaria, 2012; Peterson et al., 2013; Curzi et al., 2018). But many others show that they may have no effects on trade (Xiong and Beghin, 2012; Schuster and Maertens, 2015). Thus, despite the increasing number of empirical estimates, the standards-agrifood trade effect remains ambiguous and heterogeneous (Santeramo and Lamonaca, 2019).

A fundamental limitation in this literature is that it is almost exclusively focused on the direct trade effects of standards and ignores other welfare effects (Olper, 2016), e.g., in agricultural markets standards address market failures (Beghin et al., 2015), offset the trade-inhibiting effect of the institutional distance between countries (Fiankor et al., 2019b), or reduce the incidence of acute illnesses among farmers (Asfaw et al., 2010a). While standards are linked to quality upgrading (Gaigné and Larue, 2016), empirical evidence of the quality effects of NTMs on agricultural trade flows is rather rare in the literature. With growing interest, recent studies are either regional (see Olper et al. (2014) and Raimondi et al. (2019) for the case of the EU) or use firm-level data for specific countries (see Curzi et al. (2020), Disdier et al. (2018), and Movchan et al. (2019) for the case of Peruvian, French and Ukrainian firms). However, the standards and trade literature has failed to assess the existence and magnitude of any such quality upgrading effect of regulatory heterogeneity (i.e., different country-specific standards for the same product) on trade. ${ }^{63}$ Our paper contributes to filling this research gap.

In agriculture, chemical use is important to protect crops, and enhance yields. But, depending on exposure levels these chemicals can pose unacceptable health risks. As such, many governments and multinational bodies, e.g., the Codex Alimentarius Commission, establish maximum residue limits (henceforth MRLs) to regulate their use. Since chemical use is core to agricultural production, this paper assesses how differences in country-specific MRL regulations affect trade, prices and quality

\footnotetext{
${ }^{61}$ For instance, over the period 1997 to 2015 , global average tariff rates for agricultural products decreased from $17.9 \%$ to $10.51 \%$. In contrast, 1456 product lines were subject to at least one type of NTM for each country in 1997, increasing to 2852 product lines by 2015 (Niu et al., 2018).

${ }^{62}$ To ensure consistency with GATT Article III on national treatment, public regulations on food safety must apply to both imports and domestic production. Nevertheless, importing countries imposing the standard may do so only when domestic producers have achieved compliance or find it easier than foreign exporters to comply. In which case, the standard will still be biased towards domestic production.

${ }^{63} \mathrm{~A}$ first attempt is made at the firm level by Fernandes et al. (2019) who proxy quality with prices measured as unit values. But, as we will discuss later in the empirical framework, prices do not proxy quality perfectly.
} 
upgrading. We estimate unobserved product quality at the country-product-year level following Khandelwal et al. (2013). ${ }^{64}$ This approach follows the idea that conditional on price, a variety imported in higher volumes is assigned higher quality. ${ }^{65}$ To achieve our objectives, we exploit the bilateral difference in the MRLs set by 59 countries for 145 agrifood products over the period 2005 to 2014. In doing so, we provide new insights into other welfare effects of MRLs, but also further clarity on their direct trade effects.

Our empirical analysis is set within a structural gravity framework estimated at the product level. We establish that regulatory heterogeneity hinders trade at the extensive and intensive margins, and reduces conditional export sales; a finding consistent with the heterogeneous firms literature (Melitz, 2003; Chaney, 2008). However, in a second step we show that conditional on exporting, standards induce an increase in prices and quality-adjusted prices, but have no statistically significant effect on estimated product quality. We also explore the heterogeneity of these effects across different trade routes: the trade-reducing and the price-raising effects are strongest for South-North trade, followed by North-North trade, but do not matter for exports to the South. On the other hand, tariff liberalisation induces firms to trade more, produce higher qualities and charge lower prices.

Our work extends the existing literature in three ways. First, using MRL data to study the price and quality upgrading effects of standards improves the existing approach that uses counts of SPS and TBT notifications (Curzi et al., 2020; Disdier et al., 2018; Movchan et al., 2019). Using these count data measures to construct frequency indices, coverage ratios or define standard dummies are limited in a number of ways (Peterson et al., 2013) including: (i) it is not possible to identify product-specific regulations (ii) the data is unilateral, which makes it difficult to compare stringency of standards between countries ${ }^{66}$, and (iii) they measure the prevalence of standards but fail to measure their strictness. Using MRL data we overcome these limitations. MRLs are continuous measures of relative stringency set on specific products and thus comparable across country pairs. ${ }^{67}$ For instance, if two countries $i$ and $j$ set an MRL of 0.01 and 0.50 part-per-million (ppm) respectively on product $k$, then it is clear that standards in $i$ are stricter than in $j$. MRLs are also interesting because they are typical of most food quality standards and fundamental to both public and private standards. The limits set for product-pesticide pairs also vary substantially across countries (see Table 4.1). Thus, another novelty of our paper is that while the existing literature focuses on how unilateral measures imposed either by the importer or the exporter affect product quality upgrading, we consider a case where both the importer and the exporter set standards that in many cases differ from each other.

Second, standards may be endogenous to trade volumes. A specific case is made for MRLs by Shingal et al. (2017). But, many empirical exercises carried out within gravity-type models ignore the problem (e.g., Tran et al., 2012; Arita et al., 2017; Kareem et al., 2018). Following Baier and

\footnotetext{
${ }^{64}$ Quality is estimated as the residual from a demand-side ordinary least squares regression that controls for product characteristics, the elasticity of substitution between products and the incomes and price indices of the importing countries. Quality is considered any attribute that raises consumer demand other than price.

${ }^{65}$ The rationale behind this methodology is such that, if varieties of a good from countries $i_{1}$ and $i_{2}$ sell at the same price $p$, the country that offers a higher quality faces a higher demand from importing country $j$.

${ }^{66}$ Indeed, MRLs are also country-specific measures and by construction do not have a bilateral dimension. However, the stringency levels across country-pairs can be compared easily resulting in a bilateral measure.

${ }^{67}$ By focusing on MRLs, we provide precise estimates on the effects of a specific standard on trade, prices and estimated product quality(-adjusted prices) but lose the generality of studies using counts of SPS and TBT notifications which cover a broad range of policy instruments. However, many notifications in these databases are also related to MRLs.
} 
Bergstrand (2007), we minimise endogeneity concerns by including in our estimations a host of country-product-time and country-pair fixed effects. ${ }^{68}$ The latter are better measures of bilateral trade costs than the standard set of bilateral varying gravity variables (Egger and Nigai, 2015; Agnosteva et al., 2019). Our empirical estimates also support this fact; failing to control for endogeneity overestimates the trade effects of MRLs.

Many countries in the south are tropical and suffer from severe pest and disease pressure. To the extent to which this is true, the average effects we estimate across all countries may hide interesting heterogeneous effects. As such, we explore how the estimated effects vary across different trade routes, i.e., South-South, North-North, South-North and North-South. There is limited evidence on trade route-specific effects of standards. Known exceptions include Disdier et al. (2015) who considers only South-South and North-South trade and Xiong and Beghin (2014) who consider only South-North and North-North trade. We, on the other hand, consider all four trade routes. This is second only to Santeramo and Lamonaca (2019).

The rest of the paper proceeds as follows. The next section describes the MRL dataset in detail. This is followed by a conceptual discussion. In section 4, we present our empirical analysis and describe in detail how we measure our dependent variables. This is followed by a discussion of the results in section 5 . Section 6 concludes and offers policy recommendations.

\subsection{Data}

MRLs are the highest level of a pesticide residue that is legally tolerated in or on food or feed when pesticides are applied correctly. To protect consumers from adverse health risks, governments set MRLs measured in mg of pesticide per kg food (or parts-per-million, ppm) on pesticides and veterinary drugs. Each MRL addresses a specific substance (i.e., pesticide, fertilisers or certain chemicals) in a specific commodity in a specific country. They are mandatory regulations that condition market access as non-compliance can lead to export rejections or complete import bans. For instance, EU border notifications relating to pesticide residues increased from 24 in the year 1999 to 279 by the year 2018 (see Figure A4.1 in the appendix). As an international benchmark, the Codex Alimentarius Commission sets MRLs that are considered in many studies (e.g., Li and Beghin, 2014; Kareem et al., 2018; Curzi et al., 2018) as the social optimum. However, the WTO's agreement on Sanitary and Phyto-Sanitary (SPS) measures allows countries to deviate from this benchmark in the presence of scientific evidence based on risk assessments. Countries take advantage of this provision to set their own national MRLs. In some cases, the differences in the limits set across countries can be minor, but in most cases they vary substantially (Table 4.1). In our empirical analysis, we exploit these variations in MRLs across countries and products as a predictor of trade flows, product prices and estimated product quality.

The MRL dataset we use covers the period 2005 to 2014 for 59 countries (see Table A4.1) and 145 agrifood products identified at the HS6 digit level. The source of the data is the Agrobase-Logigram database. It is a private company that maintains Homologa, the Global Crop Protection Database,

\footnotetext{
${ }^{68}$ To address endogeneity concerns due to reverse causality will require instrumental variable estimations. However, this is not trivial as it requires identifying an instrument correlated with MRLs but not with bilateral trade flows. Lacking appropriate instruments we follow the existing literature on maximum residue limits and used lagged MRLs (see, e.g., Ferro et al., 2015; Fernandes et al., 2019) as a robustness check. Our main findings remain unchanged.
} 
Table 4.1: Comparison of maximum residue limits on selected products in 2014

\begin{tabular}{|c|c|c|c|c|c|c|c|c|}
\hline \multirow[t]{2}{*}{ Chemical } & \multirow[t]{2}{*}{ Fruit } & \multicolumn{6}{|c|}{ Countries } & \multirow[b]{2}{*}{ Codex } \\
\hline & & EU & USA & Canada & Japan & Vietnam & China & \\
\hline Carbaryl & Citrus & 0.01 & 10 & 10 & 1 & 7 & & 15 \\
\hline Methidathion & Citrus & 0.02 & 5 & 2 & 5 & 5 & $\overline{2}$ & 5 \\
\hline Captan & Apple & 3 & 25 & 5 & 5 & 25 & 15 & 15 \\
\hline Fenbutatin-Oxide & Apple & 2 & 15 & 3 & 5 & 5 & 5 & 5 \\
\hline Acetamiprid & Apple & 0.80 & 1 & 1 & 2 & _ & 0.80 & 0.80 \\
\hline Bifenthrin & Tea & 5 & 30 & - & 30 & - & _- & 30 \\
\hline Endosulfan & Tea & 30 & 24 & 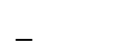 & 30 & 30 & - & 10 \\
\hline Fenpropathrin & Tea & 2 & 2 & $\overline{2}$ & 25 & . & $\overline{5}$ & 2 \\
\hline Chlorpyrifos & Wheat & 0.05 & 0.50 & _ & 0.50 & 0.50 & 0.50 & 0.50 \\
\hline Chlorpyrifos & Banana & 3 & 0.10 & - & 3 & 2 & - & 2 \\
\hline Chlorothalonil & Cranberries & 0.67 & 5 & 2 & 5 & _- & - & 5 \\
\hline
\end{tabular}

Source: Homologa dataset

Notes: - implies that there are no residue limits set by that country on the given product-pesticide pair. All residue limits are measured in parts-per-million.

using information from pertinent national ministries and legal publications. We match the HS6 digit MRL data with HS6 digit trade data from UNComtrade. The products are the HS6 digit products under the following HS2 digit product codes: HS07-10, HS12, HS14 and HS17-18 (see Figure A4.2 in the appendix). ${ }^{69}$

Countries are heterogeneous in the products and pesticides they regulate. For products, this ranges from an average of 70 in Indonesia and Mexico to 128 in the USA and for pesticides a minimum of 66 in Thailand to a maximum of 758 in the Netherlands (Figure A4.3). For the empirical analysis, we deal with countries in our dataset with missing MRLs for given product-pesticide pairs following a standard approach in the literature (Li and Beghin, 2014; Fernandes et al., 2019). First, we replace them with default values where available, e.g., the EU sets a default value of $0.01 \mathrm{ppm}$. Second, many countries defer to Codex standards when no MRLs are set for given product-pesticide pairs. Finally, where no MRLs are available we assign the least restrictive MRL value across product-pesticide pairs. Bringing the country pair, product and time dimensions together, we measure the bilateral asymmetry in MRLs, by adapting the non-linear exponential index of Li and Beghin (2014) at the product level as follows: ${ }^{70}$

$$
M R L_{i j k t}=\frac{1}{N_{k}}\left[\sum_{p \in N_{k}} \exp \left(\frac{M R L_{i k t}-M R L_{j k t}}{M R L_{i k t}}\right)\right]
$$

where $i$ is the exporting country, $j$ is the importing country, $k$ is the product, $t$ is time and $p$ is the pesticide. $M R L_{i k t}$ and $M R L_{j k t}$ are the average product and time-varying MRL set by $i$ and $j$

\footnotetext{
${ }^{69}$ Following Li and Beghin (2014), we detect and address exact redundancies in the dataset, i.e., different names for the same commodity, e.g., pistachios, nuts - pistachios, nuts - pistachios: dry. We include only countries that are present for more than half of the length of the panel. Thus, countries of the Gulf Cooperation Council are dropped since they only begin to appear in the dataset in 2012. There are also differences in the MRLs for the European countries because until 2009 they set country-specific MRLs.

${ }^{70}$ The original Li and Beghin (2014) index is measured relative to the Codex Alimentarius international standards that are established by the Food and Agricultural Organisation and the World Health Organisation. To fit our purpose, we adapt their specification following Hejazi et al. (2018) to measure standards relative to other countries that set their own MRLs. Where our index differs from Hejazi et al. (2018) is the time dimension of our index. For further details on the properties of the index, see Li and Beghin (2014) and Hejazi et al. (2018).
} 
respectively. $M R L_{i j k t}$ is the product and time-varying bilateral difference in MRL stringency between country pairs.

Equation (4.1) yields an index of the domain [0,e 2 2.718]. It is normalised at 1 when the importing and exporting countries set the same standards. It approaches its upper limit when the importing country sets a much stricter standard than the exporting country, and vice versa. The index in equation (4.1) is an improvement on Li and Beghin (2014) in three ways (see also Hejazi et al., 2018): (i) stricter importing country standards will not necessarily be restrictive if the exporter faces an MRL at home that is stricter than the level set by Codex, (ii) since Codex establishes a limited number of MRLs for pesticides (Figure A4.3), country comparisons to Codex may miss important regulatory differences that exist bilaterally, and (iii) the index is fully bilateral allowing us to exploit its time variation to properly identify the trade effect, i.e. using bilateral fixed effects. ${ }^{71}$

\subsection{Conceptual discussion}

This section discusses the different pathways through which MRLs may affect trade, product prices and product quality upgrading. It also highlights the necessary theoretical predictions needed to interpret our empirical findings.

\subsubsection{Maximum residue limits and trade}

Following Krugman (1980) more recent theoretical models (e.g., Melitz, 2003; Chaney, 2008; Helpman et al., 2008) incorporate firm heterogeneity to show that productivity differences across firms are additional sources of comparative advantage. The theoretical predictions of these models imply that the introduction of a food safety standard imposes extra costs that affect trade at both the intensive and extensive margins. ${ }^{72}$ The fixed cost component of the standard is expected to affect mainly the extensive margin. Only productive firms that meet the fixed costs imposed by the standard would export. As predicted by the Abel-Koch (2013) model, this prohibitive nature of fixed costs will lead to zero trade between some country-pairs. The variable cost component would affect both extensive and intensive trade margins. Thus, while we expect public standards to reduce the extensive margin, their impact on the intensive margin of trade is a priori ambiguous (Fontagné et al., 2015). ${ }^{73}$

Focusing on MRLs as a product standard, there are different sources of trade disruptions that could arise due to differing limits across countries. For instance, farmers producing according to good agricultural practices (GAP) approved for their domestic market - whether that is a national standard or the Codex - cannot be sure that their GAP compliant and domestically legal products will be granted access to other countries (Yeung et al., 2018). This is because different countries set national residue limits with varying stringencies for same product-pesticide pairs (see Table 4.1). To guarantee market access, producers incur information costs to acquaint themselves with standards in their target markets. Depending on how dissimilar standards are between countries, producers will

\footnotetext{
${ }^{71}$ In contrast to Hejazi et al. (2018), our empirical analysis exploits the bilateral dimension of the index by accounting for country-pair varying fixed effects.

${ }^{72}$ Note that in the Krugman (1980) model, all export variations are on the intensive margin because all firms export to all destinations.

${ }^{73}$ The fixed trade costs will affect mainly the extensive margin because exporters would have already paid the fixed cost component to be able to export. However, when variable costs are low, each exporting firm exports more (i.e., the intensive margin) and new firms enter the market (i.e., the extensive margin), and vice versa.
} 
have to invest in improved infrastructure, $R \& D$, use higher-quality inputs, or change freight modes. The associated costs can increase remarkably depending on how many markets the producers intend to export to or how often the destination country changes their tolerance levels. ${ }^{74}$

The number of MRLs regulated also vary across countries. What happens when an MRL is missing from a national list, e.g., in Table 4.1 Canada has no established residue limits for Bifenthrin and Endosulfan use in tea production in 2014. In such cases, does the importer have a default tolerance level that applies, or does the importing country reject the shipment (Yeung et al., 2018)? This is a challenge for exporters because the reaction of the importer may be unpredictable. Such a lack of transparency increases the cost of trading; even more so for developing country producers because they are mainly located in tropical areas with high pest and disease pressure and have weaker institutional capacities to set standards. Nevertheless, developed countries are not spared the trade effects of regulatory heterogeneity, e.g., US exports of pears and apples to the EU declined when the EU introduced lower standards for chemicals applied to preserve the appearance of the fruits in 2008 (Hejazi et al., 2018).

Meeting stricter importing country MRLs require sunk costs and higher marginal costs. As a result, we expect differences across national levels to affect both trade margins. The introduction of a new limit on a particular pesticide or the tightening of an existing limit will impose extra costs for producers, especially in countries where existing public regulations are weak. This includes fixed costs of investing in new production techniques or adjustments to existing ones. Only firms with productive capacities to overcome this fixed cost will export to the market imposing the standard. Thus in line with the predictions of the heterogeneous firms' literature, we expect stricter MRLs to affect the extensive margin and induce market exit. The standard will also impose higher variable costs (e.g., costly inputs, recurrent costs of quality control, and product testing), which will affect export volumes and varieties to the product-destination market maintaining the stricter standard.

\subsubsection{Maximum residue limits, product prices and quality}

Traditional theories of international trade neglect the existence of product quality differences across countries, but extensions of the firm heterogeneity literature incorporate vertical quality differentiation across firms as a key driver of firms' export performance (Hallak, 2006; Crozet et al., 2012; Kugler and Verhoogen, 2011). Successful exporters use higher-quality inputs and more skilled workers to produce higher-quality output that sell at higher prices. Standards define product characteristics and specify a level of quality, and so are a feature of differentiated product markets. The proliferation and increasing relevance of agrifood standards imply that farmers have to decide the quality and not just the quantity they produce (Korinek et al., 2008). Also, SPS measures - MRLs inclusive in the agrifood sector are less about protecting domestic producers and more about guaranteeing product quality and consumer health (Murina and Nicita, 2017). As such recent work has extended the quality upgrading literature to the agrifood sector (Curzi and Olper, 2012; Movchan et al., 2019). Following Fernandes et al. (2019), we extend this nascent literature to maximum residue limits.

\footnotetext{
${ }^{74}$ Yeung et al. (2018) make the case for exports of cranberries from Canada and the US to the EU. In 2014, the EU reduced the MRL for the fungicide chlorothalonil that prevents fruit rot in cranberries from $2 \mathrm{ppm}$ to $0.01 \mathrm{ppm}$. Exporters unable to meet the new lower EU MRL were forced to refrain from using chlorothalonil, incur adjustment costs to switch to alternative fungicides or find new export markets. Two years later, the EU revised its standard to make it less stringent which meant that the previous trade disruptions and adjustment costs had been unnecessary.
} 
The level of residues in a food crop determines its quality in terms of pesticide contamination. Thus, a citrus fruit with a residue limit of $8 \mathrm{ppm}$ Carbaryl is considered high quality in the US, Canada, and by the Codex but low quality in Vietnam, Japan and the EU (see Table 4.1) ${ }^{75}$ Final products that meet stricter MRL regulations, may indicate a higher level of sophistication of the production process and, hence, higher product quality. ${ }^{76}$ Theoretical models (see, e.g., Kugler and Verhoogen, 2011) typically treat product quality as an outcome of conscious investment decisions. This is true also for agricultural production where standards can be seen as a ban on cheaper technology (Vandemoortele and Deconinck, 2014). To produce the higher quality levels imposed by stricter MRLs, farmers need to upgrade existing farm-level production technologies to include among other things expensive inputs and specialised human capital. For instance, they must avoid using some pesticides completely and determine correct pre-harvest intervals. Thus, enforcing stricter MRLs will improve information asymmetries which makes quality claims more credible (Fernandes et al., 2019). ${ }^{77}$ Given the volatility of markets and agronomic factors affecting the quality of agricultural production, the final market for a product may be unknown at the time of pesticide applications (Yeung et al., 2018). Differences in regulations across destination markets affect the final marketing options for producers, and may lead to a redistribution of market shares among surviving firms in certain sectors.

Also of interest in this paper, is how MRL-related regulatory heterogeneity affects the pricing strategy of exporting firms. The associated costs of meeting stringent standards in a target importing country, or segregating crops for different markets, will lead to increases in product prices. This interpretation is in line with the Abel-Koch (2013) model, which show how in a Melitz-Chaney framework, product standards reduce the level of competition in the product-destination market imposing the stricter standard. As a result, these increased costs may be passed on to consumers in the importing countries as higher product prices. On the supply side, the investments and quality improvements required to comply with stricter MRLs may be rewarded by increased consumer willingness to pay a "quality premium" for products that meet their stricter domestic standard. It is also possible that by excluding low-quality exports from the destination market maintaining the stricter standard, standards limit the scope for quality differentiation, but instead induce an increase in price competition. This will occur if mandatory compliance with the public standard leads firms that before the introduction of the standard were termed "low-quality firms" to improve their quality. In this case, the difference in quality between surviving firms reduces after the introduction of the standard. This will cause an increase in price competition and, as a consequence, a reduction of quality-adjusted prices. This is consistent with the theoretical model of Ronnen (1991). Which of

\footnotetext{
${ }^{75}$ The 8 ppm limit falls below the maximum allowable limit required in the US, Canada and the Codex but falls above the maximum allowable range in Vietnam, Japan and the EU.

${ }^{76}$ Whether this implies higher food safety and health outcomes is contested (Handford et al., 2015; Winter and Jara, 2015). Winter and Jara (2015) argue that divergence in limits across countries does not necessarily lead to improvements in food safety. Because agricultural and food safety policies diverge across countries, MRLs for commodities will differ for different pesticides and markets although these limits are still safe (Handford et al., 2015). Chemical use is core to agricultural production but their use must be regulated. However, the minimum standard set by the public regulator may be stricter than needed to counteract the externality, thereby disguising protectionist intents (Fischer and Serra, 2000). Winter and Jara (2015) argue that this is the case for MRLs; violative residue limits are rarely of health significance.

${ }^{77}$ For producers, adopting higher importing country standards helps counter claims about poor quality. Through thirdparty certifications, suppliers must document their agricultural practices (e.g., how much, and which pesticide was applied and when), which serve as useful documentation to debunk claims of inferior quality by importers. Thus, even for developing country producers, standards increase the credibility of their quality claims (Hatanaka et al., 2006; Fiankor et al., 2019b).
} 
these different mechanisms will prevail in the case of bilateral dissimilarity of MRLs is an empirical question that we seek to answer in this article.

\subsection{Empirical framework}

We study the standards, trade, price, and quality relationship using structural gravity-type models. The gravity equation — one of the most successful empirical relationships in international economics - relates bilateral trade between exporting and importing countries to bilateral trade costs, exporting country characteristics, and importing country characteristics. In this section, we specify our econometric model and describe the different measures of the dependent variable.

\subsubsection{Econometric specification and identification strategy}

Our benchmark estimation model is the following product-level gravity equation, wherein we model bilateral trade costs as a CES function of the product and time-varying country-pair difference in maximum residue limits $\left(\mathrm{MRL}_{i j k t}\right)$ and tariffs $\left(\right.$ Tariff $\left._{i j k t}\right)$ :

$$
\ln X_{i j k t}=\psi_{i k t}+\lambda_{j k t}+\alpha_{i j}+\beta_{1} M R L_{i j k t}+\beta_{2} \ln \left(1+\operatorname{Tariff}_{i j k t}\right)+\epsilon_{i j k t}
$$

where $i$ is the exporting country, $j$ is the importing country, $k$ is the product and $t$ is time. Our parsimonious specification includes a host of importer-product-time $\left(\psi_{i k t}\right)$, exporter-product-time $\left(\lambda_{j k t}\right)$ and importer-exporter $\left(\alpha_{i j}\right)$ bilateral fixed effects. These fixed effects control for all country and product-specific (e.g., production and expenditure) and country-pair specific time-invariant effects (e.g., bilateral distance, common language, contiguity). In line with the structural gravity literature, $\psi_{i k t}$ and $\lambda_{j k t}$ also control for multilateral resistance (Anderson and Van Wincoop, 2003). Hence, in principle, our model can only identify the effect of variables that are country-pair varying over time. Since these fixed effects eliminate many confounding factors as possible, we are confident our estimation captures a pure trade cost effect. $\epsilon_{i j k t}$ is the error term which we cluster at the country pair-product level. We are primarily interested in $\beta_{1}$, which reflects the effect of differences in product-specific MRLs between countries on different measures of trade, prices and quality. The inclusion of country pair fixed effects $\left(\alpha_{i j}\right)$ implies that identification of $\beta_{1}$ is achieved from changes in bilateral MRL differences over time.

\subsubsection{Definitions of the different measures of $X_{i j k t}$}

The dependent variable in equation (4.2) varies depending on the specific research question. It represents for each importer-exporter-product-time the (i) extensive margin (ii) intensive margin (iii) product of both trade margins (iv) value of trade conditional on exports (v) import prices expressed as unit values (vi) quality and (vii) quality-adjusted prices. Here, we discuss these different measures.

\section{Measures of the intensive and extensive trade margins}

Using conventional gravity equations with total trade flows as the dependent variable, although now armed with solid micro-foundations (e.g., Anderson and Van Wincoop, 2003), may still be misleading as the extensive margin and intensive margins might respond differently to trade costs (Feenstra and Ma, 2014). Existing studies in the literature that have tried incorporating the two 
margins have used mainly the Heckman two-step procedures. However, these suffer two limitations; the incidental parameter problems of the first stage Probit equation in panel data contexts and the fact that the procedure only works well in bilateral trade equations when true exclusion restrictions exist (Helpman et al., 2008). Recently, several papers have also used a direct approach to decompose the impact of policies on the extensive and intensive trade margins. These include measures such as the number of products exported within a certain industry, counting categories that exceed a certain size or exports concentration indexes (see, e.g., Cadot et al., 2011; Persson and Wilhelmsson, 2016). These simple counts, although transparent, are limited by the assumption that products have the same economic weight.

Following Feenstra and Kee (2008), we consider a theoretically-founded decomposition of overall trade into the extensive and intensive margins considering the economic weight of the products. This measure is very similar to a count of the exported varieties within a certain industry, but appropriately weights categories of goods by their overall importance in exports to an importing country. The extensive margin $\left(E M_{i j k t}\right)$ is the fraction of all products $k$ exported from country $i$ to country $j$, where each product is weighted by the importance of that product in total exports to $j$ in year $t$. The intensive margin $\left(I M_{i j k t}\right)$ is the bilateral trade flow from $i$ to $j$ relative to the average world export to $j$ in the same product category. The product of the two margins equals the ratio of exports from $i$ to $j$ relative to country $j$ 's total imports, i.e., it measures the relative export performance of each exporter in an importer-product-year. We move to the Appendix 4.7, the detailed description of the methodology to measure both the extensive margin and intensive trade margin. As a fourth measure of the dependent variable, we consider the absolute value of exports of product $k$ from country $i$ to $j$ in year $t$.

\section{Measures of price, quality and quality-adjusted price}

The final bit of our analysis relates the differences in national standards to prices and quality of imports. Consumption scandals in the agrifood sector have prompted an increase in quality requirements of consumers and firms. Regulations such as the EU Food Law of 2002 makes it the responsibility of retailers to ensure that their suppliers from third countries meet EU food quality standards. As a result, besides de jure public standards, retailers enforce de facto mandatory standards as gatekeepers to filter products based on quality when dealing with geospatially dispersed producers. Exporters knowing the quality of their products will segregate and send different quality levels to different destinations. For example, in a World Bank report Jaffee et al. (2005) show that exporters in Kenya segregate low-quality produce from smallholders for less demanding destinations. For MRLs, products earlier targeted for a specific importer may end up in other markets with less stringent quality definitions, depending on the timing of chemical control preceding harvest. These differences in objective qualities of agrifood products (e.g., size, colour, production location), the presence or otherwise of pesticides and grading or certification schemes fit in the realm of vertical differentiation (Saitone and Sexton, 2010). Thus, agrifood products are not necessarily homogeneous but heterogeneous in quality.

Critical to this part of the analysis is how we measure unobservable "product quality". It is standard in the agricultural trade literature to use prices (measured as unit values) to proxy quality 
(Fernandes et al., 2019; Bojnec and Fertő, 2017). For each HS6 digit product $k$, the bilateral trade data records the total nominal value of imports in US dollars from a given exporter, as well as the quantity in tonnes associated with these imports. Taking the ratio of trade values and trade quantities, we obtain so-called unit values, i.e., $p_{i j k t}=v_{i j k t} / q_{i j k t} \cdot{ }^{78}$ While unit values are available for a wide range of products and countries, they may not be precise proxies for quality. Prices may also reflect higher production costs, exchange rates or market power. Our approach follows Khandelwal et al. (2013) and recovers quality directly from observed trade data. ${ }^{79}$ The intuition behind the Khandelwal et al. (2013) approach is simple: conditional on prices, varieties with higher quantities (market shares) are assigned higher quality. ${ }^{80}$ We assume quality is any attribute that raises consumer demand other than price (Khandelwal et al., 2013; Disdier et al., 2018). After estimating quality $\hat{q}_{i j k t}$, we obtain the quality-adjusted price component as the observed log prices less estimated quality, i.e., $\ln \hat{p}_{i j k t}=\ln p_{i j k t}-\ln \hat{q}_{i j k t}$. That is the differences in product prices for the same level of quality. See Appendix 4.7 for a detailed description of the quality estimation procedure. Applications of the Khandelwal et al. (2013) method in the agrifood sector include Curzi and Pacca (2015) and Movchan et al. (2019).

According to Feenstra and Romalis (2014), quality differences can explain some of the variations we observe in unit-values across countries. As an initial exploratory analysis to see how well our quality estimates correlate with observed unit values, we plot a graph of $\ln p_{i j k t}$ against $\ln \hat{q}_{i j k t}$ (Figure A4.2 in the appendix) that show that our estimated quality and unit values are indeed positively

Figure 4.1: Distribution of prices and estimated product quality of imports

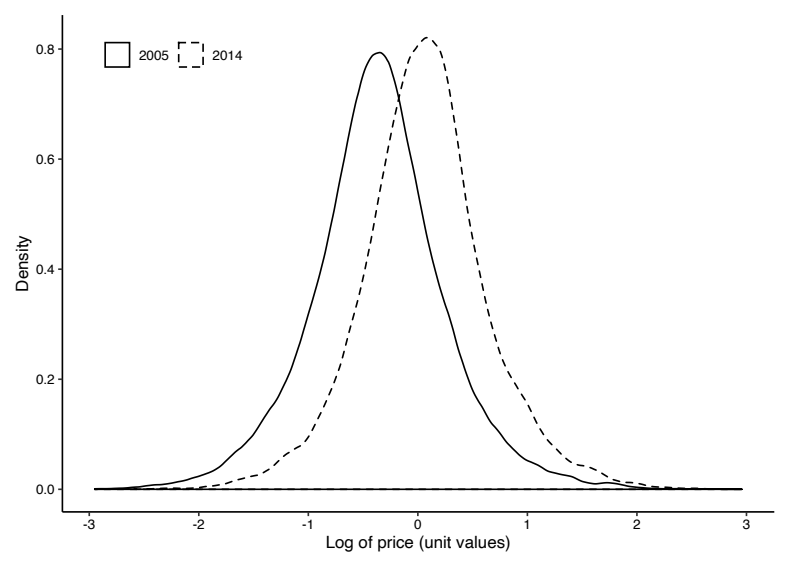

(a) Prices (unit values)

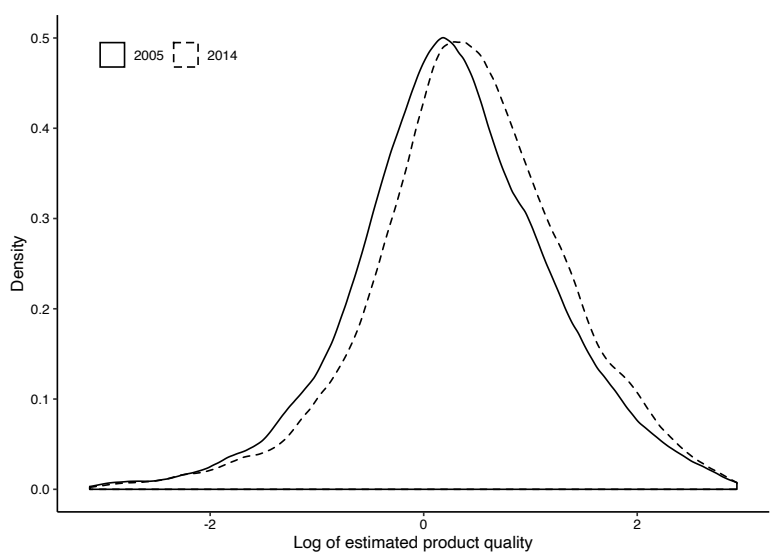

(b) Estimated product quality

\footnotetext{
${ }^{78}$ Information on unit values can be particularly noisy because the trade data may contain measurement errors at the disaggregated product level. This noise in the price data would also affect our quality estimates. To deal with potential outliers in the price and quality estimations, we screen the dataset and we exclude extreme unit values within the 1st and 99th percentiles. We also drop annual growth rates within the 1st and 99th percentiles. Finally, we drop estimated quality values within the 5 th and 95 th percentiles. This data cleaning procedure eliminates $3 \%$ of our observations.

${ }^{79}$ Whiles this method was originally applied at the firm-product-country-year level, subsequent applications have also been done at the product-country-year level, see e.g., Curzi and Pacca (2015), Breinlich et al. (2016). The limitation, however, is that different producers or firms may produce different qualities. Lack of farm/firm-level trade data implies that our quality estimates reflect the average quality of exports from a country.

${ }^{80}$ For instance, suppose bananas from Ecuador and Colombia are equally priced, but Colombia's market share in destination market $j$ is $20 \%$ and Ecuador's is $10 \%$, the quality estimate for Colombia will be higher. If bananas from Colombia were more expensive, then we would need to control for the price difference and this would reduce the quality estimate for Colombia.
} 
correlated. As a second descriptive analysis, we plot the Epanechnikov kernel density estimates of our quality estimates and unit values for the first and last years of our panel. ${ }^{81}$ The results presented in Figure (4.1) reveal that average quality and price of imports increased over the study period. However, compared to prices, average quality did not change by much. The extent to which this is driven by cross-country and product differences in MRLs over time is one goal of this paper.

\subsubsection{Estimation procedure}

We estimate the benchmark model in equation (4.2) using OLS. ${ }^{82}$ Aggregating the unit of analysis from the HS6 to the HS2-digit level to study the trade margins means zeroes are rare in the trade matrix. Also, zero-value traded products do not have a price and are excluded from the price and quality estimations. But, for analysing observed trade values, controls for zeroes may be important to avoid sample selection biases. In this case, as a robustness check, we use the Poisson-pseudo maximum likelihood (PPML) estimator (Santos Silva and Tenreyro, 2006). In all cases, we exclude singletons because maintaining them in linear regressions where fixed effects are nested within clusters might lead to incorrect inferences (Correia, 2016). ${ }^{83}$

The endogeneity of the standards-trade relationship is established, yet few studies address it empirically. Our approach improves upon the existing empirical strategy. Including the complete set of three-way fixed effects in equation (4.2) minimises endogeneity concerns arising from omitted variable biases, selection and initial conditions (Baier and Bergstrand, 2007). The dyadic fixed effects $\left(\alpha_{i j}\right)$ control for the unobserved heterogeneity that is specific to each trade flow, e.g., time-invariant observed and unobserved factors that drive both changes in $\mathrm{MRL}_{i j k t}$ and bilateral trade. This is important especially in cases where standards are set for political economy reasons; e.g., countries are more likely to set stringent standards to protect domestic sectors in which they face competition from cheaper imports. The country-product-time fixed effects capture (un)observable time-variant and invariant country-specific and product effects such as domestic institutions, comparative advantages, production and consumption patterns whose exclusion may bias $\beta_{1}$. Standards may also be the result rather than the cause of trade. To minimize this simultaneity bias, we follow the existing literature (Ferro et al., 2015; Fernandes et al., 2019) and replace the contemporaneous residue limits in our baseline model with one year lagged values (i.e., $M R L_{i j k t-1}$ ). Our main findings remain unchanged (Table A4.4).

\subsection{Results}

We present and discuss our model estimates in three sections. In section 5.1 we confirm the direct effects of standards on trade. Then we shift attention to other welfare effects in Section 5.2 and discuss how standards affect prices, quality and quality-adjusted prices. Finally, Section 5.3 assesses how the effects discussed in sections 5.1 and 5.2 vary across different trade routes.

\footnotetext{
${ }^{81}$ Here, we include only importer-product pairs that are present in both 2005 and 2014. We compare prices over time by regressing the log of unit values on country-product fixed effects before plotting the residuals.

${ }^{82} \mathrm{To}$ deal with the high-dimensional fixed effects in our model specifications, we use the user-written command reghdfe (Correia, 2016) in Stata.

${ }^{83} \mathrm{As}$ a result, the number of observations used in the estimations differ from the total number of observations in the summary statistics because the observations that are perfectly predicted by the fixed effects are dropped.
} 


\subsubsection{The effect of standards on trade}

Table 4.2 reports the estimated effects of the bilateral differences in MRLs on bilateral trade flows. ${ }^{84}$ Considering the effects on the extensive margin, column (1) suggests that the stricter the importing country standard relative to the exporting country standard, the lower the number of exported varieties. ${ }^{85}$ At the intensive margin, the pattern and sign remain consistent with the extensive margin. Stringent importing country standards have negative effects on trade at the intensive margin. The total trade effect in column (3) is also negative and shows that the standards effect on trade is higher, though not by much, on the extensive margin compared to the intensive margin. ${ }^{86}$ This is consistent with the idea that the MRL-trade effect operates through affecting fixed costs more than variable costs. Conditional on exports, the effect on observed trade value is also negative (column 4) ${ }^{87}$ In all cases, the estimated trade effects are statistically significant at the $5 \%$ level or lower. Our finding in column (4) is similar in sign but lower in economic magnitude compared to Hejazi et al. (2018). However, they focused on US exports of fruits and vegetables and did not control for country-pair effects. If we estimate all the models in Table 4.2 using traditional country-pair gravity variables bilateral distance, colony, common language and contiguity — instead of the country-pair fixed effects our coefficient estimates on the $M R L_{i j k t}$ index are indeed larger (Table A4.3). ${ }^{88}$ This is consistent with the arguments by Egger and Nigai (2015) and Agnosteva et al. (2019) that the country-pair fixed effects in our preferred specification capture more systematic information about trade costs than the standard gravity variables. Hence, failure to control adequately for the bilateral dimensions of the dataset leads to an upward bias in the standard-trade effect.

Because the dependent variable is in logs and the $M R L_{i j k t}$ variable is in levels, the economic interpretation of our results is similar to a semi-elasticity. Quantitatively a stricter importing country residue limit equivalent to an increase in $M R L_{i j k t}$ by 0.1 units at the mean - which is an increase of about $9 \%$ - reduces total trade by about $1.36 \%(0.70 \%$ at the extensive margin and $0.66 \%$ at the intensive margin) and observed trade flows in USD by $0.82 \%$, on average. ${ }^{89}$ Overall, an increase in the stringency of the standards in the importing country relative to standards in the exporting country limits trade either by reducing the varieties of goods traded (column 1), the values of goods traded (column 2) and observed trade flows (column 4). In the spirit of the Melitz (2003) and Chaney

\footnotetext{
${ }^{84}$ The differences in sample sizes are due to the different definitions of the dependent variable in equation (4.2). The lower sample size for the trade margins of trade (columns $1-3$ ) is necessitated by our definition which requires aggregating the trade data from the original HS 6-digit to the HS 2-digit level to allow for enough variation.

${ }^{85}$ As an alternative to the definition of the extensive margin used in our main analysis, we also define simple market participation and market exit dummies. Estimating a linear probability model, we find that standards decrease the probability of trading and induce market exit. See Table A4.5 in the appendix.

${ }^{86}$ The coefficient on $E M_{i j k t} \times I M_{i j k t}$ in column (3) is not equal to the coefficient estimate on $X_{i j k t}$ in column (4). Aside from the different sample sizes, the former measures the relative performance of each exporter in an importer-product-year and do not represent absolute trade volumes.

${ }^{87}$ Because observed trade flows could potentially be zero, we re-estimate the effect of MRLs on observed trade flows (i.e., column 4 of Table 4.2) including zeroes using the PPML estimator. The results presented in column (3) of Table A4.5 are consistent with the OLS.

${ }^{88}$ Using a cross-sectional variant of equation (4.1), Hejazi et al. (2018) report a much higher negative effect (i.e., 0.70) on observed trade values for US exports. However, their specification ignores the country-pair dimension and most likely over-estimates the trade reducing effect of MRLs. Furthermore, our findings on the trade margins in the model specification excluding country-pair fixed effects (i.e., Table A4.3) confirm those of Ferro et al. (2015) that restrictive MRLs decrease trade at the extensive margin, but their effect on the intensive margin is in many cases indistinguishable from zero.

${ }^{89}$ The mean $M R L_{i j k t}$ at the extensive and intensive trade margin is 1.171 and for observed trade flows the mean $M R L_{i j k t}$ is 1.123. See Table A4.2.
} 
Table 4.2: The effect of bilateral differences in MRLs on trade

\begin{tabular}{|c|c|c|c|c|}
\hline & $E M_{i j k t}^{H S 2}$ & $I M_{i j k t}^{H S 2}$ & $E M_{i j k t}^{H S 2} \times I M_{i j k t}^{H S 2}$ & $X_{i j k t}^{H S 6}$ \\
\hline & (1) & (2) & (3) & (4) \\
\hline $\mathrm{MRL}_{i j k t}$ & $\begin{array}{c}-0.070^{* * *} \\
(0.022)\end{array}$ & $\begin{array}{c}-0.066^{* *} \\
(0.033)\end{array}$ & $\begin{array}{c}-0.136^{* * *} \\
(0.036)\end{array}$ & $\begin{array}{c}-0.082^{* * *} \\
(0.023)\end{array}$ \\
\hline $\log \left(1+\operatorname{Tariff}_{i j k t}\right)$ & $\begin{array}{c}-0.021^{* * *} \\
(0.007)\end{array}$ & $\begin{array}{c}-0.075^{* * *} \\
(0.012)\end{array}$ & $\begin{array}{c}-0.095^{* * *} \\
(0.013)\end{array}$ & $\begin{array}{c}-0.259^{* * *} \\
(0.014)\end{array}$ \\
\hline Observations & 100,143 & 100,143 & 100,143 & 615,483 \\
\hline$R^{2}$ & 0.775 & 0.579 & 0.729 & 0.687 \\
\hline
\end{tabular}

Notes: Robust country-pair-product clustered standard errors in parentheses. $* * *, * *, *$ denote significance at $1 \%, 5 \%$ and $10 \%$ respectively. Importer-product-time, exporter-product-time, and importer-exporter fixed effects included in all regressions. Intercepts included but not reported. The trade margins in columns (1) - (3) are defined using the Feenstra and Kee (2004) measures. The dependent variables are log-specified. All models are estimated using OLS. $E M_{i j k t}=$ the extensive margin, $I M_{i j k t}=$ the intensive margin, and $X_{i j k t}=$ observed trade values.

(2008) type models, a stringent importing country standard by raising fixed and variable trade costs induces a selection effect that discriminates against non-compliant exporting countries. ${ }^{90}$ These findings are consistent with the standards-as-barriers strand of the literature. Exporting countries with high marginal costs that cannot generate enough revenues to cover the increased fixed costs of accessing the importing country's domestic market exit the market (see Table A4.5 in the appendix), while surviving exporters see a reduction in their trade values and number of varieties.

Regarding the other control variable, bilateral tariffs have their expected negative effect on trade. In column (4), a $10 \%$ increase in bilateral tariffs will reduce observed trade flows by about $2.6 \%$ ceteris paribus. Because the tariff variable is in logs and the MRL is in levels, the two coefficient estimates cannot be compared directly. However, consistent with Fernandes et al. (2019), we find that both variables have qualitatively similar effects on trade, but unlike MRLs, the tariff effect is predominantly via the intensive margin.

\subsubsection{The effect of standards on prices, product quality, and quality-adjusted prices}

In this section, we estimate equation (4.2) by replacing the dependent variables with unit values and their components, quality and quality-adjusted prices. ${ }^{91}$ The results are presented in Table 4.3. Conditional on exporting, differences in importing country standards lead to higher prices (column 1). This may be indicative of the fact that the increased costs to meet standards stricter than those existing domestically in the exporting country are passed on to consumers in the importing country as higher prices. Or, as we show in Table 4.2, by reducing trade and inducing non-compliant domestic producers and foreign exporters to exit the product-destination market maintaining the standard, standards reduce competition in the imposing country (Abel-Koch, 2013). Surviving exporters and domestic producers exploit this and charge higher prices. As a result, consumers in the importing country $j$ are either willing to pay a premium for the improved quality or worse off because of the

\footnotetext{
${ }^{90}$ Domestic producers in the importing country that cannot meet the standard are also discriminated against. This is because a public standard, unlike a tariff, is applied to all products sold in the domestic country whether they are imported or produced locally.

${ }^{91}$ The reduction in the number of observations is because the HS3 digit elasticities of substitutions $\left(\sigma_{j k}\right)$ which we use in equation (A4.6) are not available for all importer-product pairs. This also explains why HS10 is missing from Figure A4.2. As a check of robustness, we replace missing $\sigma_{j k}$ with the importer-specific mean across all products. The results are in line with our baseline findings.
} 
Table 4.3: The effect of standards on prices, quality and quality-adjusted prices

\begin{tabular}{|c|c|c|c|}
\hline & Price & Quality & Quality-adjusted price \\
\hline & (1) & (2) & (3) \\
\hline $\mathrm{MRL}_{i j k t}$ & $\begin{array}{l}0.027^{* * *} \\
(0.008)\end{array}$ & $\begin{array}{c}0.002 \\
(0.013)\end{array}$ & $\begin{array}{c}0.026^{* *} \\
(0.012)\end{array}$ \\
\hline $\log \left(1+\operatorname{Tariff}_{i j k t}\right)$ & $\begin{array}{l}0.035^{* * *} \\
(0.005)\end{array}$ & $\begin{array}{c}-0.078^{* * *} \\
(0.008)\end{array}$ & $\begin{array}{l}0.113^{* * *} \\
(0.008)\end{array}$ \\
\hline Observations & 399,526 & 399,526 & 399,526 \\
\hline$R^{2}$ & 0.774 & 0.436 & 0.687 \\
\hline
\end{tabular}

Notes: Robust country-pair-product clustered standard errors in parentheses. ***, ** * denote significance at 1\%, 5\% and 10\% respectively. Importer-product-time, exporter-product-time, and importer-exporter fixed effects included in all regressions. Intercepts included but not reported. Price, quality and quality-adjusted prices are in logs. All models are estimated using OLS.

higher product prices. For tariffs, we do not observe any pricing-to-market effects. Faced with higher tariffs, exporters pass through the extra cost to consumers as higher prices.

In a second step, we decompose the price effect into a quality (column 2) and quality-adjusted price (column 3) component. Because the quality-adjusted price is net-quality price, it sorts out quality embodied in price. The empirical findings show that stricter MRLs affect quality and qualityadjusted prices of imports positively. Compared to quality-adjusted prices, the effects on quality are small in magnitude and are not statistically significant. This is consistent with the distributions plotted in Figure 4.1. With these results, we can assess how much of the variation in import prices is attributable to pure prices and quality upgrading. The MRL induced price increase in column (1) is predominantly due to a pure price raising effect (i.e., $0.026 / 0.027=96 \%$ ) of the standard and less of a quality-upgrading effect. On average, a 0.1 unit increase in the MRL index at the mean is associated with a $0.02 \%$ increase in product quality and a $0.26 \%$ increase in quality-adjusted prices.

Given that estimated product qualities are barely unchanged, it suggests that conditional on trading, country-product export volumes after controlling for product prices - which form the basis of our definition of quality - remain unchanged. Surviving firms, both domestic producers and foreign exporters, take advantage of the reduced competition to exert some form of market power; they charge higher prices without necessarily increasing their market shares. The latter effect is also confirmed by the negative trade effect we see at the intensive margin; not only does the extensive margin reduce but also the volume and varieties exported by compliant countries. This is consistent with the findings in Asprilla et al. (2019) that stricter NTMs in a given market reduce the number of surviving firms and increases their market power, but if anything, only has a small positive effect on import shares.

Consistent with the literature, we observe that lower tariffs, all else equal, induce quality upgrading. ${ }^{92}$ A $10 \%$ decrease in bilateral tariffs will increase estimated product quality by $0.8 \%$ and decrease quality-adjusted prices by $1.13 \%$. Comparing the MRL and tariff coefficients in Table 3 offers interesting insights. For one, we see that an increase in both MRL stringency and tariffs have positive effects on price. But, these two trade policy instruments affect quality in ways that are not isomorphic

\footnotetext{
${ }^{92}$ Different mechanisms may be at play depending on the type of bilateral tariff applied by the importing country, e.g., specific tariffs are positively correlated with quality while ad valorem tariffs are negatively correlated with quality. See Curzi and Pacca (2015) for an empirical test of these two mechanisms in the food sector.
} 
to each other. For MRLs there is a null effect on quality whiles tariffs affect quality negatively. What accounts for these differences? While stricter MRLs induce a price increase, there are no associated changes in product quality-upgrading. This is because MRL trade policy changes affect both home and foreign producing firms. Thus, instead of displacing foreign firms in favour of domestic ones like the tariff case - NTMs displace small firms in favour of larger ones, increasing the market power of compliant firms in the process (Asprilla et al., 2019). For tariffs, price increases are accompanied by a reduction in country-product market shares and thus quality. This is the case because tariffs increase the price of imports relative to domestic production, which decreases the demand faced by foreign exporting firms and hence their market shares.

Furthermore, we test whether differences in MRLs affect differently the pricing and quality strategy when the scope for product differentiation is high (i.e., vertical differentiation) or low (i.e., horizontal differentiation). ${ }^{93}$ Following Khandelwal (2010) we measure product differentiation using the so-called product "quality ladder". We compute the quality ladder as the difference between the maximum and minimum values of estimated quality in a product category. Products with values below the median are characterised by lower product differentiation (i.e., short-quality ladder). In our sample these are mainly fruits, vegetables, nuts, spices and oilseeds. In contrast, products with values above the median (i.e., the long-quality ladder) are vertically differentiated. In our sample, these are mainly coffee, tea, certain fruits (citrus, apples, pineapples, guava, mangoes, banana, apricots, cherries), certain nuts (cashew, almonds, walnuts, pistachios, dates) and some vegetables (e.g., onions, salad beetroots, gherkins, sweetcorn, sweet potatoes). The results presented in Table 4.4 confirm the price raising effect of bilateral differences in MRLs in both product classes. However, vertically differentiated products appear to be less sensitive to changes in MRL related trade policy. ${ }^{94}$ Our baseline findings on quality and quality-adjusted prices appear to be driven by homogeneous

Table 4.4: The effect of standards on prices, quality and quality-adjusted prices: quality ladder

\begin{tabular}{|c|c|c|c|c|c|c|}
\hline & \multicolumn{3}{|c|}{ Short quality ladder } & \multicolumn{3}{|c|}{ Long quality ladder } \\
\hline & Price & Quality & QA price & Price & Quality & QA price \\
\hline & (1) & (2) & (3) & (4) & (5) & (6) \\
\hline $\mathrm{MRL}_{i j k t}$ & $\begin{array}{c}0.027^{* *} \\
(0.011)\end{array}$ & $\begin{array}{c}-0.008 \\
(0.019)\end{array}$ & $\begin{array}{c}0.036^{* *} \\
(0.018)\end{array}$ & $\begin{array}{c}0.025^{* *} \\
(0.011)\end{array}$ & $\begin{array}{c}0.001 \\
(0.017)\end{array}$ & $\begin{array}{c}0.025 \\
(0.016)\end{array}$ \\
\hline $\log \left(1+\operatorname{Tariff}_{i j k t}\right)$ & $\begin{array}{l}0.029^{* * *} \\
(0.006)\end{array}$ & $\begin{array}{c}-0.083^{* * *} \\
(0.012)\end{array}$ & $\begin{array}{l}0.112^{* * *} \\
(0.012)\end{array}$ & $\begin{array}{l}0.040^{* * *} \\
(0.007)\end{array}$ & $\begin{array}{c}-0.077^{* * *} \\
(0.012)\end{array}$ & $\begin{array}{c}0.117^{* * *} \\
(0.012)\end{array}$ \\
\hline Observations & 203,554 & 203,554 & 203,554 & 195,837 & 195,837 & 195,837 \\
\hline$R^{2}$ & 0.785 & 0.473 & 0.694 & 0.759 & 0.423 & 0.682 \\
\hline
\end{tabular}

Notes: The sample is divided according to the level of product differentiation, as indicated by the quality ladder. We compute the quality ladder as the difference between the maximum and the minimum value of estimated quality in a given product category. Products with quality ladder values below the median fall in the category short-quality ladder. Robust country-pair-product clustered standard errors in parentheses. ${ }^{* *}, * *, *$ denote significance at $1 \%, 5 \%$ and $10 \%$ respectively. Importer-product-time, exporter-product-time, and importer-exporter fixed effects included in all regressions. Intercepts included but not reported. Price, quality and quality-adjusted (QA) prices are in logs. All models are estimated using OLS.

\footnotetext{
${ }^{93}$ When two products are vertically differentiated, consumers would prefer one to the other if they were sold at the same price. With horizontal differentiation, goods are different but at the same price, some consumers will buy one or the other, depending on their preferences

${ }^{94}$ If we use interaction terms instead of the sample splits, our findings remain the same.
} 
products in which the scope for quality differentiation is limited. In such cases, compliant producers take advantage of the limited scope for product differentiation to charge higher quality-adjusted prices.

\subsubsection{Heterogeneity across country different trade routes}

In this section, we assess the heterogeneity of the standards-trade, standards-price, and standardsquality effect by considering different trade routes: South-South (i.e., trade between developing countries), North-North (i.e., trade between developed countries), South-North (i.e., exports from developing to developed countries) and North-South (i.e., exports from developed to developing countries). ${ }^{95}$ Because the MRL index is asymmetric, the direction of trade is important. ${ }^{96}$ We reestimate our benchmark models but consider the four trade routes. This exercise is timely since North-South or South-South trade flows are rarely studied in the applied trade literature yet offer important insights into the heterogeneity of the standards-trade effect. ${ }^{97}$

The results are presented in Table 4.5. To allow direct comparisons of the magnitudes of the estimated coefficients across the different samples, the reported estimates are standardised beta coefficients. Generally, the findings remain consistent with our baseline. The bigger the bilateral difference in standards the bigger the trade effect. Hence, in all but at the intensive margin, the

Table 4.5: Heterogeneities across different trade routes

\begin{tabular}{|c|c|c|c|c|c|c|c|c|}
\hline & \multicolumn{2}{|c|}{ North-North } & \multicolumn{2}{|c|}{ North-South } & \multicolumn{2}{|c|}{ South-South } & \multicolumn{2}{|c|}{ South-North } \\
\hline & $\overline{\mathrm{MRL}_{i j k t}}$ & Tariff $_{i j k t}$ & $\mathrm{MRL}_{i j k t}$ & Tariff $_{i j k t}$ & $\mathrm{MRL}_{i j k t}$ & Tariff $_{i j k t}$ & $\mathrm{MRL}_{i j k t}$ & Tariff $_{i j k t}$ \\
\hline & (1) & (2) & (3) & (4) & (5) & (6) & (7) & $(8)$ \\
\hline$E M_{i j k t}$ & $\begin{array}{c}0.002 \\
(0.011)\end{array}$ & $\begin{array}{c}0.001 \\
(0.006)\end{array}$ & $\begin{array}{c}-0.006 \\
(0.024)\end{array}$ & $\begin{array}{c}-0.016 \\
(0.015)\end{array}$ & $\begin{array}{c}-0.023 \\
(0.028)\end{array}$ & $\begin{array}{c}-0.023 \\
(0.016)\end{array}$ & $\begin{array}{c}-0.064^{* * *} \\
(0.013)\end{array}$ & $\begin{array}{c}0.009 \\
(0.007)\end{array}$ \\
\hline$I M_{i j k t}$ & $\begin{array}{c}-0.030^{* *} \\
(0.015)\end{array}$ & $\begin{array}{l}-0.036^{* * *} \\
(0.008)\end{array}$ & $\begin{array}{c}-0.018 \\
(0.025)\end{array}$ & $\begin{array}{c}-0.023 \\
(0.018)\end{array}$ & $\begin{array}{c}-0.004 \\
(0.036)\end{array}$ & $\begin{array}{c}-0.007 \\
(0.023)\end{array}$ & $\begin{array}{c}-0.023 \\
(0.020)\end{array}$ & $\begin{array}{c}-0.031^{* * *} \\
(0.010)\end{array}$ \\
\hline$E M_{i j k t} \times I M_{i j k t}$ & $\begin{array}{r}-0.021^{*} \\
(0.012)\end{array}$ & $\begin{array}{c}-0.027^{* * *} \\
(0.006)\end{array}$ & $\begin{array}{c}-0.018 \\
(0.021)\end{array}$ & $\begin{array}{r}-0.027^{*} \\
(0.014)\end{array}$ & $\begin{array}{c}-0.018 \\
(0.030)\end{array}$ & $\begin{array}{l}-0.020 \\
(0.019)\end{array}$ & $\begin{array}{c}-0.058^{* * *} \\
(0.016)\end{array}$ & $\begin{array}{c}-0.018^{* *} \\
(0.007)\end{array}$ \\
\hline $\ln \left(X_{i j k t}\right)$ & $\begin{array}{c}-0.024^{* *} \\
(0.009)\end{array}$ & $\begin{array}{c}-0.117^{* * *} \\
(0.009)\end{array}$ & $\begin{array}{c}-0.019 \\
(0.021)\end{array}$ & $\begin{array}{c}-0.057^{* * *} \\
(0.016)\end{array}$ & $\begin{array}{c}-0.011 \\
(0.027)\end{array}$ & $\begin{array}{c}0.009 \\
(0.024)\end{array}$ & $\begin{array}{c}-0.033^{* * *} \\
(0.010)\end{array}$ & $\begin{array}{c}-0.041^{* * *} \\
(0.012)\end{array}$ \\
\hline Price $_{i j k t}$ & $\begin{array}{c}0.025^{* *} \\
(0.010)\end{array}$ & $\begin{array}{l}0.032^{* * *} \\
(0.009)\end{array}$ & $\begin{array}{c}0.028 \\
(0.031)\end{array}$ & $\begin{array}{c}0.004 \\
(0.019)\end{array}$ & $\begin{array}{c}0.032 \\
(0.039)\end{array}$ & $\begin{array}{c}-0.062 \\
(0.039)\end{array}$ & $\begin{array}{c}0.008 \\
(0.011)\end{array}$ & $\begin{array}{c}0.016 \\
(0.011)\end{array}$ \\
\hline Quality $_{i j k t}$ & $\begin{array}{c}0.002 \\
(0.016)\end{array}$ & $\begin{array}{c}-0.112^{* * *} \\
(0.015)\end{array}$ & $\begin{array}{c}0.002 \\
(0.044)\end{array}$ & $\begin{array}{c}-0.022 \\
(0.037)\end{array}$ & $\begin{array}{c}0.058 \\
(0.057)\end{array}$ & $\begin{array}{c}-0.036 \\
(0.056)\end{array}$ & $\begin{array}{c}-0.027 \\
(0.017)\end{array}$ & $\begin{array}{c}-0.005 \\
(0.019)\end{array}$ \\
\hline QA Price $_{i j k t}$ & $\begin{array}{c}0.018 \\
(0.011)\end{array}$ & $\begin{array}{l}0.115^{* * *} \\
(0.012)\end{array}$ & $\begin{array}{c}0.020 \\
(0.032)\end{array}$ & $\begin{array}{c}0.021 \\
(0.028)\end{array}$ & $\begin{array}{c}-0.022 \\
(0.036)\end{array}$ & $\begin{array}{c}-0.020 \\
(0.041)\end{array}$ & $\begin{array}{c}0.028^{* *} \\
(0.013)\end{array}$ & $\begin{array}{c}0.016 \\
(0.014)\end{array}$ \\
\hline
\end{tabular}

Notes: Robust country-pair-product clustered standard errors in parentheses. Point estimates are beta coefficients calculated by standardizing the estimates from the regression analysis to have zero mean and unit standard deviation. They refer to how many standard deviations the explained variable will change per standard deviation increase in the corresponding explanatory variable.***, **, * denote significance at 1\%, 5\% and 10\% respectively. Importer-product-time, exporter-product-time, and importer-exporter fixed effects included in all regressions. Intercepts included but not reported. $\mathrm{MRL}_{i j k t}$ is measured in levels and tariffs are defined in $\operatorname{logs}$, i.e. Log $(1+$ Tariff $i j k t)$. QA Price $=$ quality-adjusted price

\footnotetext{
${ }^{95}$ We define North countries as high income countries in the last year of the panel, i.e., 2014.

${ }^{96}$ Take the case of Carbaryl use in citrus production (Table 4.1). For Vietnamese exports to the EU, the index will be $\exp [(7-0.01) / 7]=2.714$. Vietnamese imports from the EU will, however, not be affected as the index approaches its lower bound, i.e., $\exp [(0.01-7) / 0.01] \approx 0$.

${ }^{97}$ In a recent meta-analysis of the NTM and agricultural trade literature by Santeramo and Lamonaca (2019), only three papers considered South-South or South-North trade compared to 40 papers that considered North-North and North-South trade.
} 
negative effects of standards on trade flows are larger for South-North trade and do not matter for North-South and South-South trade. At the extensive margin, the standard-trade effect is only statistically significant for South-North trade flows, indicating that there are a lot less qualified exporters from the South due to the high fixed cost component of the standard. The general trend remains the same for observed trade values. The magnitude of the trade effects is larger for South-North trade compared to North-North trade. This is due to compliance-related costs (e.g., annual certification renewals, upgrading existing infrastructure or establishing new ones) and other supply-side constraints such as lower quality of domestic institutions, trade-related infrastructural deficiencies and limited capacities to produce. ${ }^{98}$ Given these challenges in many developing countries, segregating crops for different markets based on the different residue limits is a challenge that can lead to increased border rejections and reduced trade volumes. ${ }^{99}$ The effect of standards on North-North trade is predominantly via the intensive margin. So, while standards do not affect the number of different crops exported by developed countries, on trading it reduces the volume. In terms of prices, differences in MRLs lead to increased product prices, but the effects are only statistically significant for trade between developed countries. The effects on quality are also not statistically significant across the different sub-samples. If we adjust prices for quality, successful exporters from the South to the North charge higher prices.

Overall, consistent with the existing literature (Xiong and Beghin, 2014; Curzi et al., 2018), we find that MRLs hinder the export flows from the South more than those from the North. In fact, for North-South trade, tariffs, but not differences in standards, are significant barriers to trade. It is also insightful to see that the tariff effects are larger for North-North trade compared to South-North trade. Many developing countries are beneficiaries of preferential trading regimes provided by developed countries (e.g., EBA, AGOA, GSP). The quality estimates also provide evidence that setting national standards that differ widely from each other do not necessarily lead to product-quality upgrading, but induce increases in product prices.

\subsection{Conclusion}

How standards affect trade in agrifood products has been a subject of intense scrutiny. The rapid increase in the number of published studies assessing the standards-trade nexus - from about 14 in the year 2000 to about 140 studies in 2017 (Santeramo and Lamonaca, 2019) — is a good case in point. A limitation of this strand of literature is its predominant focus on the direct trade effects of standards, whiles ignoring other welfare effects. In this paper, we provide the first set of empirical evidence on the quality and quality-adjusted price effects of regulatory heterogeneity in agricultural markets. Specifically, we study the effects of bilateral differences in maximum residue limits (MRLs) on trade, product prices, quality and quality-adjusted prices. Our empirical analysis exploits bilateral

\footnotetext{
${ }^{98}$ We control adequately for these other constraints using the country fixed effects in our models.

${ }^{99}$ Take, e.g., the case of cocoa production and exports from Ghana. Given the importance of cocoa to its economy, the Ghana Cocoa Board adopted the method used by Japan in pesticide residue analysis for cocoa beans. This is because meeting Japan's MRL for cocoa beans qualifies as meeting the US and EU MRLs as Japan's is the more stringent. Thus, Ghana established domestic MRLs for cocoa beans based on pesticides of interest to Japan including fenitrothion, endosulfan, promecarb, pirimiphos-methyl fenvalerate, and chlorpyrifos. These particular pesticides are now no longer authorised for use on cocoa under the EU regulations. Ghana's cocoa exporters must now choose at the time of production which export market they wish to supply—the EU or Japan, but not both (Jonfia-Essien, 2012; Yeung et al., 2018).
} 
differences in MRLs of 59 countries across 145 products over the period 2005 to 2014 within a structural gravity framework.

We find that regulatory heterogeneity in product standards decreases trade flows. Conditional on trading, stricter importer MRLs decrease the number of varieties traded and the volume of observed trade flows. They also decrease the probability of trading and induce market exit rates. Yet successful exporters, charge higher prices (unit values). This holds even if we adjust prices for quality. However, we do not observe any statistically significant effect on the estimated product quality. This implies that MRL dissimilarity leads to higher product prices, but do not induce product quality upgrading. This may be driven by the reduced competition induced by stricter standards in the importing country which surviving firms exploit to exert some form of market power. Even so, the increased compliance costs will reduce their trade volumes. This is supported by the negative effects at the intensive margin. Exploring the heterogeneity of these findings across different trade routes, we observe that the trade reducing and price raising effects are strongest for South-North trade, followed by North-North trade, but do not matter for South-South and North-South trade. For tariffs, we find that further liberalisation will lead to consumers, enjoying higher qualities, and more variety at lower prices.

Our findings show that the differences between national MRLs do not lead to a statistically significant effect on estimated product quality. As a consequence, we observe disruptions to trade (i.e., limited varieties and quantities at higher prices) without extra benefits to consumers. This is consistent with the findings of Yeung et al. (2018) that there is no discernible gain in food safety from using national MRLs. While food safety risks are borderless and the consequences are easily transmitted across countries, approaches to tackle them are still national in scope. For policy-making, because regulatory heterogeneity of standards hinders trade and lead to higher food prices, a move towards regulatory harmonisation or mutual recognition agreements is a necessary step to dampening the standards-as-barriers effect. The idea that harmonising standards will increase trade flows, in the end, is not far-fetched and has been shown empirically in contributions by Chen and Mattoo (2008) and Disdier et al. (2015), amongst others. A well-known downside is that the stricter developing country standards will then become the de facto mandatory standard. Nevertheless, because this allows producing according to a common benchmark, it can be seen as a cost-saving mechanism in the long run. A second approach is the need to ensure that NTMs are appropriate, transparent, science-based, and do not overly restrict trade. For MRLs, this means that there should be a significant incentive for all countries to strengthen the Codex and ensure that it has the scientific capacity and resources to develop standards acceptable for most, if not all, countries.

Going forward, extensions of our analysis could consider differences in the type of chemical applied in the production process. Our analysis considers all chemicals as homogeneous. However, recently Hejazi et al. (2018) show that the effects of MRLs are heterogeneous across chemical classes such as herbicides, pesticides and fungicides. 


\subsection{Appendix}

Table A4.1: List of importing and exporting countries

Argentina, Australia, Austria, Belgium, Bulgaria, Brazil, Bahrain, Cambodia, Canada, Chile, China, Croatia, Colombia, Cyprus, Czech Republic, Denmark, Egypt, Estonia, Finland, France, Germany, Greece, Hong Kong, Hungary, India, Indonesia, Ireland, Israel, Italy, Japan, Laos, Latvia, Lithuania, Luxembourg, Malaysia, Mexico, Malta, Myanmar, the Netherlands, Norway, New Zealand, Philippines, Poland, Portugal, Russia, Singapore, South Africa, South Korea, Slovak Republic, Slovenia, Spain, Sweden, Switzerland, Taiwan, Thailand, Turkey, Ukraine, United Kingdom, United States of America, Viet Nam

Table A4.2: Summary statistics

\begin{tabular}{lrrrrl}
\hline Variable & \multicolumn{1}{c}{ Mean } & Std. Dev. & \multicolumn{1}{c}{ Min. } & \multicolumn{1}{c}{ Max. } & \multicolumn{1}{l}{ N } \\
\hline MRL $_{i j k t}^{H S 2}$ & 1.171 & 0.810 & 0 & 2.718 & 100,729 \\
MRL $_{i j k t}$ & 1.123 & 0.813 & 0 & 2.718 & 631,227 \\
Extensive margin $\left(E M_{i j k t}\right)$ & 0.008 & 0.030 & 0 & 0.559 & 100,729 \\
Intensive margin $\left(I M_{i j k t}\right)$ & 0.720 & 1.654 & 0 & 70.320 & 100,729 \\
Trade value (mln USD) & 3.048 & 70.053 & 0 & 19144.001 & 631,227 \\
Tariffs (log) & 0.718 & 1.228 & 0 & 6.686 & 631,227 \\
Price (log) & -5.744 & 1.125 & -8.643 & -2.487 & 399,526 \\
Quality (log) & 0.041 & 1.154 & -3.135 & 2.934 & 399,526 \\
Quality adjusted price $(\log )$ & -5.785 & 1.436 & -11.487 & 0.480 & 399,526 \\
\hline
\end{tabular}

Table A4.3: The effect of bilateral differences in MRLs on trade: no bilateral fixed effects

\begin{tabular}{|c|c|c|c|c|}
\hline & $E M_{i j k t}^{H S 2}$ & $I M_{i j k t}^{H S 2}$ & $E M_{i j k t}^{H S 2} \times I M_{i j k t}^{H S 2}$ & $X_{i j k t}^{H S 6}$ \\
\hline & (1) & (2) & (3) & (4) \\
\hline $\mathrm{MRL}_{i j k t}$ & $\begin{array}{c}-0.127^{* * *} \\
(0.024)\end{array}$ & $\begin{array}{c}-0.047 \\
(0.037)\end{array}$ & $\begin{array}{c}-0.174^{* * *} \\
(0.041)\end{array}$ & $\begin{array}{c}-0.195^{\text {*** }} \\
(0.024)\end{array}$ \\
\hline $\log \left(1+\operatorname{Tariff}_{i j k t}\right)$ & $\begin{array}{c}-0.073^{* * *} \\
(0.009)\end{array}$ & $\begin{array}{c}-0.108^{* * *} \\
(0.014)\end{array}$ & $\begin{array}{c}-0.181^{* * *} \\
(0.016)\end{array}$ & $\begin{array}{c}-0.404^{* * *} \\
(0.014)\end{array}$ \\
\hline Colony $_{i j}$ & $\begin{array}{l}0.275^{* * *} \\
(0.044)\end{array}$ & $\begin{array}{l}0.193^{* * *} \\
(0.073)\end{array}$ & $\begin{array}{l}0.467^{* * *} \\
(0.089)\end{array}$ & $\begin{array}{l}0.216^{* * *} \\
(0.031)\end{array}$ \\
\hline Language $_{i j}$ & $\begin{array}{c}0.165^{* * *} \\
(0.039)\end{array}$ & $\begin{array}{c}0.238^{* * *} \\
(0.063)\end{array}$ & $\begin{array}{l}0.403^{* * *} \\
(0.076)\end{array}$ & $\begin{array}{l}0.363^{* * *} \\
(0.028)\end{array}$ \\
\hline Contiguity $_{i j}$ & $\begin{array}{c}0.053 \\
(0.046)\end{array}$ & $\begin{array}{l}0.598^{* * *} \\
(0.067)\end{array}$ & $\begin{array}{l}0.652^{* * *} \\
(0.086)\end{array}$ & $\begin{array}{l}0.999^{* * *} \\
(0.027)\end{array}$ \\
\hline Log Distance $_{i j k t}$ & $\begin{array}{c}-0.704^{* * *} \\
(0.015)\end{array}$ & $\begin{array}{c}-0.925^{* * *} \\
(0.023)\end{array}$ & $\begin{array}{c}-1.628^{* * *} \\
(0.028)\end{array}$ & $\begin{array}{c}-1.037^{* * *} \\
(0.012)\end{array}$ \\
\hline Observations & 100,279 & 100,279 & 100,279 & 615,616 \\
\hline$R^{2}$ & 0.706 & 0.472 & 0.626 & 0.637 \\
\hline
\end{tabular}

Notes: Robust country-pair-product clustered standard errors in parentheses. ***, **, * denote significance at 1\%, $5 \%$ and $10 \%$ respectively. Importer-product-time and exporter-product-time fixed effects included in all regressions. Intercepts included but not reported. 
Table A4.4: The effect of bilateral differences in MRLs on trade: one year lag of MRL

\begin{tabular}{|c|c|c|c|c|}
\hline & $E M_{i j k t}$ & $I M_{i j k t}$ & $E M_{i j k t} \times I M_{i j k t}$ & $X_{i j k t}$ \\
\hline & (1) & (2) & (3) & (4) \\
\hline $\mathrm{MRL}_{i j k t-1}$ & $\begin{array}{r}-0.037^{*} \\
(0.022)\end{array}$ & $\begin{array}{c}-0.097^{* * *} \\
(0.035)\end{array}$ & $\begin{array}{c}-0.134^{* * *} \\
(0.040)\end{array}$ & $\begin{array}{c}-0.062^{* *} \\
(0.027)\end{array}$ \\
\hline $\log \left(1+\operatorname{Tariff}_{i j k t}\right)$ & $\begin{array}{r}-0.015^{*} \\
(0.008)\end{array}$ & $\begin{array}{c}-0.087^{* * *} \\
(0.012)\end{array}$ & $\begin{array}{c}-0.101^{* * *} \\
(0.013)\end{array}$ & $\begin{array}{c}-0.289^{* * *} \\
(0.019)\end{array}$ \\
\hline Observations & 80,571 & 80,571 & 80,571 & 434,918 \\
\hline$R^{2}$ & 0.791 & 0.599 & 0.742 & 0.708 \\
\hline
\end{tabular}

Notes: Robust country-pair-product clustered standard errors in parentheses. ***, **, * denote significance at 1\%, $5 \%$ and $10 \%$ respectively. Importer-product-time, exporter-product-time and importer-exporter fixed effects included in all regressions. Intercepts included but not reported.

Table A4.5: The effect of bilateral differences in MRLs on the probability of trade, market exit and trade values

\begin{tabular}{|c|c|c|c|}
\hline & $\operatorname{Pr}\left(X_{i j k t}\right)>0$ & Market exit $_{i j k t}$ & Trade value $_{i j k t}$ \\
\hline & $(1)$ & (2) & (3) \\
\hline $\mathrm{MRL}_{i j k t}$ & $\begin{array}{c}-0.003^{* * *} \\
(0.001)\end{array}$ & $\begin{array}{l}0.044^{* * *} \\
(0.001)\end{array}$ & $\begin{array}{c}-0.120^{* * *} \\
(0.028)\end{array}$ \\
\hline $\log \left(1+\right.$ Tariff $\left._{i j k t}\right)$ & $\begin{array}{l}0.008^{* * *} \\
(0.000)\end{array}$ & $\begin{array}{l}0.026^{* * *} \\
(0.000)\end{array}$ & $\begin{array}{c}-0.111^{* * *} \\
(0.012)\end{array}$ \\
\hline Observations & $3,628,820$ & $3,265,938$ & $2,682,478$ \\
\hline Estimator & LPM & LPM & PPML \\
\hline
\end{tabular}

Notes: Robust country-pair-product clustered standard errors in parentheses. ***, **, * denote significance at 1\%, 5\% and 10\% respectively. Importer-product-time, exporter-product-time, and importer-exporter fixed effects included in all regressions. Intercepts included but not reported. The dependent variables in Columns (1) and (2) are dummies defined for the probability of trading and exit respectively and are estimated using a linear probability model. Because the generation of the market exit variable requires observations in years $t$ and $t-1$, an exit in the first year in the dataset cannot be measured and observations cover the years 2006-2014. 
Figure A4.1: EU border notifications relating to pesticide residues (1999-2018)

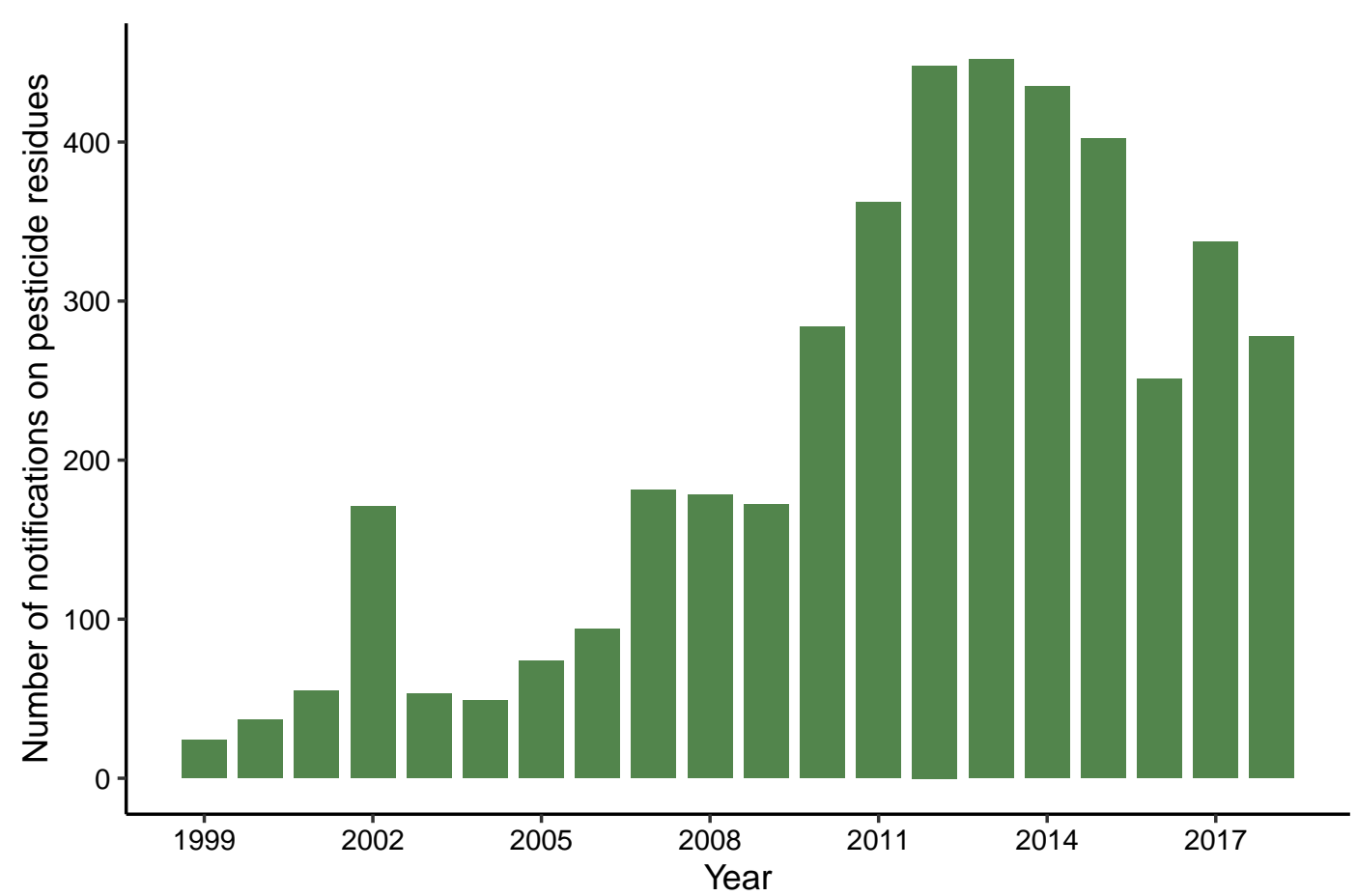

Source: EU RASFF data, authors' own construction

Figure A4.2: Relationship between estimated quality and prices by HS2 groups in 2014

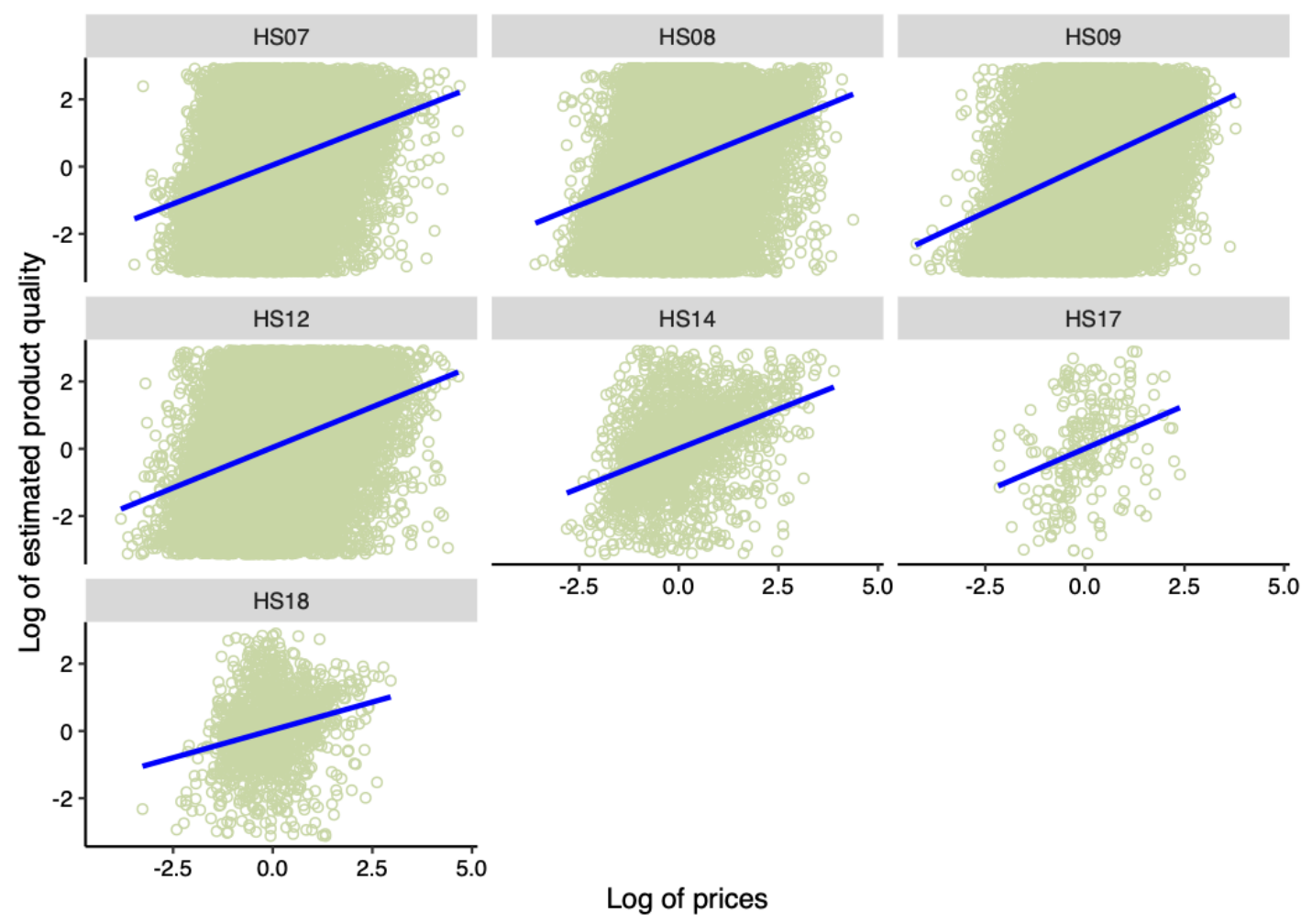

Source: Authors' own construction 
Figure A4.3: Average number of regulated pesticides per country (2005-2014)

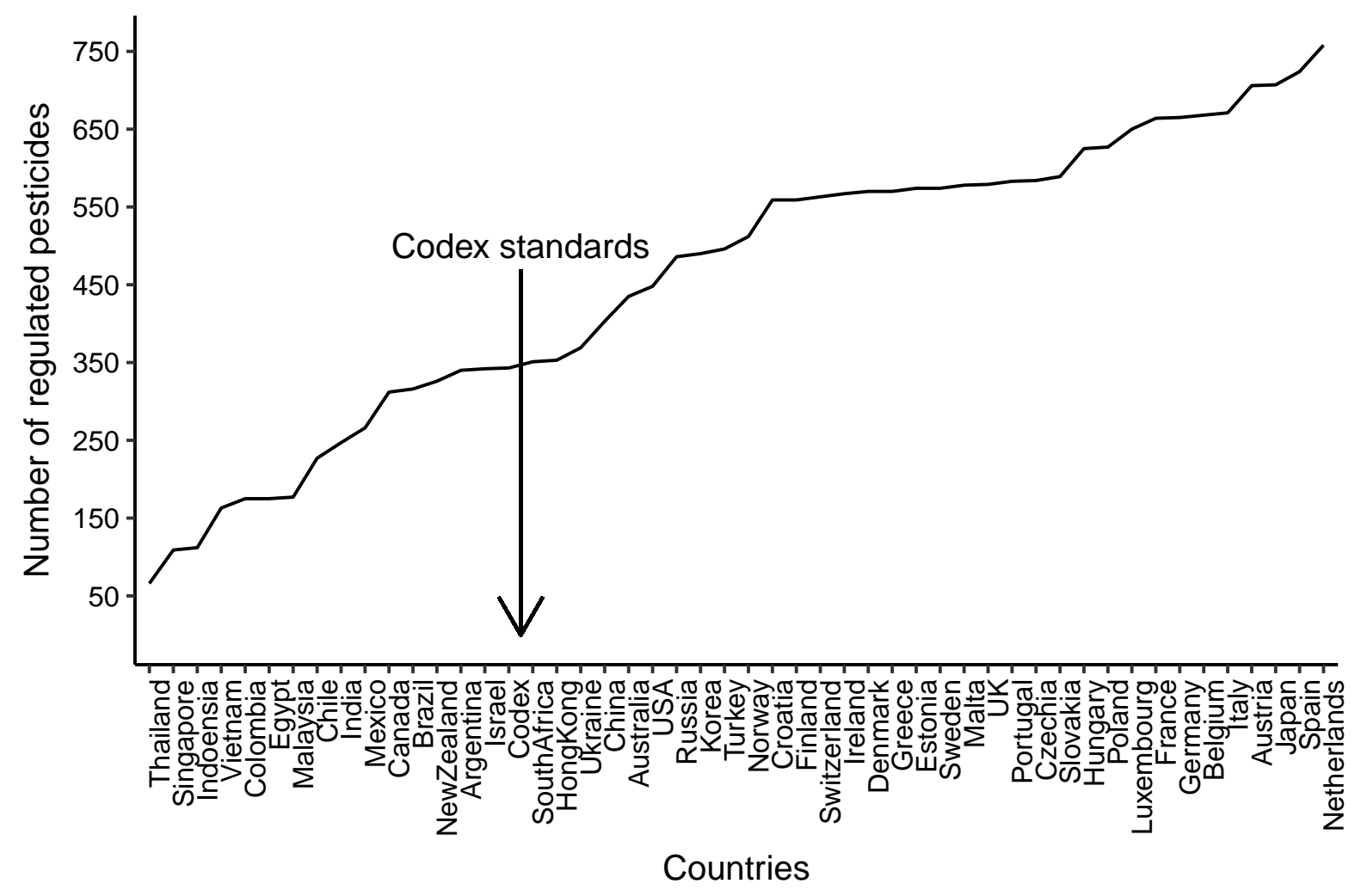

Source: Homologa database, authors' own construction

\section{Measures of the extensive and intensive margins}

We define the extensive trade margin as the worldwide average export over all years to country $j$ in those HS2 digit categories $R$ where country $i$ actually exports to $j$, relative to the worldwide average export to $j$ over all years $t$ in all categories. Formally, let $h 2$ and $h 6$ be the 2-digit and 6-digit level of the HS classification, respectively. $R_{i j t}^{h 2}$ is the exporting country $i$ 's categories set exported to $j$, in year $t$, and $R_{j W}^{h 2}$ accounts for the set of world categories exported to the country $j$ over all the considered years. Defining $\bar{V}_{j W, h 6}^{h 2}$ as the average value of the world's exports to country $j$ of the category $h 6$ over time, then the bilateral extensive margin for industry $h 2$ in year $t$ is given as:

$$
E M_{i j h 2, t}=\frac{\sum_{h 6 \epsilon R_{i j t}^{h 2}} \bar{V}_{j W, h 6}^{h 2}}{\sum_{h 6 \epsilon R_{j W}^{h 2}} \bar{V}_{j W, h 6}^{h 2}}
$$

Similarly, let $V_{i j h 6 t}^{h 2}$ be the value of exports of country $i$ to $j$ of the category $h 6$ at time $t$, then the bilateral intensive margin in industry $h 2$ compares the export trade values of country $i$ to country $j$ of products in a certain set of goods in year $t$ with the average export value of the world to country $j$ for the same set of products.

$$
I M_{i j h 2, t}=\frac{\sum_{h 6 \epsilon R_{i j t}^{h 2}} V_{i j h 6 t}^{h 2}}{\sum_{h 6 \epsilon R_{i j t}^{h 2}} \bar{V}_{j W, h 6}^{h 2}}
$$


Hence, it measures country $i$ 's overall market share within the set of categories it exports to $j$. A nice property of the decomposition is that the product of the margins equals the ratio of exports from $i$ to $j$ relative to country $j$ 's total imports. Taking the natural logs and using some algebra, Hummels and Klenow (2005) show that the $\log$ of the value of the trade flow from $i$ to $j, \ln X_{i j k t}$, can be decomposed linearly into:

$$
\ln X_{i j k t}=\ln E M_{i j k t}+\ln I M_{i j k t}+\ln X_{j k t}
$$

where the value of $j$ 's imports from the world, $X_{j k t}$, is accounted for by the $\psi_{j k t}$ term in equation (4.2).

\section{Estimating quality following Khandelwal et al. (2013)}

Consider the following CES utility function, which expresses the preferences of consumers for a variety $v$ in country $j$, assuming that consumers' preferences incorporate quality:

$$
U=\left[\int_{v \in V}[\lambda(v) q(v)]^{\frac{\sigma-1}{\sigma}} d v\right]^{\frac{\sigma}{(\sigma-1)}}
$$

where $q(v)$ is the consumed quantity of $v$ and $\lambda(v)$ is its quality, while $\sigma>1$ is the elasticity of substitution parameter which is assumed to be constant. Maximising (A4.4) under the usual budget constraint gives the demand of consumers in country $j$ for product $k$ coming from country $i$ as depending on the price and quality of the product, prices of substitute products and on the income of the consumer, yielding:

$$
q_{i j k t}=\lambda_{i j k t}^{\sigma-1} p_{i j k t}^{-\sigma} P_{j t}^{\sigma-1} Y_{j t}
$$

where $p_{i j k t}$ and $\lambda_{i j k t}$ are the price and the relative quality attributed by country $j$, to product $k$, exported by country $i$, respectively. The terms $P_{j t}$ and $Y_{j t}$ account, respectively, for the importing countries' price index and income level. Log linearising equation (A4.5) and moving the endogenous price to the left-hand side of the equation we can estimate the quality for each country-product-year as the residual from the following ordinary least squares (OLS) regression:

$$
\ln q_{i j k t}+\sigma_{j k} \ln p_{i j k t}=\alpha_{k}+\alpha_{j t}+e_{i j k t}
$$

where $q_{i j k t}$ and $p_{i j k t}$ are, respectively, the quantity and the price (unit value) of product $k$, exported by country $i$ to country $j$ at time $t . \alpha_{k}$ are product fixed effects that capture differences in prices and quantities across product categories due to the inherent characteristics of products. $\alpha_{j t}$ are importer-year fixed effects that account for both the destination price index $P_{j t}$ and income $Y_{j t}$. Estimating (A4.6) separately for each country and HS4-digit industry, the estimated quality is given as $\ln \hat{q}_{i j k t} \equiv \hat{e}_{i j k t} /\left(\sigma_{j k}-1\right)$. We allow the elasticity of substitution to differ across HS3-digit product classes using data from Broda et al. (2017). 


\title{
5 Conclusion
}

\begin{abstract}
"Food regulations in different countries are often conflicting and contradictory. Legislation governing ... acceptable food standards often varies widely from country to country. New legislation not based on scientific knowledge is often introduced. [This] conflicting nature of food regulations may be an obstacle to trade in foodstuffs between countries" - (WHO, 1950, pg. 24)
\end{abstract}

As multilateral and bilateral initiatives lower custom tariffs and other traditional trade barriers to near-zero, we have seen an upsurge in behind-the-border non-tariff measures (NTMs). NTMs are policy measures besides tariffs that can affect trade flows, e.g. domestic legislation covering health, product safety and biosecurity, safety standards, institutional red tapes. So, while it may look like countries are substituting tariff protection for NTMs, such simple arguments ignore the potential consumer or societal benefits of NTMs. For instance, NTMs address information asymmetries, mitigate consumption risks and enhance sustainability. That said, NTMs can indeed also be motivated by protectionism or based on outdated science. It is often challenging to determine if a particular regulation is protectionist or serves public interests because both motives are often combined in a single measure. Hence, the trade and welfare effects of NTMs are much less evident than the equivalent case of tariffs and other quantity restrictions. For example, the costs associated with NTMs may lock out non-compliant producers from global value chains, but by addressing information asymmetries NTMs may also be measures for market creation. If we focus narrowly on the agrifood sector, standards are the most important NTMs. How they affect agrifood trade and welfare remain empirical questions, with existing answers nuanced at best. This dissertation contributes three essays on this relevant trade policy instrument using the case of food safety standards in agricultural trade.

\subsection{Synopsis of main findings}

The first essay offers further insights into the ambiguous relationship between food standards and their associated certification schemes and bilateral trade flows using the case of GlobalGAP standards. The study is new in two ways. First, it questions the external validity of existing studies because of their country- or product-specific approaches and contributes the first multi-country and -product study. Second, using the share of the certified area in total harvest area as an additional measure of certification, we deviate from the existing literature - which uses counts of certified producers, production area, or firms (Vural and Akgüngör, 2015; Ehrich and Mangelsdorf, 2018; Andersson, 2018). The existing approach overlooks the scale of certified production across countries. Our approach improves the precision of the estimates by isolating the trade effect of certification from confounding 
factors that emerge from general growth trends in agricultural production. Our structural gravity estimates confirm a general trade enhancing effect of GlobalGAP certification on the probability of trade (i.e., the extensive margin) and the value of exports conditional on trade (i.e., the intensive margin). In general, our findings are consistent with the "standards-as-catalyst" strand of the literature. However, the effect sizes are heterogeneous. By product, the trade effect is lowest for bananas compared to apples and grapes. Once certified, the positive trade effects remain regardless of the development status of the exporting country. The trade effects are higher for exports to high-value EU and OECD markets but are substantial even for exports to markets outside these regions. Thus, while voluntary certification poses extra costs for producers, it also sustains high-value market access.

The second essay revisits the "standards-as-catalyst" debate, but with a distinctive twist. Existing work has shown that governance and institutions are important drivers of trade and economic growth. Retailers in countries with good institutions prefer suppliers from countries with similar or better domestic institutions. Besides the reputational damage associated with potential food scares, institutional dissimilarities impose significant costs for trade. Much less attention has been paid to how exporters in low-quality institutional regimes overcome these differences. This essay evaluates first, the effect of cross-country bilateral differences in governance and related institutions on agrifood trade. Retailers, especially in high-value markets such as the EU and EFTA, are becoming more and more concerned about traceability, quality of production processes and final products. Thus, second, we argue that private food standards and certifications act as surrogate institutions that help to overcome institutional differences at the country level. We are not aware of any existing studies that test this argument empirically in the agricultural trade literature. Our gravity model estimates confirm the trade reducing effect of bilateral governance distance on trade flows. But we also find that the trade impeding effects vary depending on whether the exporting country is GlobalGAP certified. For certified exporters, the trade impeding effects are 50\% lower compared to their non-certified counterparts, especially for exports to the EU and the EFTA. Hence, we document a new finding: GlobalGAP certification exerts a pro-export effect that partially offsets the trade-inhibiting effects of institutional differences at the country level. Our findings are robust to the product-specific analyses of apples, bananas, and grapes but also the aggregate fruits and vegetable sector, and to different measures of institutional quality.

Finally, the existing literature has studied mainly the direct trade effects of standards, ignoring in large part their other welfare effects. But as our findings in Essay 2 confirm, these other non-direct trade effects of standards are crucial. The third essay provides the first set of empirical evidence on the price and quality upgrading effects of regulatory heterogeneity in agricultural markets. Our empirical analysis exploits the cross-country and -product variation in maximum residue limits (MRLs) over time for 59 countries and 145 products within structural gravity-type models. We find that regulatory heterogeneity decreases trade flows. Conditional on trading, stricter importing country MRLs decrease the number of varieties traded, export market shares, and the value of observed trade flows. They also decrease the probability of trading and induce market exit. Qualified exporters charge higher prices, in part because of the reduced competition in the importing country maintaining the stricter standard. The price effect holds even if we adjust observed prices for quality. However, we do not observe any statistically significant effect on the estimated product quality. Thus, the unambiguous 
increase in product prices induced by MRL related trade policy is driven more by compliance costs and less of quality-upgrading. Exploring the heterogeneity of these findings across different trade routes, we observe that the trade reducing and price raising effects are strongest for South-North trade, followed by North-North trade, but do not matter for South-South and North-South trade. Overall, stricter MRLs lead to trade disruptions (lower trade volumes and increased market power for survivors) and welfare losses (i.e., limited product varieties at higher prices) to consumers.

\subsection{Implications for policy}

The focus of this dissertation, standard-like NTMs, is what John Beghin and co-authors - fieldexperts on agrifood standards and value chains - call a "challenge for the profession because there is no blanket policy recommendation paralleling those on tariffs or quotas" (Beghin et al., 2015, pg. 443). With this in mind, this dissertation draws context-specific recommendations for policymakers.

In Chapter 2, we show that voluntary GlobalGAP certification is fast becoming a de facto mandatory global standard that promotes agrifood exports. It goes without saying that non-compliance hinders export participation. We need to facilitate the adoption of private standards, especially in developing countries (DCs) where the trade-enhancing effects of certification are even more pronounced. The compliance cost factor is especially important since the associated annual costs of certification are the responsibility of the producer. Even for group certifications, these could amount to 1000s of US dollars. Meeting these initial certification costs requires technical and financial support from the public sector and multinational initiatives such as the Aid-for-Trade agenda. Continued education through extension delivery would ensure that farmers understand the benefits of voluntary certification and are more willing to pay the associated costs in subsequent years. For governments and private-sector policy-makers in DCs, introducing stringent domestic standards or benchmarking them to globally recognised standards must be the long-term priority. In this regard, GlobalGAP offers substantial leeway through their localg.a.p. schemes. These are cost-effective solutions for emerging markets, that serve as a stepping stone toward full GlobalGAP certification. This is an opportunity that DCs must seize to benefit from the increasing trend of certification. Indeed, some countries are already making use of this opportunity and reaping positive outcomes, e.g., MalaysiaGAP, ChinaGAP, MexicoGAP and KenyaGAP. In the short run, establishing local certification bodies will also reduce the direct cost of certification. The success stories of AfriCert in Kenya, AgriCert in Mexico and the Fundación para el Desarollo Frutícola in Chile are good examples.

In Chapter 3 we see that weak public institutions are bad for international trade, but voluntary certification can play a moderating role. This has policy implications. For exporters targeting highvalue markets but are located in countries with low quality of existing domestic public institutions, getting certified to a standard that is accepted in the importing country can help to overcome the negative reputation effects associated with their geographical locations. Certification in itself is an imperfect substitute for weak public institutions at the country level. But as an alternative to reduce trade costs and enhance trade; certification works. As the recent World Development Report reiterates, "the emergence of well-defined product standards can help firms in developing countries overcome ... reputational barriers to market access" (World Bank, 2020, pg. 168). To reap these benefits, the policy recommendations of Chapter 2 are again relevant here. 
Chapter 4 focuses on national differences in standards and their effects on consumer welfare via three channels: product varieties, product prices, and product quality. Our research shows that regulatory heterogeneity hinders trade and reduces product varieties available to consumers but lead to higher product prices. A move towards regulatory harmonisation or equivalence as guaranteed under Articles III and IV of the WTO SPS Agreement is recommended to reduce the "standardsas-barriers" effect and its associated welfare losses. To see the potential benefits of harmonisation let us revisit Figure 1.2 in Chapter $1 .{ }^{100}$ If standards are harmonised between Home and Foreign, exporting firms at Foreign no longer have to incur the compliance cost of the standard. As a result, trade increases as foreign exports enter the Home country at the lower price $P_{x}$. Food safety risks are borderless and their consequences are easily transmitted across countries. It is imperative that approaches to tackle them move from the current nationalist approach to one that is multinational in scope. This knowledge is as old as the first meeting of the Joint FAO/WHO Expert Committee on Nutrition in 1950 as the opening quote of this chapter suggests. Yet, as this dissertation confirms, we have made little, if any, progress at all. This is a timely reminder for all countries to strengthen the rules-based trading system. As tariff barriers have gone down, liberalising NTMs must be the top priority. We need to ensure that NTMs are appropriate, transparent and based on science. The multinational trading system is weakening; strengthening it will ensure that intergovernmental bodies like the Codex Alimentarius Commission have the scientific capacity, resources and earn the trust of different governments to develop standards acceptable for most, if not all, member countries. The EU especially has very strict MRLs. The EU commission needs to revive trade initiatives such as the Pesticides Initiative Programme with the African, Caribbean and Pacific community. This will support efforts by exporting firms in these regions to develop ways of adapting to EU pesticide use.

\subsection{Limitations}

The research presented in this dissertation is subject to limitations, many of which are mentioned in the individual essays. In this section I acknowledge the more prominent ones.

Typical of many demand-side gravity equations, the underlying theoretical models in our specifications assume homothetic CES expenditure functions. Inherent in this class of models is the limiting assumption that the elasticity of trade with respect to trade costs is a constant. This feature means that in our specific case ceteris paribus, an increase in the stringency of MRLs or the spread of GlobalGAP certification has the same proportionate effect on bilateral trade regardless of initial trade levels. Furthermore, the implication of $\sigma>1$ in the CES model (equation 1.3) is that some volume of the product is purchased no matter how high the price. Hence, it is not straight forward to justify zeroes in our trade matrices, unless we assume fixed costs of exporting on the supply side. A much more flexible functional form that could address the issue of zeroes while also allowing for variable trade

\footnotetext{
${ }^{100}$ Harmonisation is not without its limitations. If domestic standards reflect strong consumer tastes and preferences, then harmonisation to a common standard or equivalence may reduce the utility that domestic consumers enjoy from consuming such products. But, if consumers have no strong attachments to existing national standards, harmonisation is a legitimate food policy goal. See, e.g., Sawyer et al. (2008) for the case of organic standards. Another well-known downside of harmonisation is that stricter developing country standards often become the de facto mandatory standard. This implies higher compliance costs for developing country producers. Nevertheless, because this allows producing according to a common benchmark, it can be seen as a cost-saving mechanism in the long run. These limitations are, however, less important for MRLs since the multinational Codex Alimentarius Commission sets MRLs that can be the social optimum. The fact that they are scientifically referenced benchmarks regulated by the FAO and the WHO is telling.
} 
cost elasticities is the translog expenditure functions as in Novy (2013). From an analytical point of view this is important. As James Anderson argues "more general translog treatments [of the gravity model] are feasible and desirable" (Anderson, 2011, pg. 147). It is also important from a public policy point of view; working with country-pair specific estimates of a trade policy shock — instead of the usual average effect across all country-pairs — will enhance evidence-based policy-making in the agrifood sector. ${ }^{101}$

At the most fundamental level, international trade takes place between firms. Due to the lack of firm-level transaction and customs data this thesis applies insights from heterogeneous firms models at the country level. As a result, our estimations ignore productivity and quality differences across firms within a country. Take the case of the price and quality analysis in Chapter 4; different firms in country $i$ might be offering bananas of different quality levels. Lack of finer trade data implies that we cannot estimate quality for individual firms in country $i$, and our quality estimates reflect the average quality of bananas from country $i$. However, as shown by Helpman et al. (2008) theoretical predictions of firm-level trade models can be properly estimated using country-level data. ${ }^{102}$ Also, the mere existence of firm heterogeneity is not necessarily a problem for international trade theories. The assumption of a representative firm per country could be a convenient, if not perfectly realistic, simplification (Bernard et al., 2007). Nevertheless, to test the exact mechanisms underlying our findings, extensions of our results with firm-level transactions and customs data is recommended.

While Anderson and Van Wincoop (2003) forms the theoretical foundation for the gravity models estimated in this thesis, the individual studies contained in here have not explored the full general equilibrium comparative static effects of trade cost changes related to food standards. These general equilibrium effects are, however, the second contribution of the now-famous Anderson and Van Wincoop (2003) paper. To appreciate how important this contribution is, return to equation (1.3) in Chapter 1 . A change in the bilateral trade cost from $i$ to $j, t_{i j}$ will have a direct effect on the bilateral trade flow, $X_{i j}$. This is the mechanism we exploit in this dissertation. However, a fall in $t_{i j}$ also lowers multilateral resistance in $j, P_{j}$ causing an increase in imports from all countries, and potentially decreasing trade from $i$ to $j$ as other countries' products substitute for $i$ 's goods. A fall in $t_{i j}$ also puts downward pressure on $i$ 's multilateral price index, $\Pi_{i}$, tending to reduce $X_{i j}$ as well. These two general equilibrium effects tend to offset the direct trade effects of the trade cost changes we

\footnotetext{
${ }^{101}$ In this regard, I explored further the heterogeneity of the standards-trade effect using a more flexible specification. The point of departure from this thesis is the argument that the negative trade effect of public standards is not constant as imposed by the CES expenditure function — but decreases in size as the share of the exporter in the importing country's total imports increase. The reasoning is simple but hopefully intuitive; bigger trading partners find it more profitable to invest in meeting the costs of importer-specific standards. To test this argument empirically, I use the theory-founded translog gravity model of Novy (2013) combined with theoretical predictions from the heterogeneous firms' literature. Consistent with the model predictions, the results support my argument. We confirm that stricter standards are indeed trade-restrictive. However, the estimated trade cost elasticity varies depending on how intensively two countries trade, which means that for countries trading large volumes, standards have limited negative effects. This work is novel in showing that the standards-trade debate misses out on the important role of ex-ante import shares. This paper has been presented at Tropentag 2019 and the Environmental Science and Policy Seminar at the University of Milano. It is, however, excluded from this dissertation only to ensure theoretical consistency in the empirical analysis; all the empirical models in this dissertation are estimated using variants of the CES gravity model in equation (1.3).

102 "This property results from the fact that the characteristics of the marginal exporters to different destinations can be identified from the variation in features of the destination countries and of observable bilateral trade costs. As a result, there exist sufficient statistics, which can be computed from aggregate data, that predict the selection of heterogeneous firms into export markets and their associated aggregate trade volumes" (Helpman et al., 2008, pg. 445)
} 
analyse (Bergstrand and Egger, 2013). Exploring these additional general equilibrium effects will complement the findings in this dissertation.

In chapter 3, we measure institutional quality using the World Bank's World Governance Indicators, the Legatum Prosperity Index and the Economic Freedom of the World index. While these datasets have enriched the set of institutional quality measures available for empirical analysis, they are only available as national aggregates. At the product level, the quality of domestic institutions will matter more for some products than for others. Our results in Chapter 3 confirm this (see Table 3.4). In Chapter 4, our quality estimations use elasticities of substitution $\left(\sigma_{j k}\right)$ at the HSO3 level but our quality estimations are done at the higher HSO4 level. It is possible that this aggregation over products biases our quality estimates downward. For now, these two data issues lie beyond the control of researchers employing publicly available institutional quality data or importer-product-specific elasticities of substitution.

\subsection{Outlook for further research}

While this dissertation has contributed to the empirical standards and agricultural trade literature, many questions remain unanswered. In fact, I conclude this dissertation with more open questions than answers. Going forward, I see five exciting research areas that deserve attention.

The trade volume effects of agrifood standards may still be nuanced, but we have ample empirical evidence to guide policy-making. The recent meta-analysis of the NTM-agrifood trade effect by Santeramo and Lamonaca (2019) summarizes the magnitude and directions of the effects. What remains unexplored empirically are the political economy implications of food standards (one exception is Disdier and Marette, 2010). Which segments of the economy, e.g., producers, consumers, importers or governments, benefit from the introduction, tightening, harmonisation or mutual recognition of standards? A possible reason for this gap in the literature is that standards often address market imperfections, thus, their welfare implications are more complex than those of traditional price-based trade barriers such as tariffs (Xiong and Beghin, 2014). However, this would be a clear way to extend this literature. As we show in Chapter 4, country-specific differences in NTMs reduce trade and available product varieties, increase product prices but have no quality upgrading effects. This is a clear case where standards reflect a welfare loss for consumers.

A natural extension of the finding that certification to voluntary standards enhances trade is to assess if certification attracts a price premium. GlobalGAP does not pay any price premium to their producers but ensures market access. Even so, it is worthwhile to assess if certified producers pass on their extra costs of production to retailers in their target importing countries as higher prices. Why is this important? If certified products indeed fetch higher prices, then measuring observed trade as import values may be inappropriate since the gravity model estimations will pick up the effects of the higher prices rather than the effect of more trade (see, e.g., Andersson, 2018). This discussion also lends itself as a natural test of the Alchian-Allen "shipping the good apples out" effect which predicts that per-unit trade costs lead to a shift in demand toward high-quality goods (Alchian and Allen, 1964). This raises the research question; faced with a fixed trade cost-e.g., absolute tariffs, freight costs or bilateral distance-does the export of certified products, as a proxy for quality, increase relative to exports of non-certified products? 
Third, are standards set to protect consumers' health and safety or shield domestic producers from import competition? Before countries set standards, there must be science-based analyses of the risks involved in allowing consumption of regulated substances over a threshold in a product. However, the minimum standard set by public regulators may be stricter than needed to counteract the externality, thereby disguising protectionist intents (Fischer and Serra, 2000). Take the case of MRLs which is the focus of Chapter 4. Winter and Jara (2015) argue that violative MRLs are rarely of health significance. They present a complementary approach to MRLs, called pesticide food safety standard (PFSS), to develop scientifically defensible levels of safety concern. Using this approach, the chronic and acute PFSS levels for captan use in strawberry production was $2000 \mathrm{mg} \mathrm{kg}^{-1}$ and $250 \mathrm{mg} \mathrm{kg}^{-1}$, respectively. Both levels are far above the existing MRL that ranges from $3 \mathrm{mg} \mathrm{kg}^{-1}$ to $20 \mathrm{mg} \mathrm{kg}^{-1}$. Hence, there is a need to link standards to health outcomes at the macro-level. This will be a necessary addition to the literature and prove or dispel the notion that national standards are set for protectionist intents. The result of such an analysis has clear policy implications for the agrifood sector that are particularly relevant for the EU Commission who faces a lot of backlash from other countries for setting overly stringent standards. ${ }^{103}$

Also pressing is the need to decouple standards-related export rejections from those caused by export-related administrative procedures. There is at least anecdotal evidence that some of the product rejections we see at the border are due to such things as incomplete paperwork. Empirically, a recent contribution by Kareem and Martínez-Zarzoso (forthcoming) shows that the high counts of EU border rejections of fish exports from Africa are not due to standards. Their work and the peripheral finding in Chapter 3 that institutional differences hinder trade points to an interesting fact; we cannot attribute the marginalisation of developing countries from participation in global value chains only to standard-like NTMs. Thus, disentangling the effects of weak domestic trade facilitation measures from standard-like barriers will be a much-welcome addition to the literature.

Last, but probably the most pressing, is how NTM-induced changes in agricultural trade patterns affect climate change. While there is limited evidence on the net effect of agrifood trade on greenhouse gas emissions, open borders facilitate trade between surplus and deficit regions. Standards remain a barrier to open borders, but they are also changing food production systems. In a recent thought-provoking paper on the environmental bias of trade policy, Shapiro (2019) shows convincingly that in most countries, tariffs and NTMs are substantially lower on dirty than on clean industries, where an industry's dirtiness is measured by its carbon dioxide emissions per dollar of output. This appears to be a strong empirical regularity that remains stable across different countries. Even more interesting, the estimated effects are smaller in magnitude when the food and agricultural sector is excluded from the sample. Hence, the NTMs, agricultural trade and climate change nexus is a nascent but promising avenue to conduct policy-relevant research.

\footnotetext{
${ }^{103}$ As recent as a July 2019 meeting of the WTO Committee on SPS measures, China raised concerns on the EU for lowering MRLs for the pesticide lambda-cyhalothrin in tea from $1 \mathrm{mg} \mathrm{kg}^{-1}$ to $0.01 \mathrm{mg} \mathrm{kg}^{-1}$. The Chinese delegation argued that the EU proposal was not based on results of a risk assessment but an alleged lack of relevant data, and asked the EU to further evaluate the potential health risk to consumers. At this same meeting Colombia, Costa Rica, the Dominican Republic and Ecuador complained about the EU amendments to MRLs for imazalil, a fungicide widely used in the production of citrus fruit and bananas. They criticised the EU's precautionary stance as disregarding scientific evidence presented by relevant international organisations recognised by the SPS Agreement. For more on this, see https://bit.ly/33Y0ZFR.
} 
This page intentionally left blank 


\section{Bibliography}

Abdi, M. and Aulakh, P. S. (2012). Do country-level institutional frameworks and interfirm governance arrangements substitute or complement in international business relationships? Journal of International Business Studies 43: 477-497.

Abel-Koch, J. (2013). Endogenous Trade Policy with Heterogeneous Firms. Tech. rep., Gutenberg School of Management and Economics, Johannes Gutenberg-Universität.

Agnosteva, D. E., Anderson, J. E. and Yotov, Y. V. (2019). Intra-national trade costs: assaying regional frictions. European Economic Review 112: 32-50.

Alchian, A. A. and Allen, W. R. (1964). University Economics. Belmont, CA: Wadsworth.

Álvarez, I. C., Barbero, J., Rodríguez-Pose, A. and Zofío, J. L. (2018). Does institutional quality matter for trade? Institutional conditions in a sectoral trade framework. World Development 103: 72-87.

Anders, S. M. and Caswell, J. A. (2009). Standards as barriers versus standards as catalysts: assessing the impact of HACCP implementation on US seafood imports. American Journal of Agricultural Economics 91: 310-321.

Anderson, J. E. (2011). The gravity model. Annual Review of Economics 3: 133-160.

Anderson, J. E. and Marcouiller, D. (2002). Insecurity and the pattern of trade: an empirical investigation. The Review of Economics and Statistics 84: 342-352.

Anderson, J. E. and Van Wincoop, E. (2003). Gravity with gravitas: a solution to the border puzzle. American Economic Review 93: 170 - 192.

Anderson, J. E. and Van Wincoop, E. (2004). Trade costs. Journal of Economic Literature 42: 691-751. Andersson, A. (2018). The trade effect of private standards. European Review of Agricultural Economics 46: 267-290.

Arita, S., Beckman, J. and Mitchell, L. (2017). Reducing transatlantic barriers on US-EU agri-food trade: what are the possible gains? Food Policy 68: 233-247.

Armington, P. S. (1969). A theory of demand for products distinguished by place of production. IMF Staff Papers 16: 159-178.

Arndt, C. and Oman, C. (2006). Uses and Abuses of Governance Indicators. Development Centre Studies, Organization for Economic Development and Co-operation.

Asfaw, S., Mithöfer, D. and Waibel, H. (2010a). Agrifood supply chain, private-sector standards, and farmers' health: evidence from Kenya. Agricultural Economics 41: 251-263.

Asfaw, S., Mithöfer, D. and Waibel, H. (2010b). What impact are EU supermarket standards having on developing countries' export of high-value horticultural products? Evidence from Kenya. Journal of International Food and Agribusiness Marketing 22: 252-276.

Asprilla, A., Berman, N., Cadot, O. and Jaud, M. (2019). Trade policy and market power: Firm-level evidence. International Economic Review 60: 1647-1673. 
Baier, S. L. and Bergstrand, J. H. (2007). Do free trade agreements actually increase members' international trade? Journal of International Economics 71: 72-95.

Baldwin, R. and Taglioni, D. (2007). Trade effects of the Euro: a comparison of estimators. Journal of Economic Integration 22: 780-818.

Battese, G. E. (1997). A note on the estimation of Cobb-Douglas production functions when some explanatory variables have zero values. Journal of Agricultural Economics 48: 250-252.

Beghin, J. C., Maertens, M. and Swinnen, J. (2015). Nontariff measures and standards in trade and global value chains. Annual Review of Resource Economics 7: 425-450.

Berden, K., Bergstrand, J. H. and Etten, E. (2014). Governance and globalisation. The World Economy 37: 353-386.

Bergeijk, P. A. van and Brakman, S. (2010). The Gravity Model in International Trade: Advances and Applications. Cambridge University Press.

Bergstrand, J. H. and Egger, P. (2013). Gravity equations and economic frictions in the world economy. In Greenaway, D., Falvey, R., Kreickemeier, U. and Bernhofen, D. (eds), Palgrave Handbook of International Trade. Springer, 1, chap. 17, 532-570.

Bernard, A. B., Jensen, J. B., Redding, S. J. and Schott, P. K. (2007). Firms in international trade. Journal of Economic Perspectives 21: 105-130.

Bojnec, Š. and Fertô, I. (2009). The institutional determinants of bilateral agricultural and food trade. APSTRACT 4: 53-57.

Bojnec, Š. and Fertő, I. (2012). Does EU enlargement increase agro-food export duration? The World Economy 35: 609-631.

Bojnec, Š. and Fertő, I. (2017). Quality upgrades of EU agri-food exports. Journal of Agricultural Economics 68: 269-279.

Bojnec, Š., Fertő, I. and Fogarasi, J. (2014). Quality of institutions and the BRIC countries agro-food exports. China Agricultural Economics Review 6: 379-394.

Breinlich, H., Dhingra, S. and Ottaviano, G. I. (2016). How have EU's trade agreements impacted consumers? CEP Discussion Paper 1417, Centre for Economic Performance, London School of Economics and Political Science.

Broda, C., Greenfield, J. and Weinstein, D. E. (2017). From groundnuts to globalization: a structural estimate of trade and growth. Research in Economics 71: 759-783.

Busch, L. (2011). Standards: Recipes for reality. MIT Press.

Cadot, O., Carrère, C. and Strauss-Kahn, V. (2011). Export diversification: what's behind the hump? Review of Economics and Statistics 93: 590-605.

Cao, X. and Prakash, A. (2011). Growing exports by signaling product quality: trade competition and the cross-national diffusion of ISO 9000 quality standards. Journal of Policy Analysis and Management 30: 111-135.

Carrére, C., Mrázová, M. and Neary, J. P. (2019). Gravity without Apology: The Science of Elasticities, Distance, and Trade. In 21st Annual European Trade Study Group Conference (Bern, 12 - 14 September).

Chaney, T. (2008). Distorted gravity: the intensive and extensive margins of international trade. American Economic Review 98: 1707-1721. 
Chen, M. X. and Mattoo, A. (2008). Regionalism in standards: good or bad for trade? Canadian Journal of Economics 41: 838-863.

Cioffi, A. and dell'Aquila, C. (2004). The effects of trade policies for fresh fruit and vegetables of the European Union. Food Policy 29: 169-185.

Cioffi, A., Santeramo, F. G. and Vitale, C. D. (2011). The price stabilization effects of the EU entry price scheme for fruit and vegetables. Agricultural Economics 42: 405-418.

Cipollina, M. and Salvatici, L. (2010). The trade impact of European Union agricultural preferences. Journal of Economic Policy Reform 13: 87-106.

Clarke, R. (2010). Private food safety standards: their role in food safety regulation and their impact. Paper prepared for presentation and discussion at the 33rd session of the codex alimentarius commission, Food And Agriculture Organization Of The United Nations.

Clougherty, J. A. and Grajek, M. (2008). The impact of ISO 9000 diffusion on trade and FDI: a new institutional analysis. Journal of International Business Studies 39: 613-633.

Colen, L., Maertens, M. and Swinnen, J. (2012). Private standards, trade and poverty: GlobalGAP and horticultural employment in Senegal. The World Economy 35: 1073-1088.

Correia, S. (2016). REGHDFE: Stata module to perform linear or instrumental-variable regression absorbing any number of high-dimensional fixed effects. Statistical Software Components, Boston College Department of Economics.

Crozet, M., Head, K. and Mayer, T. (2012). Quality sorting and trade: firm-level evidence for French wine. The Review of Economic Studies 79: 609-644.

Curzi, D., Luarasi, M., Raimondi, V. and Olper, A. (2018). The (lack of) international harmonization of EU standards: import and export effects in developed versus developing countries. Applied Economics Letters : $1-5$.

Curzi, D. and Olper, A. (2012). Export behavior of Italian food firms: does product quality matter? Food Policy 37: 493-503.

Curzi, D. and Pacca, L. (2015). Price, quality and trade costs in the food sector. Food policy 55: 147-158.

Curzi, D., Raimondi, V. and Olper, A. (2015). Quality upgrading, competition and trade policy: evidence from the agri-food sector. European Review of Agricultural Economics 42: 239-267.

Curzi, D., Schuster, M., Maertens, M. and Olper, A. (2020). Standards, trade margins and product quality: firm-level evidence from Peru. Food Policy 91, doi:10.1016/j.foodpol.2020.101834.

De Sousa, J. (2012). The currency union effect on trade is decreasing over time. Economics Letters 117: 917-920.

Dimitrova, B. V., Korschun, D. and Yotov, Y. V. (2017). When and how country reputation stimulates export volume. International Marketing Review 34: 377-402.

Disdier, A.-C., Fontagné, L. and Cadot, O. (2015). North-South standards harmonization and international trade. The World Bank Economic Review 29: 327-352.

Disdier, A.-C., Fontagné, L. and Mimouni, M. (2008). The impact of regulations on agricultural trade: evidence from the SPS and TBT agreements. American Journal of Agricultural Economics 90: 713-726. 
Disdier, A.-C., Gaigné, C. and Herghelegiu, C. (2018). Do standards improve the quality of traded products? European Center for Advanced Research in Economics and Statistics Working Papers.

Disdier, A.-C. and Marette, S. (2010). The combination of gravity and welfare approaches for evaluating nontariff measures. American Journal of Agricultural Economics 92: 713-726.

Dolan, C. and Humphrey, J. (2000). Governance and trade in fresh vegetables: the impact of UK supermarkets on the African horticulture industry. Journal of Development Studies 37: 147-176.

Drogué, S. and DeMaria, F. (2012). Pesticide residues and trade, the apple of discord? Food Policy 37: 641-649.

Eaton, J. and Kortum, S. (2002). Technology, geography, and trade. Econometrica 70: 1741-1779.

Egger, P. H. and Nigai, S. (2015). Structural gravity with dummies only: constrained ANOVA-type estimation of gravity models. Journal of International Economics 97: 86-99.

Ehrich, M. and Mangelsdorf, A. (2018). The role of private standards for manufactured food exports from developing countries. World Development 101: 16-27.

Emlinger, C., Jacquet, F. and Lozza, E. C. (2008). Tariffs and other trade costs: assessing obstacles to Mediterranean countries' access to EU-15 fruit and vegetable markets. European Review of Agricultural Economics 35: 409-438.

Feenstra, R. and Kee, H. L. (2008). Export variety and country productivity: estimating the monopolistic competition model with endogenous productivity. Journal of International Economics 74: 500-518.

Feenstra, R. and Kee, L. H. (2004). On the measurement of product variety in trade. American Economic Review 94: 145-149.

Feenstra, R. C. and Ma, H. (2014). Trade facilitation and the extensive margin of exports. The Japanese Economic Review 65: 158-177.

Feenstra, R. C. and Romalis, J. (2014). International prices and endogenous quality. The Quarterly Journal of Economics 129: 477-527.

Felbermayr, G. J. and Toubal, F. (2010). Cultural proximity and trade. European Economic Review 54: 279-293.

Fernandes, A. M., Ferro, E. and Wilson, J. S. (2019). Product standards and firms' export decisions. The World Bank Economic Review 33: 353-374.

Ferro, E., Otsuki, T. and Wilson, J. S. (2015). The effect of product standards on agricultural exports. Food Policy 50: 68-79.

Fiankor, D.-D. D., Flachsbarth, I., Masood, A. and Brümmer, B. (2019a). Does GlobalGAP certification promote agrifood exports? European Review of Agricultural Economics doi:10.1093/erae/jbz023.

Fiankor, D.-D. D., Martínez-Zarzoso, I. and Brümmer, B. (2019b). Exports and governance: the role of private voluntary agrifood standards. Agricultural Economics 50: 341-352.

Fischer, R. and Serra, P. (2000). Standards and protection. Journal of International Economics 52: 377-400.

Fontagné, L., Orefice, G., Piermartini, R. and Rocha, N. (2015). Product standards and margins of trade: firm-level evidence. Journal of International Economics 97: 29-44.

Gaigné, C. and Larue, B. (2016). Quality standards, industry structure, and welfare in a global economy. American Journal of Agricultural Economics 98: 1432-1449. 
GLOBALGAP (2012). GLOBALGAP Annual Report 2012. Tech. rep., GLOBALG.A.P. c/o FoodPLUS. GLOBALGAP (2015). GLOBALGAP Annual Report 2015. Tech. rep., GLOBALG.A.P. c/o FoodPLUS. Goedhuys, M. and Sleuwaegen, L. (2013). The impact of international standards certification on the performance of firms in less developed countries. World Development 47: 87-101.

Goedhuys, M. and Sleuwaegen, L. (2016). International standards certification, institutional voids and exports from developing country firms. International Business Review 25: 1344-1355.

Goldbeck, M. and Yalcin, E. (2018). The rise of non-tariff measures and consequences for global trade. In 2017/2018, S. A. (ed.), Schwerpunkt Außenwirtschaft 2017/2018, chap. 8, 165-191.

Groot, H. L. de, Linders, G.-J., Rietveld, P. and Subramanian, U. (2004). The institutional determinants of bilateral trade patterns. Kyklos 57: 103-123.

Guimaraes, P. and Portugal, P. (2010). A simple feasible procedure to fit models with high-dimensional fixed effects. The Stata Journal 10: 628-649.

Hallak, J. C. (2006). Product quality and the direction of trade. Journal of International Economics 68: $238-265$.

Handford, C. E., Elliott, C. T. and Campbell, K. (2015). A review of the global pesticide legislation and the scale of challenge in reaching the global harmonization of food safety standards. Integrated Environmental Assessment and Management 11: 525-536.

Haq, Z. U., Meilke, K. and Cranfield, J. (2012). Selection bias in a gravity model of agrifood trade. European Review of Agricultural Economics 40: 331-360.

Hatanaka, M., Bain, C. and Busch, L. (2006). Differentiated standardization, standardized differentiation: The complexity of the global agrifood system. In Between the Local and the Global. Emerald Group Publishing Limited, 39-68.

Head, K. and Mayer, T. (2014). Gravity equations: workhorse, toolkit, and cookbook. In Gopinath, G., Helpman, E. and Rogoff, K. (eds), Handbook of International Economics. Elsevier B.V., 4, chap. 3, 131-195.

Hejazi, M., Grant, J. H. and Peterson, E. (2018). Hidden trade costs? Maximum residue limits and US exports of fresh fruits and vegetables. Research report CAT-2018-06, Center for Agricultural Trade.

Helpman, E., Melitz, M. and Rubinstein, Y. (2008). Estimating trade flows: trading partners and trading volumes. The Quarterly Journal of Economics 123: 441-487.

Henson, S. and Humphrey, J. (2010). Understanding the complexities of private standards in global agri-food chains as they impact developing countries. The Journal of Development Studies 46: 16281646.

Henson, S. and Jaffee, S. (2008). Understanding developing country strategic responses to the enhancement of food safety standards. The World Economy 31: 548-568.

Henson, S., Masakure, O. and Cranfield, J. (2011). Do fresh produce exporters in sub-Saharan Africa benefit from GlobalGAP certification? World Development 39: 375-386.

Herzfeld, T., Drescher, L. S. and Grebitus, C. (2011). Cross-national adoption of private food quality standards. Food Policy 36: 401-411.

Honda, K., Otsuki, T. and Wilson, J. S. (2015). Food safety standards and international trade: the impact on developing countries' export performance. In Food Safety, Market Organization, Trade 
and Development. Springer, 151-166.

Horsewood, N. and Voicu, A. M. (2012). Does corruption hinder trade for the new EU members? Economics: The Open-Access, Open-Assessment E-Journal 6: 1-28.

Huchet-Bourdon, M. and Cheptea, A. (2011). Informal barriers and agricultural trade: does monetary integration matter? Agricultural Economics 42: 519-530.

Hudson, J. and Jones, P. (2003). International trade in 'quality goods': signalling problems for developing countries. Journal of International Development 15: 999-1013.

Hummels, D. and Klenow, P. J. (2005). The variety and quality of a nation's exports. American Economic Review 95: 704-723.

Jaffee, S., Meer, K. van der, Henson, S., Haan, C. de, Sewadeh, M., Ignacio, L., Lamb, J. and Lisazo, M. B. (2005). Food Safety and Agricultural Health Standards: Challenges and Opportunities for Developing Country Exports. Report 31207, The World Bank.

Jonfia-Essien, W. A. (2012). Emerging international standards in cocoa trade: recent treatise on MRL. In Proceedings of the 9th International Conference on Controlled Atmosphere and Fumigation in Stored Products, 15-19.

Kareem, F. O. and Martínez-Zarzoso, I. (forthcoming). Are EU standards detrimental to Africa's exports? Journal of Policy Modeling .

Kareem, F. O., Martínez-Zarzoso, I. and Brümmer, B. (2018). Protecting health or protecting imports? Evidence from EU non-tariff measures. International Review of Economics \& Finance 53: 185-202.

Kaufmann, D., Kraay, A. and Mastruzzi, M. (2011). The worldwide governance indicators: methodology and analytical issues. Hague Journal on the Rule of Law 3: 220-246.

Khandelwal, A. (2010). The long and short (of) quality ladders. The Review of Economic Studies 77: 1450-1476.

Khandelwal, A. K., Schott, P. K. and Wei, S.-J. (2013). Trade liberalization and embedded institutional reform: evidence from Chinese exporters. American Economic Review 103: 2169-95.

Kleemann, L., Abdulai, A. and Buss, M. (2014). Certification and access to export markets: adoption and return on investment of organic-certified pineapple farming in Ghana. World Development 64: 79-92.

Kogut, B. and Singh, H. (1988). The effect of national culture on the choice of entry mode. Journal of International Business Studies 19: 411-432.

Korinek, J., Melatos, M. and Rau, M.-L. (2008). A review of methods for quantifying the trade effects of standards in the agri-food sector. OECD Trade Policy Papers 79, OECD Publishing, Paris.

Krugman, P. (1980). Scale economies, product differentiation, and the pattern of trade. The American Economic Review 70: 950-959.

Kugler, M. and Verhoogen, E. (2011). Prices, plant size, and product quality. The Review of Economic Studies 79: 307-339.

Latouche, K. and Chevassus-Lozza, E. (2015). Retailer supply chain and market access: evidence from French agri-food firms certified with private standards. The World Economy 38: 1312-1334.

Lernoud, J., Potts, J., Sampson, G., Voora, V., Willer, H. and Wozniak, J. (2015). The State of Sustainable Markets-Statistics and Emerging Trends 2015. ITC, Geneva. 
Levchenko, A. A. (2007). Institutional quality and international trade. The Review of Economic Studies 74: 791-819.

Li, S. and Samsell, D. P. (2009). Why some countries trade more than others: the effect of governance environment on trade flows. Corporate Governance: an International Review 17: 47-61.

Li, Y. and Beghin, J. C. (2014). Protectionism indices for non-tariff measures: an application to maximum residue levels. Food Policy 45: 57-68.

Lind, N. (2014). Legatum prosperity index. In Michalos, A. C. (ed.), Encyclopedia of Quality of Life and Well-Being Research. Springer Netherlands, 3529-3530.

Linnemann, H. (1966). An econometric study of international trade flows. North-Holland Publishing Company, Amsterdam: North-Holland.

Lio, M. and Liu, M.-C. (2008). Governance and agricultural productivity: a cross-national analysis. Food Policy 33: 504-512.

Lippe, R. S. and Grote, U. (2017). Determinants affecting adoption of GLOBALG.A.P. standards: a choice experiment in Thai horticulture. Agribusiness 33: 242-256.

Lockie, S., McNaughton, A., Thompson, L.-J. and Tennent, R. (2013). Private food standards as responsive regulation: the role of national legislation in the implementation and evolution of GLOBALG.A.P. The International Journal of Sociology of Agriculture and Food 20.

Lockie, S., Travero, J. and Tennent, R. (2015). Private food standards, regulatory gaps and plantation agriculture: social and environmental (ir)responsibility in the Philippine export banana industry. Journal of Cleaner Production 107: 122-129.

MaCurdy, T. E. and Pencavel, J. H. (1986). Testing between competing models of wage and employment determination in unionized markets. Journal of Political Economy 94: S3-S39.

Maertens, M. and Swinnen, J. (2009a). Food standards, trade and development. Review of Business and Economics 54: 314-326.

Maertens, M. and Swinnen, J. F. (2009b). Trade, standards, and poverty: evidence from Senegal. World development 37: 161-178.

Mangelsdorf, A., Portugal-Perez, A. and Wilson, J. S. (2012). Food standards and exports: evidence for China. World Trade Review 11: 507-526.

Martínez-Zarzoso, I. and Márquez-Ramos, L. (2019). Exports and governance: is the Middle East and North Africa region different? The World Economy 42: 143-174.

Masood, A. and Brümmer, B. (2014). Impact of GlobalGAP certification on EU banana imports: a gravity modeling approach. GlobalFood Discussion Papers 49, University of Goettingen.

Mausch, K., Mithöfer, D., Asfaw, S. and Waibel, H. (2009). Export vegetable production in Kenya under the EurepGAP standard: is large 'more beautiful' than small? Journal of Food Distribution Research 40: 115-129.

Maze, A. (2017). Standard-setting activities and new institutional economics. Journal of Institutional Economics 13: 599-621.

Melitz, M. J. (2003). The impact of trade on intra-industry reallocations and aggregate industry productivity. Econometrica 71: 1695-1725.

Melo, J. de and Nicita, A. (2018). Non-tarriff measures: Scope and overview. In Melo, J. de and Nicita, A. (eds), Non-tariff Measures: Economic Assessment and Policy Options for Development. 
United Nations Conference on Trade and Development, Geneva, chap. 1, 1-11.

Melo, O., Engler, A., Nahuehual, L., Cofre, G. and Barrena, J. (2014). Do sanitary, phytosanitary, and quality-related standards affect international trade? Evidence from Chilean fruit exports. World Development 54: 350-359.

Mendonça, T. G. de, Lirio, V. S., Braga, M. J. and Silva, O. M. da (2014). Institutions and bilateral agricultural trade. Procedia Economics and Finance 14: 164-172.

Meulen, B. M. van der (2011). The anatomy of private food law. In Der Meulen, B. van (ed.), Private food law: governing food chains through contract law self-regulation, private standards, audits and certification schemes. Wageningen Academic Publishers, chap. 3, 75-111.

Mohammed, R. and Zheng, Y. (2017). International diffusion of food safety standards: the role of domestic certifiers and international trade. Journal of Agricultural and Applied Economics 49: 296-322.

Montiel, I., Husted, B. W. and Christmann, P. (2012). Using private management standard certification to reduce information asymmetries in corrupt environments. Strategic Management Journal 33: 1103-1113.

Movchan, V., Shepotylo, O. and Vakhitov, V. (2019). Non-tariff measures, quality and exporting: evidence from microdata in food processing in Ukraine. European Review of Agricultural Economics doi:10.1093/erae/jbz034.

Murina, M. and Nicita, A. (2017). Trading with conditions: the effect of sanitary and phytosanitary measures on the agricultural exports from low-income countries. The World Economy 40: 168-181.

Murphy, R. H. and Lawson, R. A. (2018). Extending the economic freedom of the world index to the cold war era. Cato Journal 38: 265.

Niu, Z., Liu, C., Gunessee, S. and Milner, C. (2018). Non-tariff and overall protection: evidence across countries and over time. Review of World Economics 154: 675-703.

Novy, D. (2013). International trade without CES: Estimating translog gravity. Journal of International Economics 89: 271-282.

Olper, A. (2016). The political economy of trade-related regulatory policy: environment and global value chain. Bio-based and Applied Economics 5: 287-324.

Olper, A., Curzi, D. and Pacca, L. (2014). Do food standards affect the quality of EU imports? Economics Letters 122: 233-237.

Olper, A. and Raimondi, V. (2009). Patterns and determinants of international trade costs in the food industry. Journal of Agricultural Economics 60: 273-297.

Otsuki, T., Wilson, J. S. and Sewadeh, M. (2001). What price precaution? European harmonisation of aflatoxin regulations and African groundnut exports. European Review of Agricultural Economics 28: $263-284$.

Ouma, S. (2010). Global standards, local realities: private agrifood governance and the restructuring of the Kenyan horticulture industry. Economic Geography 86: 197-222.

Persson, M. and Wilhelmsson, F. (2016). EU trade preferences and export diversification. The World Economy 39: 16-53.

Peterson, E., Grant, J., Roberts, D. and Karov, V. (2013). Evaluating the trade restrictiveness of phytosanitary measures on US fresh fruit and vegetable imports. American Journal of Agricultural 
Economics 95: 842-858.

Qaim, M. (2017). Globalisation of agrifood systems and sustainable nutrition. Proceedings of the Nutrition Society 76: 12-21.

Raimondi, V., Falco, C., Curzi, D. and Olper, A. (2019). Trade effects of geographical indication policy: the EU case. Journal of Agricultural Economics doi:doi.org/10.1111/1477-9552.12349.

Ronnen, U. (1991). Minimum quality standards, fixed costs, and competition. The RAND Journal of Economics 22: 490-504.

Russo, C., Perito, M. A. and Di Fonzo, A. (2014). Using private food safety standards to manage complexity: a moral hazard perspective. Agricultural Economics Review 15: 113-127.

Saitone, T. L. and Sexton, R. J. (2010). Product differentiation and quality in food markets: industrial organization implications. Annual Review of Resource Economics 2: 341-368.

Santeramo, F. G. and Cioffi, A. (2012). The entry price threshold in EU agriculture: deterrent or barrier? Journal of Policy Modeling 34: 691-704.

Santeramo, F. G. and Lamonaca, E. (2019). The effects of non-tariff measures on agri-food trade: a review and meta-analysis of empirical evidence. Journal of Agricultural Economics 70: 595-617.

Santos Silva, J. M. C. and Tenreyro, S. (2006). The log of gravity. The Review of Economics and Statistics 88: 641-658.

Santos Silva, J. M. C. and Tenreyro, S. (2011). Further simulation evidence on the performance of the poisson pseudo-maximum likelihood estimator. Economics Letters 112: 220-222.

Sawyer, E. N., Kerr, W. A. and Hobbs, J. E. (2008). Consumer preferences and the international harmonization of organic standards. Food Policy 33: 607-615.

Schuster, M. and Maertens, M. (2015). The impact of private food standards on developing countries' export performance: an analysis of asparagus firms in Peru. World Development 66: 208-221.

Schuster, M. and Maertens, M. (2017). Worker empowerment through private standards. evidence from the peruvian horticultural export sector. The Journal of Development Studies 53: 618-637.

Scoppola, M., Raimondi, V. and Olper, A. (2018). The impact of EU trade preferences on the extensive and intensive margins of agricultural and food products. Agricultural Economics 49: 251-263.

Shapiro, J. (2019). The Environmental Bias of Trade Policy. In Association of Environmental and Resource Economists' Summer Conference, Lake Tahoe, NV, May, 30-31.

Shepherd, B. and Wilson, N. L. (2013). Product standards and developing country agricultural exports: the case of the European Union. Food Policy 42: 1-10.

Shingal, A., Ehrich, M. and Foletti, L. (2017). Re-estimating the effects of stricter standards on trade: endogeneity matters. RSCAS research papers No. 2017/20, Robert Schuman Centre for Advanced Studies.

Staiger, R. W. (2019). Non-tariff measures and the WTO. In Zissimos, B. (ed.), The WTO and Economic Development. MIT Press, chap. 1.

Stern, R. M. (1973). Tariffs and other measures of trade control: a survey of recent developments. Journal of Economic Literature 11: 857-888.

Subervie, J. and Vagneron, I. (2013). A drop of water in the Indian Ocean? The impact of GlobalGAP certification on lychee farmers in Madagascar. World Development 50: 57-73. 
Swinnen, J. (2016). Economics and politics of food standards, trade, and development. Agricultural Economics 47: 7-19.

Tadesse, B. and White, R. (2010). Cultural distance as a determinant of bilateral trade flows: do immigrants counter the effect of cultural differences? Applied Economics Letters 17: 147-152.

Tinbergen, J. (1962). Shaping the World Economy; Suggestions for an International Economic Policy. Twentieth Century Fund, New York.

Tran, N., Wilson, N. L. and Anders, S. (2012). Standard harmonization as chasing zero (tolerance limits): the impact of veterinary drug residue standards on crustacean imports in the EU, Japan, and North America. American Journal of Agricultural Economics 94: 496-502.

Trefler, D. (1995). The case of the missing trade and other mysteries. The American Economic Review 85: 1029-1046.

UNCTAD (2012). International Classification of Non-Tariff measures, February 2012 version (UNCTAD/DITC/TAB/2012/2). Tech. rep., United Nations Conference on Trade and Development.

UNCTAD (2016). BANANA: an INFOCOMM Commodity Profile. Tech. rep., United Nations Conference on Trade and Development.

Vandemoortele, T. and Deconinck, K. (2014). When are private standards more stringent than public standards? American Journal of Agricultural Economics 96: 154-171.

Vural, B. M. T. and Akgüngör, S. (2015). Fresh produce regulation and private standards in Turkey: Implications for export markets. In Hammoudi, A., Grazia, C., Surry, Y. and Traversac, J.-B. (eds), Food Safety, Market Organization, Trade and Development. Springer, 229-249.

WHO (1950). Joint FAO/WHO Expert Committee on Nutrition: report on the first session, Geneva, 24-28 October 1949. WHO Technical Report Series : 1-24.

Wilson, J. S. (2008). Standards and developing country exports: a review of selected studies and suggestions for future research. Journal of International Agricultural Trade and Development 4: $35-45$.

Winter, C. K. and Jara, E. A. (2015). Pesticide food safety standards as companions to tolerances and maximum residue limits. Journal of Integrative Agriculture 14: 2358-2364.

Winters, L. A. (1987). Negotiating the abolition of non-tariff barriers. Oxford Economic Papers 39: 465-480.

World Bank (2020). World Development Report 2020: Trading for Development in the Age of Global Value Chains. Washington, DC: World Bank, doi:10.1596/978-1-4648-1457-0.

Xiong, B. and Beghin, J. (2012). Does European aflatoxin regulation hurt groundnut exporters from Africa? European Review of Agricultural Economics 39: 589-609.

Xiong, B. and Beghin, J. (2014). Disentangling demand-enhancing and trade-cost effects of maximum residue regulations. Economic Inquiry 52: 1190-1203.

Yeats, A. J. (1979). Trade barriers facing developing countries: commercial policy measures and shipping. Palgrave Macmillan, London.

Yeung, M., Kerr, W. A., Coomber, B., Lantz, M. and McConnell, A. (2018). Declining harmonization in maximum residue levels for pesticides. British Food Journal 120: 901-913.

Yotov, Y. V., Piermartini, R., Monteiro, J.-A. and Larch, M. (2016). An Advanced Guide to Trade Policy Analysis: The Structural Gravity Model. WTO Publications, Geneva. 
Yu, M. (2010). Trade, democracy, and the gravity equation. Journal of Development Economics 91: 289-300. 